UNIVERSIDADE DE BRASÍLIA

INSTITUTO DE CIÊNCIAS BIOLÓGICAS

DEPARTAMENTO DE ECOLOGIA

\title{
MARCADORES ISOTÓPICOS DA ORIGEM DA PESCA DO PIRARUCU NA BACIA AMAZÔNICA, BRASIL
}

\author{
Luciana Alves Pereira
}

Orientador: Prof. Dr Roberto Santos Ventura

Brasília, julho de 2016 


\author{
UNIVERSIDADE DE BRASÍLIA \\ INSTITUTO DE CIÊNCIAS BIOLÓGICAS \\ PROGRAMA DE PÓS GRADUAÇÃO EM ECOLOGIA
}

Marcadores isotópicos da origem da pesca do pirarucu na bacia

Amazônica, Brasil

\title{
Luciana Alves Pereira
}

Dissertação apresentada ao Instituto de Biologia da Universidade de Brasília como parte dos requisitos para a obtenção do título de Mestre em Ecologia.

Orientador: Prof. Dr. Roberto Ventura Santos

Brasília, 2016 
Dissertação de Mestrado

Luciana Alves Pereira

Marcadores isotópicos da origem da pesca do pirarucu na bacia Amazônica, Brasil

Banca examinadora:

Prof Dr. Roberto Santos Ventura

Presidente /Orientador $I G / U n B$

$\overline{\text { Profa. Dra. Mercedes Maria da Cunha Bustamante }}$ Membro Titular ECL/UnB

$\overline{\text { Prof. Dr. Guilherme Henrique Braga de Miranda }}$

Membro externo

Polícia Federal

Prof. Dr. Guarino Rinaldi Colli

Membro Suplente

Zoo/UnB

Brasília,15 agosto de 2016. 
Dedico esta dissertação aos meus pais

Geralda e Ivaldo, 


\section{AGRADECIMENTOS}

Agradeço primeiramente à Deus, por ter me abençoado, protegido e permitido concluir essa experiência de vida.

Agradeço ao Programa de Pós-Graduação em Ecologia da UnB, ao Laboratório de Estudos geocronológicos, geodinâmicos e ambientais da UnB, à CAPES e ao laboratório MARBEC da França pela oportunidade e financiamento da pesquisa. E ao meu orientador Roberto Ventura Santos, por ter acreditado em mim, me ensinado e me apoiado. Obrigada professor!

Ao Marc Pouilly, que me ensinou, corrigiu e indicou os caminhos com a maior boa vontade do mundo. Obrigada Professor! Ao Fabrice Duponchelle pelo apoio. Este trabalho foi iniciado no contexto dos projetos FRB- Marmiped e LMI-Edia, fundados pelo IRD (Institut de recherch pour le développement).

Especialmente, à Marília, meu anjo da guarda, que me incentivou, ensinou, apoiou, coletou e analisou quando foi preciso. Obrigada amiga!

Aos meus professores que me ensinaram com amor e paciência.

À toda equipe Geochron, ao Eltinho, Jeane, Rachel, Karin, Bárbara, Erico, Marcelo, Dudu, Rafa, Aninha, Maths, Jake, Lets, Felipe, Poliana, Tia Lucy, Natalia e Mancini por todo apoio, paciência e ajuda sem fim durante todo esse processo.

À minha família, ao meu amor Victor, por todo apoio, paciência e cuidado comigo nestes últimos dois anos. À minha mãe, meu pai e minha irmã, por todo apoio e carinho.

Ao Seu Nego, Maria Claudia e a todos da RDSM pela ajuda em Tefé, ao Édipo pela coleta de amostras. E às minhas amigas da associação, da geologia, da ecologia pela força nos momentos difíceis. Enfim agradeço a todos que contribuíram e ajudaram a construir este trabalho! O meu muito obrigada de coração! 
"Andar com fé eu vou, que a fé não costuma faiá” Gilberto Gil

"Tudo que move é sagrado e remove as montanhas com todo cuidado, meu amor"Beto Guedes 


\section{SUMÁRIO}

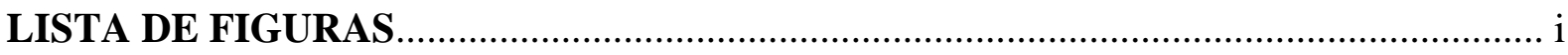

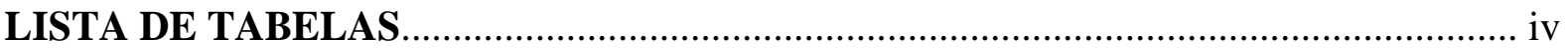

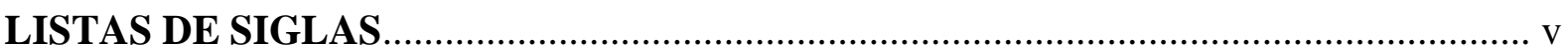

RESUMO

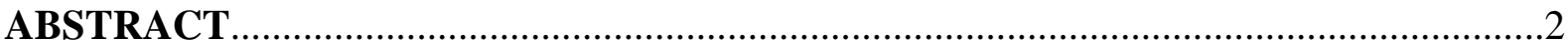

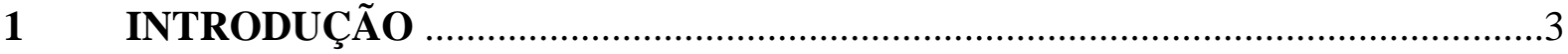

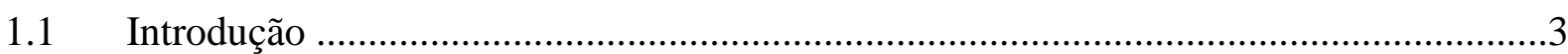

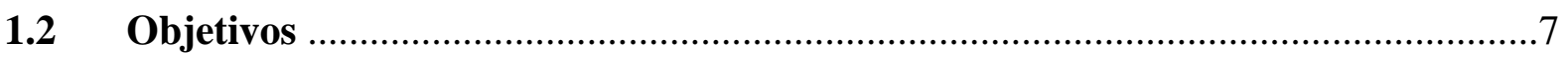

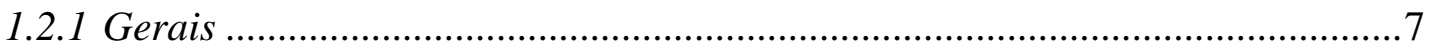

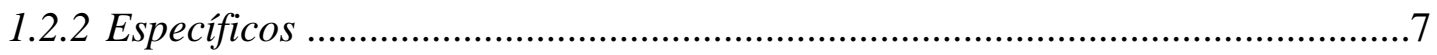

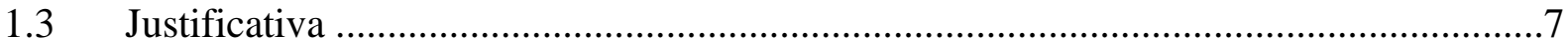

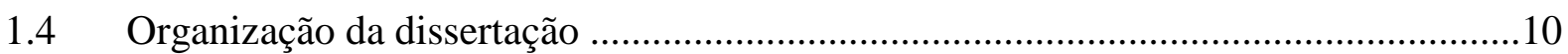

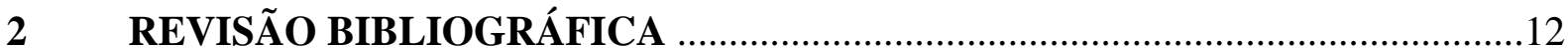

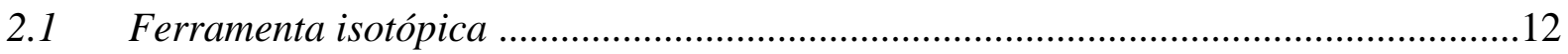

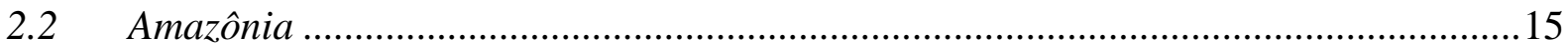

2.2.1 Composição hidrogeoquímica da bacia Amazônica .......................................15

2.2.2 Contexto isotópico ${ }^{87} \mathrm{Sr}{ }^{86} \mathrm{Sr}$ das sub-bacias dos rios Solimões, Amazonas e

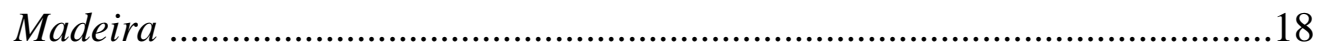

2.3 Aspectos gerais sobre a ecologia do pirarucu, manejo e criação em cativeiro ...........21

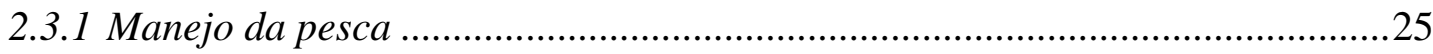

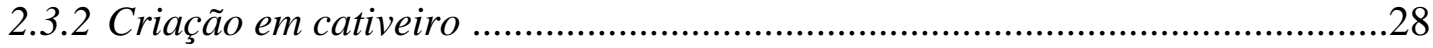

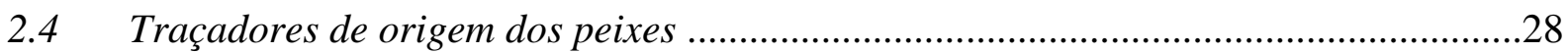

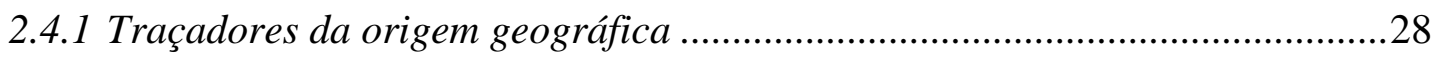


2.4.3 Traçadores de origem de peixes em relação à dieta .........................................32

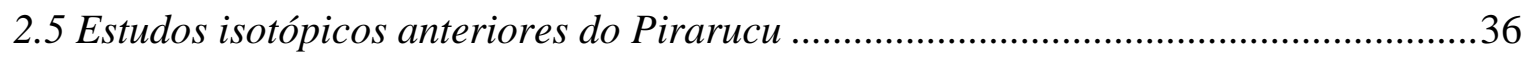

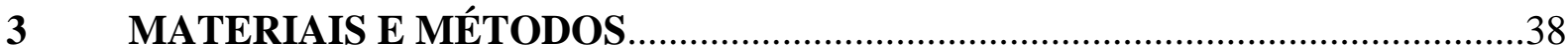

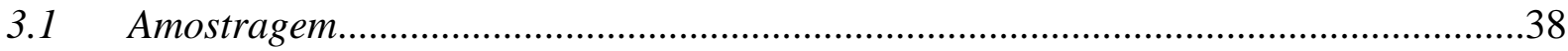

3.1.1 Estudo de caso da Reserva de Desenvolvimento Sustentável de Mamirauá ....42

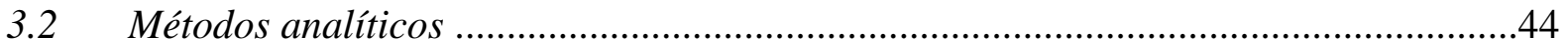

3.2.1 Preparação e análise das amostras de água ..................................................44

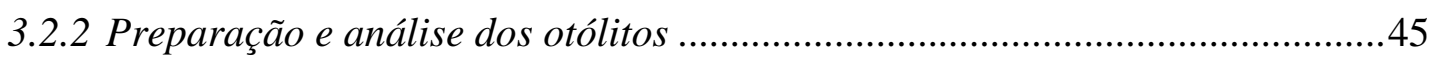

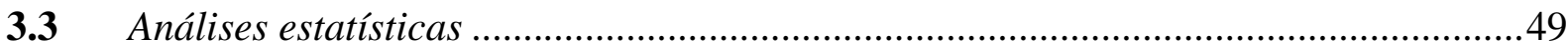

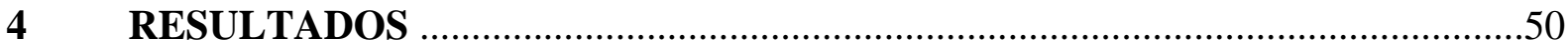

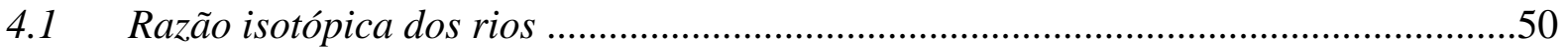

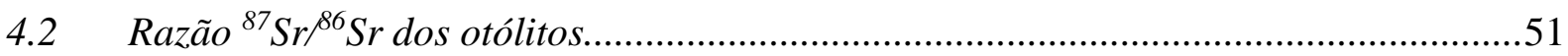

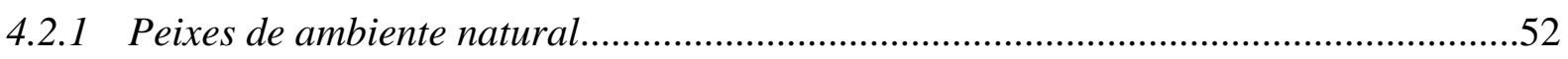

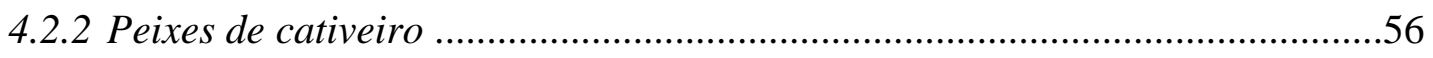

4.2.2.1 Composição isotópica da ração dos indivíduos de cativeiro ................60

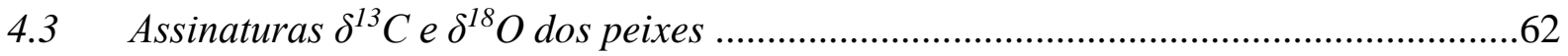

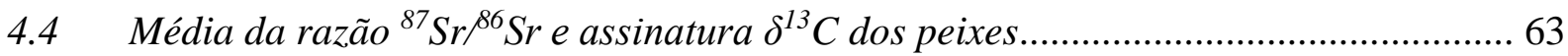

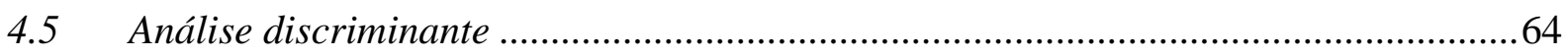

4.6 Estudo de Caso Mamirauá- Uso de marcadores isotópicos em uma escala local ......65

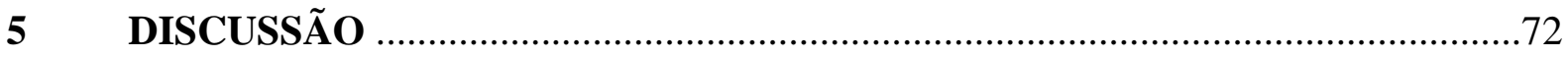

5.1 Variações naturais e o registro isotópicos dos peixes de ambiente natural ................72

5.2 Padrão de sedentarismo e migração lateral ............................................................73

5.3 Variações no registro isotópico dos peixes de cativeiro .............................................75 


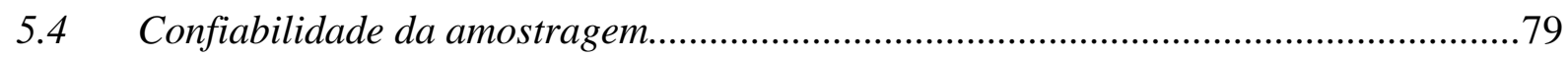

5.5 Pirarucu de Mamirauá e as variações isotópicas...........................................................86

5.6 Comparando espécimes de cativeiro e de ambiente natural........................................87

5.7 Relação entre composição isotópica da ração e dos peixes de cativeiro.......................88

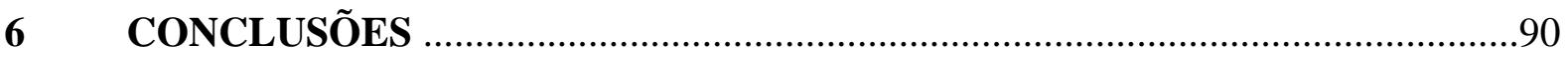

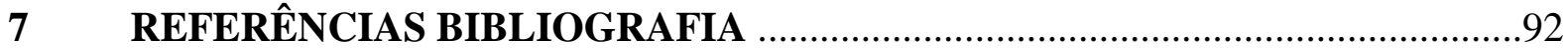




\section{LISTA DE FIGURAS}

FIGURA 1. Representação esquemática dos componentes básicos (fonte de íons, campo magnético e coletores) do espectrômetro de massa de termo-ionização (Figura adaptada de Állegre, 2008).

FIGURA.2 Mapa geológico da Amazônia mostrando as províncias geocronológicas do Cráton da Amazônia e as regiões das redondezas Tassinari \& Macambira (1999), Fuck et al (2008), Cardona et al. (2009) e Decou et al. (2013). Adaptado de Fuck et al., 2008

FIGURA 3 Representa o mapa geológico da região Amazônica com os valores isotópicos (em cima) de $\mathrm{Sr}$ e suas concentrações em ppb (em baixo) dos rios Solimões (azul), Beni-Madeira (amarelo), Tapajós (cinza) e Óbidos (verde). Adaptada de Santos et al. (2015).

FIGURA 4. Indivíduos de três espécies de pirarucu que correspondiam ao Arapaima gigas. A) Arapaima leptossoma; B) Arapaima leptossoma, holótipo, Instituto Nacional de Pesquisas da Amazônia (INPA)16847; C) Arapaima sp. incertae sedis juvenil, INPA, 26582; D) Arapaima agassizii, holótipo. As setas indicam as principais diferenças morfológicas. (Figura retirada de Castello et al., 2013)

FIGURA 5. Valores médios das razões isotópicas ${ }^{87} \mathrm{Sr} /{ }^{86} \mathrm{Sr}( \pm \mathrm{SD})$ dissolvidos na água e nas escamas de dois peixes amazônicos sedentários de água doce (Hoplias malabaricus e Schizodon fasciatus) provenientes de cinco regiões amazônicas. Figura adaptada de Pouilly et al., 2014.

FIGURA 6. Histograma de distribuição da assinatura isotópica de carbono $\delta^{13} \mathrm{C}$.

FIGURA 7. Mapa de localização do estudo. Os marcadores amarelos representam os locais de coleta de água na bacia Amazônica

FIGURA.8 Localização da Reserva de Desenvolvimento Sustentável de Mamirauá (RDSM) (Fonte: www.mamiraua.org.br)

FIGURA 9. Mapa de coleta de água na RDSM. As amostras foram coletadas nos lagos Tefé (A1), Tucuxi (A2) e Arapaima (A8), e. nos rios Japurá (A3, A4 e A5), Aranapu (A6), e Solimões (A7).

FIGURA 10. Ablação a laser no otólito de Arapaima sp. O Centro e a borda estão representados como $\mathrm{C}$ e $\mathrm{B}$, respectivamente.

FIGURA 11. Mapa das razões isotópicas de ${ }^{87} \mathrm{Sr} /{ }^{86} \mathrm{Sr}$ na bacia Amazônica. Os números correspondem aos pontos de coleta de água com suas respectivas razões ${ }^{87} \mathrm{Sr} /{ }^{86} \mathrm{Sr}$. A localização dos pontos de coleta é: 1) Manacapuru; 2) Itacoatiara; 3) Novo Airão; 4) RDSM; 5) Santarém; 7) Porto Velho; 8) Ariquemes; 9) rio Beni; 10) confluência do rio Beni e Madre Dios; 11) rio Yata. 
FIGURA 12. ${ }^{87} \mathrm{Sr} /{ }^{86} \mathrm{Sr}$ dos indivíduos de pirarucu de Santarém. A faixa em azul anil representa a faixa de variação do rio Solimões e a faixa azul claro representa a variação do rio Amazonas de acordo com Santos et al. (2015).

FIGURA 13. Razão ${ }^{87} \mathrm{Sr} /{ }^{86} \mathrm{Sr}$ dos indivíduos de pirarucu do Solimões e médio Amazonas. A faixa azul representa a variação da razão ${ }^{87} \mathrm{Sr} /{ }^{86} \mathrm{Sr}$ dos rios Solimões e Amazonas, e a faixa rosa representa a variação da razão ${ }^{87} \mathrm{Sr} /{ }^{86} \mathrm{Sr}$ do rio Madeira de acordo com Santos et al. (2015).

FIGURA 14. Razão ${ }^{87} \mathrm{Sr} /{ }^{86} \mathrm{Sr}$ dos indivíduos de pirarucu da Bolívia nos rios Beni, Madre Dios e Yata. As faixas representam a variação da razão ${ }^{87} \mathrm{Sr} /{ }^{86} \mathrm{Sr}$ nos rios Yata (rosa), Mamoré (laranja), Beni (verde) e Madre Dios (cinza) de acordo com Pouilly et al. (2014) e Duponchelle et al (2016).

FIGURA 15. Razão ${ }^{87} \mathrm{Sr} /{ }^{86} \mathrm{Sr}$ dos peixes de cativeiro do Solimões e Amazonas. As Faixas representam a variação da razão ${ }^{87} \mathrm{Sr} /{ }^{86} \mathrm{Sr}$ dos rios Solimões e Amazonas (azul) e negro (laranja) de acordo com Santos et al. (2015).

FIGURA 16. Razão ${ }^{87} \mathrm{Sr} /{ }^{86} \mathrm{Sr}$ dos peixes de cativeiro do baixo Amazonas. As faixas representam a variação da razão ${ }^{87} \mathrm{Sr} /{ }^{86} \mathrm{Sr}$ nos rios Negro (laranja), Tapajós (rosa), Amazonas (azul) de acordo com Santos et al. (2015).

FIGURA 17. Razão ${ }^{87} \mathrm{Sr} /{ }^{86} \mathrm{Sr}$ dos indivíduos de pirarucu de cativeiro do rio Madeira. A faixa rosa representa a variação da razão ${ }^{87} \mathrm{Sr} /{ }^{86} \mathrm{Sr}$ do rio Madeira Santos et al. (2015) e Duponchelle et al (2016).

FIGURA 18. Razão ${ }^{87} \mathrm{Sr} /{ }^{86} \mathrm{Sr}$ dos otólitos dos peixes de cativeiro, da média das águas das respectivas bacias e das rações utilizadas na alimentação em cativeiro. A faixa azul representa a variação da razão $87 \mathrm{Sr} / 86 \mathrm{Sr}$ das rações utilizadas na alimentação dos peixes.

FIGURA 19. Relação $\delta^{13} \mathrm{C}$ e $\delta^{18} \mathrm{O}$ da pesca do pirarucu na bacia Amazônica. As faixas em azul e rosa representam a faixa de assinatura isotópica $\delta^{13} \mathrm{C}$ das plantas $\mathrm{C} 3$ e $\mathrm{C} 4$, respectivamente.

FIGURA 20. Razão ${ }^{87} \mathrm{Sr} /{ }^{86} \mathrm{Sr}$ média e assinatura $\delta^{13} \mathrm{C}$ dos pirarucus da bacia Amazônica.

FIGURA 21. Mapa da condutividade dos rios Japurá (A3, A4 e A5), Aranapu (A6), Solimões (A7), e lagos Tefe (A1), Tucuxi (A2) e Arapaima (A8). Os lagos estão em azul e os rios em verde.

FIGURA 22. Mapa da razão isotópica $\delta^{18} \mathrm{O}$ dos rios Japurá (A3, A4 e A5), Aranapu (A6), Solimões (A7), e lagos Tefé (A1), Tucuxi (A2) e Arapaima (A8). Os lagos estão em azul e os rios em verde.

FIGURA 23. Mapa da razão isotópica $\delta \mathrm{D}$ dos rios Japurá (A3, A4 e A5), Aranapu (A6), Solimões (A7), e lagos Tefé (A1), Tucuxi (A2) e Arapaima (A8). Os lagos estão em azul e os rios em verde.

FIGURA 24. Relação entre $\delta^{18} \mathrm{O}$ e $\delta \mathrm{D}$. A linha contínua azul representa a reta de água meteórica global (GMWL) e a linha tracejada laranja representa as águas coletadas na RDSM. 
No círculo azul estão as águas dos lagos Tefé, Tucuxi e Arapaima e no círculo verde as águas dos rios Japurá, Aranapu e Solimões. O ponto A9 representa a água subterrânea.

FIGURA 25. Razão isotópica ${ }^{87} \mathrm{Sr} /{ }^{86} \mathrm{Sr}$ dos rios Japurá (A3, A4 e A5), Aranapu (A6), Solimões (A7), e lagos Tefé (A1), Tucuxi (A2) e Arapaima (A8). Os lagos estão representados em símbolos em azul e os rios em verde.

FIGURA 26. Razão ${ }^{87} \mathrm{Sr} /{ }^{86} \mathrm{Sr}$ dos pirarucus da RDSM. As faixas representam as variações nas razões ${ }^{87} \mathrm{Sr} /{ }^{86} \mathrm{Sr}$ dos rios Negro (amarelo) e Solimões (azul).

FIGURA 27. Comparação entre as razões ${ }^{87} \mathrm{Sr} /{ }^{86} \mathrm{Sr}$ dos indivíduos de ambiente natural e de cativeiro do médio Amazonas. As faixas representam o intervalo de variação dos rios Solimões e Amazonas (azul) e do rio Negro (laranja) de acordo com Santos et al. (2015).

FIGURA 28. Comparação entre as razões ${ }^{87} \mathrm{Sr} /{ }^{86} \mathrm{Sr}$ dos indivíduos de ambiente natural e de cativeiro do baixo Amazonas. As faixas representam o intervalo de variação dos rios Solimões e Amazonas (azul), do Tapajós (laranja) e do Negro (amarelo) de acordo com Santos et al. (2015). 


\section{Lista de Tabelas}

TABELA 1. Registro de aquicultores na região Norte. Fonte: Ministério da Agricultura, pecuária e Abastecimento (MAPA), 2016.

TABELA.2 Agenda do treinamento alimentar do pirarucu em cativeiro (temperatura $27^{\circ} \mathrm{C}$ $\left.30^{\circ} \mathrm{C}\right)$.

TABELA 3. Origem do material biológico (município e tipo de ambiente).

TABELA 4. Variação dos isótopos de $\mathrm{Sr}$ nos pirarucus de cativeiro e ambiente natural indicando os: rios de origem, número de indivíduos, média da razão ${ }^{87} \mathrm{Sr} /{ }^{86} \mathrm{Sr}$ do otólito, desvio padrão, razão ${ }^{87} \mathrm{Sr} /{ }^{86} \mathrm{Sr}$ mínima do otólito e razão ${ }^{87} \mathrm{Sr} /{ }^{86} \mathrm{Sr}$ máxima do otólito. (ANOVA, $\mathrm{F}=19.566 ; \mathrm{p}=<0,01$ ).

TABELA 5. Tipos de ração e assinatura $\delta^{13} \mathrm{C}\left(\%\right.$ ) (Erro associado: $\delta^{13} \mathrm{C}=0,05 \%$ ) e razão ${ }^{87} \mathrm{Sr} /{ }^{86} \mathrm{Sr}$

TABELA 6. Resultados da QDA e do teste de acurácia Jackknife dos indivíduos de pirarucu agrupados por rios segundo a razão ${ }^{87} \mathrm{Sr} /{ }^{86} \mathrm{Sr}$ e por método de produção segundo a assinatura $\delta^{13}$ C. (N.A. significa não se aplica). 


\section{Lista de Siglas}

\begin{tabular}{|c|c|c|c|}
\hline & & & \\
\hline FAO & \begin{tabular}{lll} 
Organização & das & \multicolumn{2}{c}{ Nações } \\
Unidas para & Agricultura & e \\
Alimentação & &
\end{tabular} & $\delta^{15} \mathrm{~N}$ & $\begin{array}{l}\text { Assinatura isotópica de } \\
\text { nitrogênio }\end{array}$ \\
\hline OMS & Organização Mundial da Saúde & $\delta^{18} \mathrm{O}$ & $\begin{array}{l}\text { Assinatura isotópica de } \\
\text { oxigênio }\end{array}$ \\
\hline LA-MC-ICPMS & $\begin{array}{l}\text { Laser Ablation Multi Collector } \\
\text { Spectromery Mass Isotopic } \\
\text { Coupled Plasma }\end{array}$ & $\delta \mathrm{D}$ & $\begin{array}{l}\text { Assinatura isotópica de } \\
\text { deutério }\end{array}$ \\
\hline CITES & $\begin{array}{l}\text { Convention on International } \\
\text { Trade in Endangered Species }\end{array}$ & ${ }^{87} \mathrm{Sr} /{ }^{86} \mathrm{Sr}$ & $\begin{array}{l}\text { Razão isotópica de } \\
\text { estrôncio }\end{array}$ \\
\hline CIIES & of Wild Fauna and Flora & $\mathrm{CaCO}_{3}$ & Carbonato de calcio \\
\hline IBAMA & $\begin{array}{l}\text { Instituto Brasileiro de Meio } \\
\text { Ambiente }\end{array}$ & $\mathrm{H}_{2} \mathrm{PO}_{4}$ & Ácido fosfórico \\
\hline WWF & World Wildlife Found & $\mathrm{CO}_{2}$ & $\begin{array}{l}\text { Gás carbônico } \\
\text { THERMO SCIENTIFIC }\end{array}$ \\
\hline IAEA & $\begin{array}{l}\text { Agência Internacional de } \\
\text { Energia Atômica }\end{array}$ & N-TIMS & TRITON \\
\hline V-SMOW & $\begin{array}{l}\text { Vienna Standard Mean Ocean } \\
\text { Water }\end{array}$ & LCABIE & $\begin{array}{lr}\text { Laboratoire de } & \text { Chimie } \\
\text { Analytique } & \text { Bio- } \\
\text { inorganique } & \text { et } \\
\text { Environnement } & \end{array}$ \\
\hline INPA & $\begin{array}{l}\text { Belemnitella Americana da } \\
\text { formação Peedee do Cretáceo } \\
\text { Instituto Nacional de Pesquisa } \\
\text { da Amazônia }\end{array}$ & IPREM & $\begin{array}{l}\text { Institut Pluridisciplinaire } \\
\text { de Recherche sur } \\
\text { l'Environnement et les } \\
\text { Matériaux }\end{array}$ \\
\hline RDSM & $\begin{array}{l}\text { Reserva de Desenvolvimento } \\
\text { Sustentável de Mamirauá }\end{array}$ & QDA & $\begin{array}{l}\text { Análise de discriminante } \\
\text { quadrática }\end{array}$ \\
\hline RESEX & Reserva Extrativista & ANOVA & Análise de variância \\
\hline $\mathrm{RM}$ & Reserva Municipal & GMWL & $\begin{array}{l}\text { Global Meteoric Water } \\
\text { Line }\end{array}$ \\
\hline & Instituto de Proteção & & \\
\hline IPAAM & Ambiental do Amazonas & & Organização das Nações \\
\hline MAPA & $\begin{array}{l}\text { Ministério da Agricultura } \\
\text { Pecuária e Abastecimento }\end{array}$ & UNESCO & $\begin{array}{l}\text { Unidas para a Educação, } \\
\text { Ciência e Cultura }\end{array}$ \\
\hline$\delta^{13} \mathrm{C}$ & $\begin{array}{l}\text { Assinatura isotópica de } \\
\text { carbono }\end{array}$ & GNIR & $\begin{array}{l}\text { Global Network } \\
\text { Isotopes in Rivers }\end{array}$ \\
\hline
\end{tabular}




\section{RESUMO}

O desenvolvimento de ferramentas analíticas para determinar a origem de peixes é útil para o entendimento de padrões de uso do habitat e podem auxiliar no monitoramento, manejo e no controle de recursos naturais, bem como na certificação da origem de alimentos. A aplicação da metodologia de análise isotópica em estruturas calcificadas fornece informações integradas sobre a origem geográfica dos peixes provenientes de diferentes ambientes. $\mathrm{O}$ objetivo deste trabalho foi desenvolver marcadores isotópicos de estrôncio $(\mathrm{Sr})$, carbono $(\mathrm{C})$ e oxigênio $(\mathrm{O})$ para traçar a origem geográfica do pirarucu (Arapaima sp.) comercializado na bacia Amazônica, por meio da análise cronológica de Sr nos otólitos em alta resolução com LA-MC-ICPMS, visando distinguir indivíduos criados em cativeiro e capturados em ambiente natural. Foram coletados espécimes de diferentes ambientes, bem como a água e as rações utilizadas na alimentação do pirarucu em cativeiro. Os principais resultados encontrados foram: a discriminação total da pesca do pirarucu quanto a origem geográfica e ao método de produção com $70,5 \%$ e $94,16 \%$ de classificação correta, respectivamente; a integração cronológica entre as variações das razões ${ }^{87} \mathrm{Sr} /{ }^{86} \mathrm{Sr}$ dos peixes em relação as sub-bacias amazônicas, bem como a confirmação do padrão de sedentarismo e migração lateral do pirarucu. A ferramenta isotópica desenvolvida apresenta diversas aplicações no rastreamento da pesca do pirarucu na bacia Amazônia, sendo assim importante para o desenvolvimento tecnológico e ecológico desta espécie no ecossistema Amazônico.

Palavras-chave: Arapaima sp. Isótopos estáveis, Estrôncio, Carbono, Oxigênio 


\begin{abstract}
The development of an analytical tool to determine the origin of fish is useful for the understanding of habitat use patterns and can assist in monitoring, management and control of natural resources, as well as the certification of food origin. The application of isotopic analyses methodology in calcificated structures provides integrate information about a fish's geographic origin from different environments. The objective of this study was to develop a method using $\mathrm{Sr}, \mathrm{C}$ and $\mathrm{O}$ isotopic markers to trace the geographical origin of pirarucu (Arapaima sp) sold in Amazonian basin, through the chronological otolith analyses in high resolution with LA-MC-ICPMS, in order to distinguish captive fishes from those caught in their natural environment. Individuals were collected from different environments, as well as water and food used for feeding pirarucu in captivity. The main findings were total discrimination of Arapaima fishing for the geographic origin and production method with $70,5 \%$ e $94,16 \%$ of correct classification, respectively; chronological integration between the variation of fish ${ }^{87} \mathrm{Sr} /{ }^{86} \mathrm{Sr}$ ratio in relation to the Amazon sub basins, as well as confirmation of pirarucu sedentary pattern and lateral migration. The isotopic tool developed has several applications in tracking the Arapaima sp. fishing in Amazon basin, therefore important for technological and ecological development about these species in Amazon ecosystem.

Keywords: Arapaima sp. Stable Isotopes, Strontium, Carbon, Oxygen
\end{abstract}




\section{INTRODUÇÃO}

\subsection{Introdução}

A hidrogeoquímica de grandes bacias hidrográficas e suas relações com compartimento biótico podem auxiliar no manejo, conservação, controle e regulamentação de recursos naturais (Pracheil et al., 2014). O uso de traçadores biogeoquímicos tem sido cada vez mais aplicado na determinação da origem de recursos naturais, a exemplo dos recursos pesqueiros com fins de certificação da origem de alimentos, manejo dos estoques pesqueiros e entendimento sobre a história de vida e ecologia das espécies de peixes (Pracheil et al., 2014; Pouilly et al., 2014; Duponchelle et al., 2016; Beffi \& Trincherini, 2016). Esse conhecimento pode auxiliar os processos de regulamentação existentes, visto que possibilita o desenvolvimento de ferramentas que permitam maior controle e monitoramento no manejo de recursos naturais (Beffi \& Trincherini, 2016).

O entendimento sobre a ecologia dos peixes e suas histórias de vida constituem um desafio para a conservação e consequentemente para a manutenção destes recursos. Esse conhecimento além de contribuir para definição das rotas de comércio de pescados, auxilia na identificação de hábitats críticos das espécies de peixes. Dessa forma, estudos sobre a origem da pesca são extremamente relevantes para o estabelecimento de estratégias de manejo de estoques pesqueiros em todo mundo (Pracheil et al., 2014).

Dentre as várias metodologias utilizadas para traçar a origem e migração de animais, as análises isotópicas são ferramentas extremamente úteis, precisas e eficazes (Hobson, 1999), pois integram as informações sobre processos de ciclagem biogeoquímica nos compartimentos dos ecossistemas (Fry, 2008), com aplicações diretas para o setor de aquicultura, órgãos reguladores do governo, pescadores e gestores de comunidades que realizam o manejo de espécies de peixes (Pracheil et al., 2014). Como exemplo, essa técnica 
tem sido cada vez mais aplicada para determinar a origem, a movimentação e a idade de peixes. Dentro das aplicações recentes das análises isotópicas destacam-se a diadromia, dispersão larval, o comportamento de homing (migração com retorno às regiões de eclosão), identificação de hábitats berçários e a discriminação de estoques (Campana et al., 1995; Campana and Thorrold, 2001; Woodhead et al., 2004).

Além das aplicações em estudos ecológicos, há também a adequação da metodologia na regulação da origem dos alimentos. Moretti et al. (2003) enfatizam que as normas de segurança internacionais de alimentos têm estabelecido padrões para as cadeias de produção relativos aos produtos pesqueiros e da aquicultura. Por exemplo, desde 2001 a União Europeia e nações da Ásia, como Índia e Austrália, vêm requerendo dos estabelecimentos comerciais informações mais detalhadas sobre os peixes consumidos em seus territórios, incluindo os métodos de produção (criação em cativeiro ou pesca em ambiente natural) (Turchini et al., 2009). Tais normas são baseadas em guias e princípios designados pela Organização das Nações Unidas para Agricultura e Alimentação (FAO) e pela Organização Mundial da Saúde (OMS) (Turchini et al., 2009). Essa certificação fornece ao consumidor informações sobre as características dos produtos e sua adequação às regras estabelecidas pelos órgãos de regulação, como por exemplo, se a pesca é oriunda de uma área natural permitida ou de um cativeiro licenciado.

Em revisão recente sobre o uso de isótopos de $\mathrm{Sr}$ como traçador da origem de alimentos, Beffi \& Trincherini (2016) destacam que desde o início dos anos 90 essa técnica tem gerado dados robustos, precisos e confiáveis para garantir a autenticidade e origem de alimentos, bem como para evitar possíveis fraudes. Neste sentido, os autores apresentam pesquisas desenvolvidas para discriminar a origem de alimentos tais como: vegetais, bebidas, laticínios, carnes e peixes. (Fortunato et al., 2004; Barnett- Johnson, 2004; Di Paola-Naranjo 
et al., 2011; Rummel et al., 2012; Trincherini et al., 2014). A semelhança desses produtos, o setor pesqueiro também conta com um eficiente sistema de monitoramento, cujas perguntas norteadoras são (Beffi \& Trincherini, 2016): 1) quais espécies? 2) de onde elas vêm? e 3) e são pescadas em ambiente natural ou criadas em cativeiro? Além disso, uma variedade de outras técnicas, como análise de glicerídeos, análises de marcadores genéticos, proteômica, microquímica e análise de isótopos estáveis, podem ser utilizadas em associação à análise da razão isotópica ${ }^{87} \mathrm{Sr} /{ }^{86} \mathrm{Sr}$ para responder a essas e outras questões.

Vários estudos têm utilizado isótopos estáveis de carbono, oxigênio ou nitrogênio com a finalidade de distinguir a origem e o método de produção de recursos pesqueiros (Bell et al., 2007; Rojas et al., 2007; Barnett - Johnson, 2008; Turchuni et al., 2009;). Por exemplo, Turchuni et al. (2009) distinguiram tipos de cultivo do bacalhau Murray australiano (Maccullochella peelii peelii) em diferentes áreas geográficas utilizando análises isotópicas de $\delta^{13} \mathrm{C}, \delta^{15} \mathrm{~N}$ e $\delta^{18} \mathrm{O}$. Em outro estudo, Bell et al. (2007) utilizaram a composição isotópica do C e O da gordura da carne e do $\mathrm{C}$ dos ácidos graxos do badejo (Dicentrarchus labrax) para identificar os indivíduos provenientes de ambientes naturais e de cativeiro. Rojas et al. (2007), por sua vez, determinaram valores isotópicos de $\delta^{13} \mathrm{C}$ e $\delta^{15} \mathrm{~N}$ no músculo da dourada (Sparus aurata) provenientes de quatro países do Mediterrâneo a fim de distinguir o método de produção. Estes trabalhos exemplificam o uso da metodologia isotópica para este fim e demostram a viabilidade e a necessidade de se distinguir os peixes provenientes dos diferentes ambientes.

Além das análises de tecidos moles, determinações isotópicas têm sido realizadas também em estruturas calcificadas de peixes com o objetivo de identificar indivíduos de diferentes ambientes (Pracheil et al., 2014). Em geral, essa metodologia é utilizada para determinar a composição isotópica de otólitos, que são estruturas ósseas do ouvido interno do 
peixe (Kerr e Campana, 2014). Além de otólitos, alguns estudos têm analisado outras estruturas calcificadas, como escamas (Kennedy et al., 2000; Domingues et al., 2002; Pouilly et al., 2014;). Em geral esses trabalhos têm concluido que a composição isotópica do ambiente onde o peixe viveu fica registrada cronologicamente nessas estruturas (Kerr e Campana, 2014).

A maioria dos estudos com a metodologia isotópica para traçar a origem de peixes e identificar padrões de uso do hábitat são desenvolvidos com espécies marinhas e em regiões temperadas (Swearer et al., 2003; Gillanders, 2005; Comyns et al., 2008). Em regiões tropicais em rios de água doce, publicações sobre esses assuntos são mais raras (Walther et al., 2011; Pouilly et al., 2014; Garcez et al., 2014; Hegg et al., 2015; Souza et al., 2016; Duponchelle et al., 2016; Hermann et al.,2016). Na Amazônia, padrões de determinação da origem de peixes são difíceis de observar, caracterizar e modelar em função do tamanho, fragmentação e complexidade das múltiplas sub-bacias existentes na região. A escassez de trabalhos e a necessidade de manejar, monitorar e caracterizar a pesca na região, requerem o desenvolvimento e a utilização de ferramentas de rastreamento aplicáveis a peixes de água doce no sistema Amazônico.

Diante dessas necessidades, busca-se, por meio deste trabalho, contribuir para o avanço do conhecimento já existente, cujo objetivo é identificar marcadores para traçar a origem geográfica e o ambiente do pescado de pirarucu comercializado na bacia Amazônica, por meio de parâmetros isotópicos. Além dos isótopos de carbono e oxigênio, serão apresentados também análises com LA-MC-ICPMS, Laser Ablation Multicolector Inductive Couple Plasma Mass Spectrometry, que permite obter variações isotópicas de Sr de otólitos com alta resolução cronológica. Os dados obtidos contribuirão para a melhor compreensão dos padrões de história de vida da espécie estudada e auxiliar no manejo, conservação, 
controle e regulamentação de recursos naturais, além de contribuir para a elucidação das rotas de comércio e elos da cadeia produtiva, a fim de evitar possíveis fraudes quanto a origem dos alimentos comercializados.

\subsection{OBJETIVOS}

\subsubsection{Objetivos Gerais}

O presente estudo tem por objetivo identificar por meio de marcadores químicos e geoquímicos a origem geográfica e o ambiente de crescimento do pirarucu (Arapaima sp.) comercializado na Bacia Amazônica, visando distinguir indivíduos criados em cativeiros e capturados em ambiente natural.

\subsubsection{Objetivos específicos}

a. Comparar a composição isotópica $\left({ }^{87} \mathrm{Sr} /{ }^{86} \mathrm{Sr}, \delta^{13} \mathrm{C}\right.$ e $\left.\delta^{18} \mathrm{O}\right)$ de otólitos de pirarucu capturados em diferentes ambientes naturais com os criados em cativeiro;

b. Estudar a variação temporal da composição isotópica de $\mathrm{Sr}$ dos otólitos de pirarucu capturados em diferentes ambientes naturais e de cativeiro, bem como da água em que o peixe viveu;

c. Verificar a mobilidade geográfica do pirarucu por meio das variações isotópicas de $\mathrm{Sr}$ em um ambiente da Reserva de Desenvolvimento Sustentável de Mamirauá ;

d. Definir a base alimentar de peixes criados em cativeiro tendo por base a composição isotópica da ração (C e Sr).

\subsection{Justificativa}

Neste trabalho foi utilizado como modelo o pirarucu (Arapaima sp.) para traçar a origem de sua pesca na bacia Amazônica utilizando a metodologia de análise isotópica. Este gênero é um modelo apropriado para este tipo de estudo devido a sua importância econômica, 
social e ecológica. O pirarucu é uma importante fonte alimentar para as pessoas da região amazônica, apresenta alto valor econômico e por isso é superexplorado pela pesca (Figueiredo et al., 2013). Consequentemente, a espécie foi classificada como vulnerável (World Conservation Monitoring Centre, 1999; CITES). A super exploração pela pesca desencadeou uma série de restrições legais temporais e espaciais da pesca na região (Figueiredo et al., 2013).

Este gênero também possui uma ampla distribuição na bacia Amazônica (Castello et al., 2013; Araripe et al., 2013; Queiroz, 2000), é comumente criado em cativeiro (Imbiriba, 2001) e é considerado como grupo de espécies sedentárias em seu hábitat, características que atendem aos pressupostos de discriminação de estoques pesqueiro como o uso da metodologia isotópica, pois os diferentes grupos devem apresentar valores isotópicos distintos (Keer \& Cammpana, 2014; Pracheil et al., 2014).

A partir dos anos 90, estratégias para preservação, conservação e manejo do pirarucu na Amazônia resultaram na recuperação dos estoques locais com sucesso. Estas estratégias incluem normas técnicas de manejo, novos métodos de avaliação, bem como a participação efetiva dos pescadores na elaboração dessas medidas (Figueiredo et al., 2013). Por conseguinte, a pesca do pirarucu na bacia Amazônica brasileira aumentou, passando de 495 toneladas em 2001, para 1.236 toneladas em 2006 (IBAMA, 2006). Desse total, a produção no estado do Amazonas em 2006 correspondeu a 961 toneladas (78\%) e o restante (22\%) distribuiu-se, em ordem de importância, entre os seguintes estados: Pará, Goiás, Tocantins, Amapá, Acre, Rondônia e Roraima.

Em 2004, a Instrução Normativa IBAMA no 34/2004 regulamentou uma série de parâmetros quanto à pesca e comercialização do pirarucu, incluindo o período de defeso, tamanho mínimo de captura $(150 \mathrm{~cm})$, restrições de pesca com permissão de procedência 
apenas em ambientes naturais de áreas manejadas, ou com acordo de pesca; ou ainda, se provenientes de cativeiro. Este método de produção apresenta uma importante atividade complementar à pesca, tendo como objetivo aumentar a produção pesqueira a médio e longo prazo e diminuir a pressão de super exploração causada pela pesca (Imbiriba, 2001).

Apesar de todos estes esforços para a conservação do pirarucu é sabido que hoje a maior parte da pesca comercial é oriunda de atividades ilegais (Hrbek et al., 2008; Castello et al., 2013). Como ressaltou Queiroz (2000), mesmo com todas as medidas adotadas, o IBAMA, que detém a competência de fiscalizar a atividade pesqueira, não possui meios adequados, como recursos humanos e financeiros, para assegurar a aplicabilidade das leis e punir aqueles que a infringem em uma bacia de extensão continental.

Em Rondônia, a Lei Estadual $n^{\circ} 1038$ de 22 de janeiro de 2002 estabelece que é proibida a captura, transporte e criação de pirarucu, exceto com prévia autorização do órgão competente. No entanto, a pesca do pirarucu é permitida em comunidades isoladas do Estado, com fins de subsistência, se praticada de forma artesanal, e uma vez obedecido o período de defeso e observado o tamanho mínimo de captura estabelecido. Dessa forma, a comercialização da espécie só é permitida se oriunda da aquicultura no estado de Rondônia.

Há mais de trinta anos, estratégias para conservação dessa espécie envolvem: 1) o manejo participativo e monitoramento realizado pelos pescadores e técnicos nas áreas de manejo permitidas; 2) a regulamentação da pesca pela legislação brasileira; e 3) o desenvolvimento da atividade de criação em cativeiro (Imbirira, 1991 e 1994; Moura Carvalho \& Nascimento, 1992; Imbiriba et al., 1996; Queiroz, 2000; WWF, 2011; Figueiredo et al., 2013). Nesse contexto, o desenvolvimento de técnicas para determinação de origem da pesca pode fortalecer os esforços que estão sendo desenvolvidos para a conservação do 
pirarucu, visto que a rastreabilidade da origem da pesca é um fator chave para a efetividade das estratégias conservacionistas para essa espécie.

\subsection{Organização da dissertação}

Esta dissertação está organizada em seis seções: Introdução, Revisão bibliográfica do tema; Materiais e métodos; Resultados; Discussão e Conclusões. A primeira seção introduz o tema da dissertação, seus objetivos e revela a importância do desenvolvimento da ferramenta.

A segunda seção contempla a Revisão bibliográfica por meio da qual é abordado o conhecimento sobre a ferramenta analítica, as variações geoquímicas e composição hidrogeoquímica da bacia Amazônica, os aspectos gerais sobre a ecologia do pirarucu, bem como o contexto atual sobre seu manejo e criação em cativeiro. São também apresentados uma revisão dos trabalhos para traçar a origem de peixes utilizando a metodologia de análise isotópica em otólitos e os principais estudos isotópicos realizados com o gênero Arapaima sp.

A terceira seção versa sobre materiais e métodos, na qual são descritos os procedimentos de amostragem de água e otólitos, bem como a localização e áreas de coleta de amostras. São também detalhados os procedimentos analíticos realizados para as análises isotópicas de $\mathrm{Sr}, \mathrm{C}, \mathrm{O}$ e D em amostras de material ósseo (otólito), ração e água, bem como as análises estatísticas realizadas no trabalho.

Na seção de resultados são apresentados os dados obtidos neste estudo em relação à amostragem de água e aos registros cronológicos das razões ${ }^{87} \mathrm{Sr} /{ }^{86} \mathrm{Sr}$, nos otólitos dos indivíduos de diferentes rios da bacia Amazônica. Os dados são apresentados de acordo com os métodos de produção da pesca do pirarucu, em ambiente natural e em criação em cativeiro, para entender os padrões de movimentação e uso do habitat do pirarucu. São também apresentadas as assinaturas $\delta^{13} \mathrm{C}$ e $\delta^{18} \mathrm{O}$ dos indivíduos de pirarucu e a integração da razão 
${ }^{87} \mathrm{Sr} /{ }^{86} \mathrm{Sr}$ com a assinatura $\delta^{13} \mathrm{C}$. A fim de melhor compreender a base alimentar de peixes criados em cativeiro, são apresentados a base da composição isotópica da ração (C e $\mathrm{Sr})$. E por fim, é apresentado o estudo de caso realizado na Reserva de Desenvolvimento Sustentável de Mamirauá, onde as condições fisico-químicas e as composições isotópicas foram caracterizadas a fim de entender o habitat do pirarucu nos ambientes de várzea em uma escala local, juntamente com as razões isotópicas de ${ }^{87} \mathrm{Sr} /{ }^{86} \mathrm{Sr}$ dos peixes adquiridos na reserva.

Na quinta seção é realizada a discussão dos resultados obtidos no que tange às variações naturais e aos registros isotópicos dos espécimes de peixe de ambiente natural; ao padrão de sedentarismo e migração lateral do pirarucu; às variações no registro isotópico dos peixes de cativeiro; à confiabilidade da amostragem; ao pirarucu de Mamirauá e suas variações isotópicas; à comparação de espécimes de cativeiro e de ambiente natural e a relação entre composição isotópica da ração e dos peixes de cativeiro.

E por fim, são apresentadas conclusões gerais dessa dissertação e as questões em aberto e que requerem estudos mais detalhados. 


\section{REVISÃO BIBLIOGRÁFICA}

\subsection{Ferramentas isotópicas}

Esse trabalho utiliza variações isotópicas de carbono, oxigênio e estrôncio como marcadores da alimentação e do local de vida do pirarucu. As variações isotópicas de estrôncio fornecem informações sobre a origem geográfica de peixes (Pouilly et al., 2014; Hegg et al., 2015; Duponchelle et al.,2016), uma vez que a composição isotópica desse elemento na água dos rios está relacionada a geologia das sub-bacias- hidrográficas na Amazônia (Palmer \& Edmond et al., 1992; Gaillardet et al., 1997; Viers et al., 2008; Santos et al., 2015). Os isótopos de carbono estão relacionados às fontes alimentares dos peixes amazônicos nos seus ambientes (Forsberg et al., 1993; Araujo-Lima et al., 1986; Jepsen \& Winemiller, 2007; Watson et al., 2013; Mortillato et al., 2014; Marshall et al. 2007). Já os isótopos de oxigênio fornecem informações do ciclo hidrológico do habitat do peixe (Bell et al., 2007). Logo, as análises isotópicas possuem aplicações importantes para traçar o origem e movimentação de animais em seus hábitats, pois o registro isotópico dos peixes revelam as variações físico-químicas e a ciclagem de nutrientes nos ambientes (Kerr e Campana, 2014).

Isótopos são elementos químicos que possuem núcleo com mesmo número de prótons, mas diferentes números de massa, resultantes de uma quantidade diferente de nêutrons em seus núcleos. Os isótopos podem ser divididos em estáveis e radioativos. Os isótopos estáveis são aqueles que não sofrem decaimento radioativo, já os radioativos decaem por meio de emissão de partículas $\alpha$ ou $\beta$ ou radiação $\gamma$. Ao longo deste trabalho, o desenvolvimento de marcadores geográficos é realizado com a metodologia de isótopos estáveis, ou seja, são nuclídeos que não sofrem decaimento radioativo, se comportando, portanto como traçadores conservativos (Fry, 2008; Allegre, 2008). 
As razões isotópicas são determinadas por meio de espectrômetros de massa, que são equipamentos que conseguem separar os diferentes isótopos através de um sistema que consiste de uma fonte de íons, um campo magnético e um conjunto de coletores (Allegre, 2008). No espectrômetro de massa, a amostra é ionizada e acelerada em condição de vácuo, formando um feixe de íons com o auxílio de lentes eletromagnéticas. A presença de um campo magnético faz com que os átomos ionizados realizem trajetórias diferentes de acordo com a sua massa e carga elétrica. No final desta trajetória, coletores, especificamente posicionados de acordo com a massa e carga elétrica dos diferentes isótopos, contabilizam a proporção de cada nuclídeo. (Figura 1)

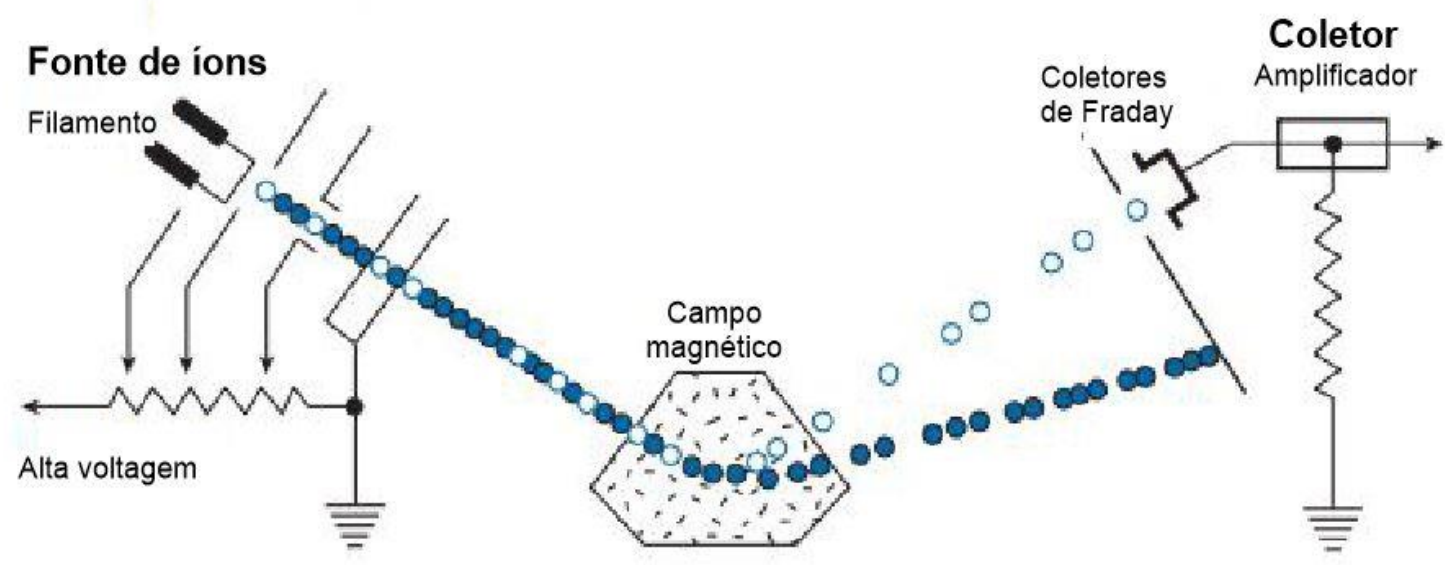

Figura 1. Representação esquemática dos componentes básicos (fonte de íons, campo magnético e coletores) do espectrômetro de massa de termo-ionização (Figura adaptada de Állegre, 2008)

A razão isotópica é dita como a razão entre a abundância do isótopo pesado pelo leve. No entanto, usualmente usamos o termo assinatura isotópica, dita notação delta que é obtida comparando-se a razão isotópica da amostra com a de um padrão previamente definido. $\mathrm{O}$ 
parâmetro delta é apresentado em por mil (\%o) e é definido pela seguinte relação: (Allegre, 2008; Fry, 2008)

$$
\delta^{\mathrm{A}} \mathrm{X}=[(\mathrm{R} \text { amostra/ R padrão }-1)]^{*} 1000,
$$

onde, A é o número de massa, e X o elemento químico.

As determinações de $\delta^{18} \mathrm{O}$ e $\delta \mathrm{D}$ são referenciadas ao padrão V-SMOW estabelecido pela IAEA (Agência Internacional de Energia Atômica) e que possui composição isotópica próxima à média da composição da água dos oceanos. As determinações de $\delta^{13} \mathrm{C}$ são referenciadas ao padrão o PDB (Belemnitella Americana da formação Peedee do Cretáceo), que é uma belemnita de calamar pré-histórico (McCrea, 1950; Allegre, 2008). E para Sr são utilizados os padrões NBS987e NIES certificado pela IAEA e pelo Instituto Nacional de Estudos Ambientais do Japão, respectivamente (Beffi \& Trincherini, 2016).

Existem três tipos de processos de fracionamento isotópico que afetam os isótopos leves (Allegre, 2008): 1) cinético; 2) por difusão; e 3) por efeitos termodinâmicos. Nas reações cinéticas, os isótopos leves reagem mais rápido, enquanto que em reações de troca, os isótopos pesados se concentram onde as barreiras são mais fortes. Os isótopos mais pesados também fazem ligações químicas mais fortes, o que acarreta no fracionamento isotópico em equilíbrio termodinâmico. À esta diferença da quantidade entre os isótopos leves e pesados é dado o nome de fracionamento isotópico, que confere a possibilidade de traçar processos diversos tais como rotas metabólicas fotossintéticas pela assinatura isotópica do carbono $\left(\delta^{13} \mathrm{C}\right)$ (Araujo-Lima et al., 1986; Forsberg, 1993; Fry, 2008). 
Para traçar a origem geográfica do pirarucu com a metodologia de análise isotópica de Sr na bacia Amazônica é preciso compreender o ambiente físico em relação às variações geoquímicas da bacia e da composição hidrogeoquímica dos rios que a formam.

\subsection{Amazônia}

A Amazônia é uma das maiores áreas de floresta tropical existentes, e também é a maior bacia hidrográfica do planeta, abrangendo uma área de $6,1 \times 10^{6} \mathrm{Km}^{2}$, o que representa 45\% da América do Sul (Dultra Maia, 2008). Muito embora a maior porção da Amazônia situe-se em território brasileiro, ela também faz parte dos territórios da Bolívia, Peru, Colômbia, Equador, Venezuela, Guiana e Suriname. O bioma amazônico é coberto por uma extensa floresta tropical primária entremeado por rios, canais, brejos e outras formações florestais, abrigando mais de $10 \%$ da diversidade do planeta (Queiroz, 2000). No entanto, este bioma vem sofrendo forte pressão antrópica no último século pela exploração das florestas, atividade agrícolas, pecuárias, de mineração, urbanização e construção de hidroelétricas (Queiroz, 2000; Dultra Maia, 2008; Hermann et al., 2016).

\subsubsection{Composição hidrogeoquímica da Bacia Amazônica}

Estudos biogeoquímicos de grandes rios fornecem informações importantes sobre a variação espacial e temporal dos elementos químicos (Laraque et al., 2009; Trevethan et al., 2016; Paca et al., 2014). A composição hidroquímica dos rios está relacionada ao ambiente físico da bacia de drenagem principalmente quando se consideram as áreas com baixa alteração antrópica (Queiroz et al., 2009). Fatores que podem afetar a características hidroquímicas de uma dada bacia incluem a natureza e idade geológica das rochas, taxas de 
intemperismo e erosão das áreas fontes, além de outros (Gaillardet et al, 1997; Santos et al., 2015).

O rio Amazonas é o maior rio tropical do planeta com fluxo médio de vazão de 20.900 $\mathrm{m}^{3} \mathrm{~s}^{-1}$ e com uma área de drenagem de 6 milhões de $\mathrm{Km}^{2}$ (Goulding et al., 2003). Este rio nasce no Peru, na confluência dos rios Marañon e Ucayali, e recebe águas o rio Napo antes de entrar no Brasil. No território brasileiro, essa drenagem passa a se chamar rio Solimões, quando recebe o rio Purus na sua margem direita. Ao longo do seu curso, desaguam afluentes do rio Negro, e em Manaus ocorre o encontro dos rios Solimões e Negro, passando a se chamar então de Amazonas. Em seu curso médio a baixo, o rio Amazonas tem outros importantes tributários em sua margem direita, como os rios Madeira, Tapajós e Xingu (Goulding et al.,2003).

Em relação ao contexto geológico, a bacia Amazônica é intracratônica e é limitada ao norte pelo Escudo das Guianas, ao sul pelo Escudo Brasileiro (Cunha, 1994). Outras importantes feições geográficas são os arcos de Purus e de Gurupá (Figura 3). Esta Bacia é composta por rochas sedimentares detríticas, formadas predominantemente pelo produto de intemperismo físico da Cadeia dos Andes, e por rochas sedimentares químicas, que são formadas a partir da precipitação química em ambiente aquoso. A composição química e isotópica dessas rochas reflete principalmente a composição da área fontes dos sedimentos bem como os processos intempéricos do ambiente de sedimentação. (Faure, 1972) 


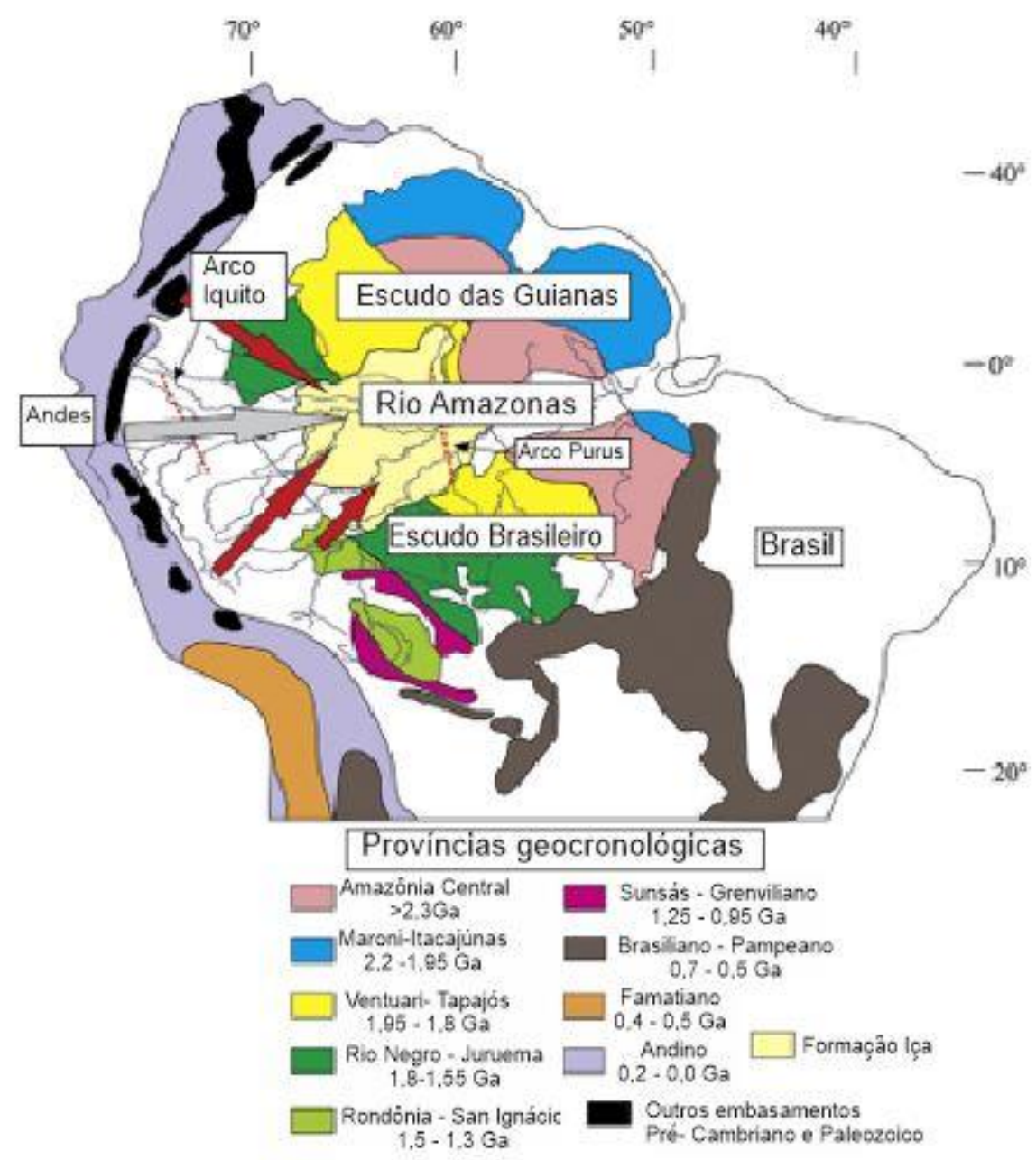

Figura.2 Mapa geológico da Amazônia mostrando as províncias geocronológicas do Cráton da Amazônia e as regiões das redondezas Tassinari\&Macambira (1999), Fuck et al (2008), Cardona et al. (2009) e Decou et al. (2013). Adaptado de Fuck et al 2008 .

Rubídio e Estrôncio são elementos traço que ocorrem na maioria das rochas ígneas, metamórficas e sedimentares. $\mathrm{O} \mathrm{Rb}^{+}$tende a substituir o $\mathrm{K}^{+}$em silicatos minerais, como micas $\left(\mathrm{K}_{2} \mathrm{O} \quad 3 \mathrm{Al}_{2} \mathrm{O}_{3} \quad 6 \mathrm{SiO}_{2}\right)$ e feldspatos potássicos $\left(\mathrm{KAlSi}_{3} \mathrm{O}_{8}\right)$, enquanto o $\mathrm{Sr}^{+2}$ tende a substituir o $\mathrm{Ca}^{+2}$ em plagioclásios cálcicos $\left(\mathrm{CaAlSi}_{3} \mathrm{O}_{8}\right)$, apatitas $\left(\mathrm{CaPO}_{4}\right)$ e carbonatos $\left(\mathrm{CaCO}_{3}\right)$. Dentre os isótopos do elemento $\mathrm{Rb}, \mathrm{o}{ }^{87} \mathrm{Rb}$ é radioativo e decai para ${ }^{87} \mathrm{Sr}$ com tempo

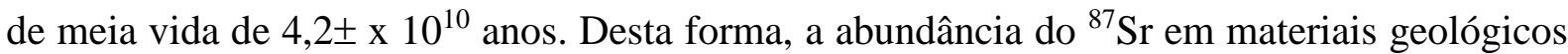
não é constante pois depende de dois fatores principais: da razão $\mathrm{Rb} / \mathrm{Sr}$ e da idade das rochas, 
ou seja, do tempo necessário para o decaimento radioativo do ${ }^{87} \mathrm{Rb}$ (Faure, 1972). O Sr possui quatro isótopos $\left({ }^{84} \mathrm{Sr},{ }^{86} \mathrm{Sr},{ }^{87} \mathrm{Sr}\right.$ e $\left.{ }^{88} \mathrm{Sr}\right)$, dentre os quais somente o ${ }^{87} \mathrm{Sr}$ é radiogênico. Em termos de evolução crustal, o Rb tende a ser mais concentrado na crosta terrestre, enquanto o Sr tende a ser mais concentrado no manto terrestre. Assim, rochas crustais antigas, retrabalhadas apresentam maior razão isotópica de ${ }^{87} \mathrm{Sr} /{ }^{86} \mathrm{Sr}$ do que rochas jovens e mantélicas, que apresentam razões isotópicas ${ }^{87} \mathrm{Sr} /{ }^{86} \mathrm{Sr}$ mais baixas (Faure, 1972; Allegre 2008; Santos et al., 2015).

O intemperismo físico e químico, associados a processos erosivos, são os principais responsáveis pelo aporte de sedimentos em suspensão para as drenagens e, consequentemente, para as características hidroquímicas dos rios (Palmer e Edmond 1992; Gaillardet et al. 1997). Vários estudos abordaram a composição isotópica de Sr do rio Amazonas e seus afluentes (Gibbs, 1967; Stallard 1980; Stallard e Edmond 1983,1987; Palmer e Edmond 1992; Queiroz et al., 2009; Santos et al., 2015). Esses estudos revelam que em função da diversidade geológica, as sub-bacias hidrográficas da bacia Amazônica apresentam diferenças significativas na composição isotópica de $\mathrm{Sr}$ das águas. Essa variação isotópica permite, assim, que esse parâmetro isotópico seja utilizado como marcado geográfico de origem no âmbito da bacia.

2.2.2. Contexto isotópico ${ }^{87} \mathrm{Sr} /{ }^{86} \mathrm{Sr}$ das sub-bacias dos rios Solimões, Amazonas e Madeira

Santos et al. (2015) demonstraram a partir de amostras coletadas durante 8 anos em diferentes drenagens da bacia Amazônica que a composição isotópica do Sr dissolvido possui uma ampla variação temporal e espacial correlacionada com a geologia das áreas fontes dos sedimentos em suspensão. Esses autores observaram que o rio Beni-Madeira apresenta ampla 
variação isotópica sazonal, contrastando com o rio Solimões, onde não foi encontrada uma grande flutuação na composição isotópica de Sr no seu ciclo hidrológico. A média descrita da razão isotópica ${ }^{87} \mathrm{Sr} /{ }^{86} \mathrm{Sr}$ para o rio Solimões foi de 0,709 , flutuando entre 0,705 e 0,710 , pois as rochas drenadas por este rio são menos radiogênicas. Este rio, drena as rochas do Fanerozóico do norte do Peru e Equador, que possuem uma baixa razão isotópica Sr quando comparadas às razões dos rios Beni-Madeira e Negro.

A cabeceira do rio Solimões fica situada na Cordilheira dos Andes, onde as razões isotópicas de ${ }^{87} \mathrm{Sr} /{ }^{86} \mathrm{Sr}$ são mais baixas $\approx 7,01$ (Queiroz et al., 2009). O seu percurso inclui a bacia sedimentar Paleozoica do Solimões e depois na bacia sedimentar Paleozoica do Amazonas. Geologicamente, as Cordilheiras dos Andes apresentam uma composição complexa, sendo composta por uma variedade de tipos litológicos, com coberturas Cenozoicas (Shobbenhaus, 1984; Gaillardet et al.,1997). De acordo com Queiroz (2009), as águas do rio Solimões são caracterizadas como águas brancas cálcicas-bicarbonatadas, sendo assim levemente mais ácidas e condutivas.

A bacia do Solimões é formada por rochas sedimentares e ígneas. As principais formações são arenitos vermelhos, folhelhos negros e carbonatos fraturados do Paleozoico e Mesozoico, que recobrem a formação pré-cambriana. A parte baixa da drenagem do rio Solimões é do pós-Paleozoico e sedimentos do Terciário. Estes diferentes tipos de formação se refletem na drenagem das rochas dos rios como diferentes assinaturas isotópicas, dependendo da região de escoamento (Queiroz et al., 2009).

O rio Madeira é formado por três rios principais, o rio Madre de Dios que nasce nos Andes Peruanos, e os rios Mamoré e Beni, que nascem na Bolívia. Na planície de inundação do Beni, na cidade de Riberalta, Bolívia, ocorre a confluência entre o Madre Dios e o Beni. Já na porção brasileira, o rio Mamoré recebe afluentes como os rios Yata e o Guaporé e desagua 
no rio Beni, é quando passa a ser chamado de rio Madeira. Assim, a bacia do rio Madeira tem origem no sudoeste da planície Amazônica e drena rochas do cráton amazônico datados do Pré-Cambriano e do Ordovinciano (Santos et al., 2015). Santos et al. (2015) argumentam que o rio Beni drena as rochas radiogênicas antigas expostas a leste da cordilheira dos Andes e na borda oeste do embasamento Antofalla, cujas idades podem ser de até $2 \mathrm{Ga}$ anos. As rochas deste período geológico são arenitos provenientes do Pré-Cambriano, do começo do Proterozoico e rochas metamórficas e magmáticas policíclicas.

Pamer e Edmond (1992) relataram uma diferença acentuada entre as razões isotópicas de Sr dissolvido entre os rios Madeira e Solimões, já que as rochas do primeiro são mais radiogênicas do que as do segundo. Viers et al. (2008) observou uma razão isotópica que variou entre 0,72769 e 0,74108 para o rio Madeira ao passo que Santos et al. (2015) encontraram razões que flutuaram entre 0,717 e 0,718 . Entretanto, o rio Beni apresenta razões localmente mais altas em sua planície de 0,726. (Pouilly et al., 2014; Duponchelle et al., 2016)

Para o rio Amazonas, Gaillardet et al. (1997) descreveram uma razão isotópica de 0,71148, confirmado por Santos et al. (2015) que encontraram uma assinatura isotópica de 0,711, em Santarém e apresentam pouca variação quando comparadas ao Solimões e ao Madeira. As razões isotópicas descritas por Santos et al. (2015) estão representadas no mapa da Figura 3. 


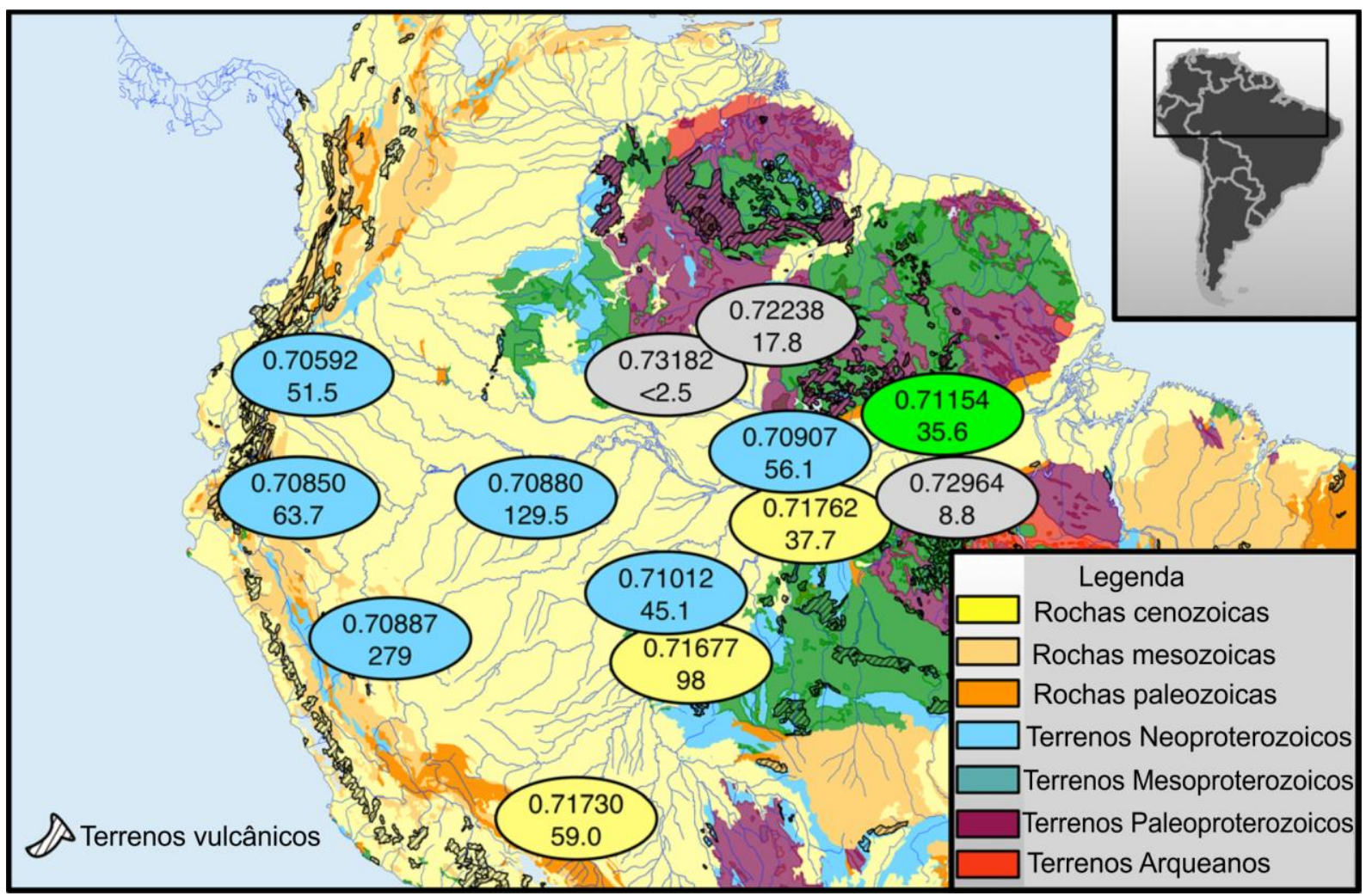

Figura 3 Representa o mapa geológico da região Amazônica com os valores isotópicos (em cima) de Sr e suas concentrações em ppb (em baixo) dos rios Solimões (azul), Beni-Madeira (amarelo), Tapajós (cinza) e Amazonas (verde). Adaptada de Santos et al. 2015.

\subsection{Aspectos gerais da ecologia do pirarucu, do manejo e da criação em cativeiro}

O pirarucu pertence a Classe Actinopterygii, que são os peixes com nadadeiras radiais.

Ordem Osteoglossiformes, umas das ordens mais primitivas e ancestrais nos peixes. Ela é resultado da primeira radiação de Teleostei, que data do Jurássico e possui distribuição na Austrália, Ásia, África e América do Sul. Sua principal característica são as línguas ósseas (Queiroz, 2000). Sua Família é Arapaimatidae e gênero Arapaima, que por 140 anos foi considerado monotípico, contendo apenas a espécie Arapaima gigas (Schinz, 1822). Posteriormente foram descritas as espécies A. agassizii, A. mapae e A. arapaima. (Figura 4). Todas essas novas espécies correspondiam a A. gigas, no entanto a identificação taxonômica 
dessas espécies é difícil, bem como a sua distribuição geográfica. (Castello et al., 2013). Visto a necessidade de estudos sobre a taxonomia do pirarucu, essa dissertação considerou o nível do gênero Arapaima., no qual todas as espécies são consideradas popularmente como pirarucu. No Brasil esse peixe é conhecido como pirarucu (pira = peixe, urucu= vermelho) ao passo que no Peru, Equador e Bolívia e chamado de paiche (WWF, 2011).

O Pirarucu, Arapaima sp, é um dos grupos com os maiores peixes com escamas de água doce do mundo (Nelson, 1994; Queiroz, 2000; Hrbek et al., 2007). Sua área de ocorrência abrange as planícies das bacias hidrográficas dos rios Tocantins-Araguaia e Solimões-Amazonas. (Castello et al., 2013). No alto do rio Beni-Madeira na Bolívia é considerado uma espécie exótica invasora. Sua introdução ocorreu na parte norte da bacia do rio Madeira na década de 1970, pelo governo peruano, de onde dispersou pelo território boliviano (Carvajal-Vallejos et al., 2013). Nesta região, tem apresentado uma grande importância socioeconômica para os pescadores ribeirinhos rurais, indígenas e comerciais, entretanto, estudos sobre o impacto ecológico na região ainda não foram realizados (CarvajalVallejos et al., 2013). 


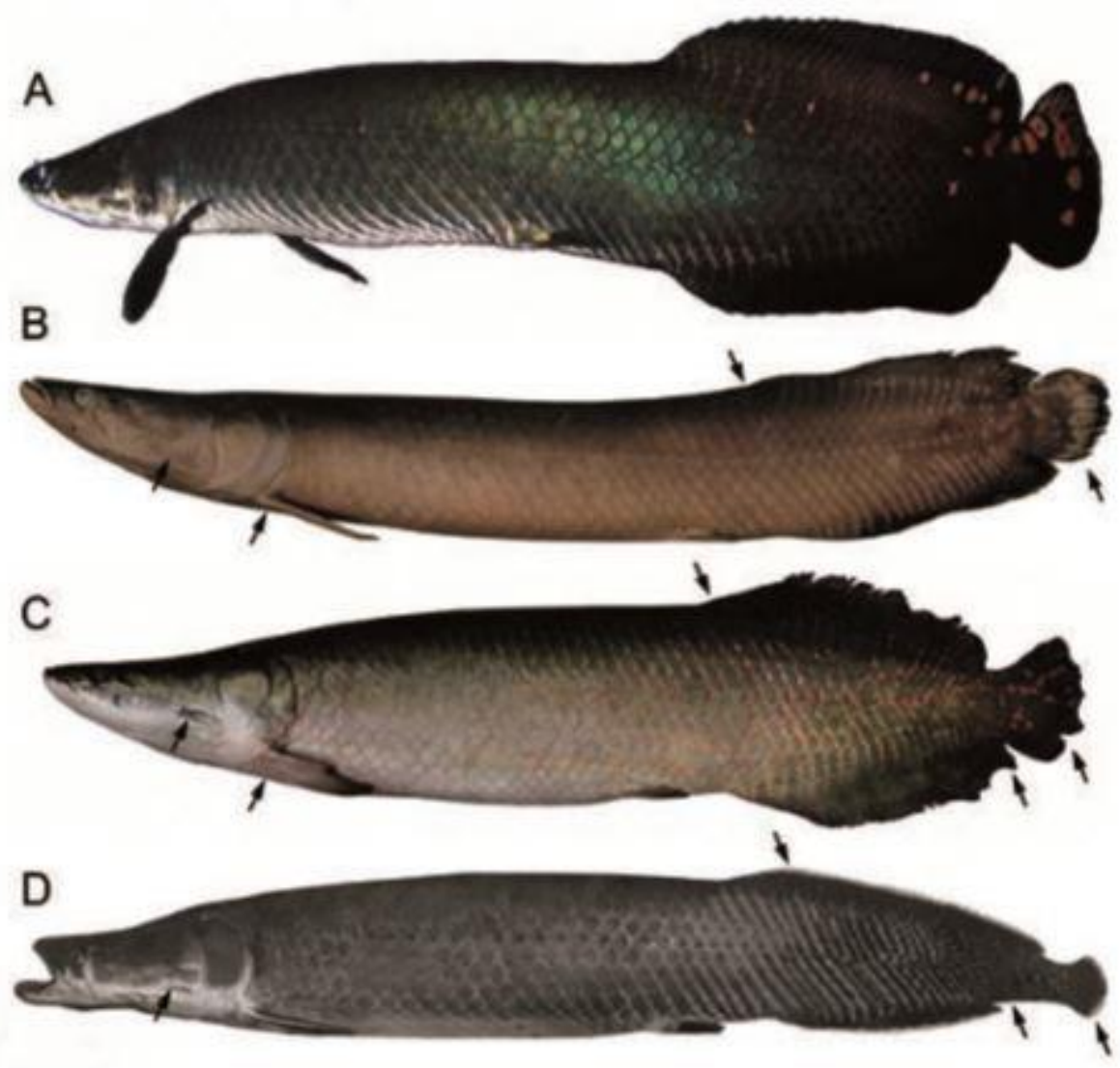

Figura 4. Indivíduos de três espécies de pirarucu que correspondiam ao Arapaima gigas. A) Arapaimma leptossoma; B) Arapaima leptossoma, holótipo, Instituto Nacional de Pesquisas da Amazônia (INPA)16847; C) Arapaima sp. icertae serdis juvenil, INPA, 26582; D) Arapaima agassizii, holótipo. As setas indicam as principais diferenças morfológicas. (Figura retirada de Castello et al, 2013)

O pirarucu é frequentemente encontrado em hábitats lênticos, como rios com pouca correnteza, lagos e algumas drenagens costeiras onde há conexão entres os canais e lagos. Sua principal barreira geográfica são cachoeiras e partes do rio com correnteza forte (Castello et al., 2013). Apesar de tradicionalmente ter sido descrito como sedentário na literatura (Queiroz, 2000; WWF, 2011; Araripe et al., 2013; Hermann, et al., 2016), nas regiões de várzea, definidas como lagos da planície de inundação de água branca da bacia do Solimões, Castello (2008) descreveu migrações laterais do pirarucu de acordo com o regime de 
inundação como parte do seu ciclo reprodutivo (Castello, 2008; Castello et al., 2013). No entanto, este padrão ainda não foi observado para outras populações de Arapaima sp. ao longo das suas áreas de ocorrência. Ressaltando-se, portanto, a importância da análise isotópica, por meio da razão ${ }^{87} \mathrm{Sr} /{ }^{86} \mathrm{Sr}$, como ferramenta para o melhor entendimento de padrões migratórios desse grupo, fornecendo assim subsídio para a compreensão de dinâmica das populações.

O padrão de migração lateral descrito por Castello (2008) e Castello et al. (2013), foi observado nos ambientes de várzea da Reserva de Desenvolvimento Sustentável de Mamirauá. Durante a época da seca, os casais são formados, e com a elevação do nível dos rios, estes constroem ninhos em buracos na beira das florestas de restinga, ocorrendo então, a deposição, fertilização e eclosão dos ovos. O cuidado parental é realizado pelo macho que migra com a prole para as florestas alagadas em busca de alimento. Os adultos se alimentam preferencialmente de outras espécies de peixes que também migram para a região inundada com alta disponibilidade de recursos, enquanto que os filhotes comem pequenos insetos e camarões. Com o rebaixamento do nível da água, novamente, adultos e filhotes migram para os canais de paraná e depois para os lagos, iniciando o ciclo novamente.

Quanto à posição trófica do pirarucu, há controvérsias na literatura. Sánchez (1969) e Queiroz (2000) descreveram o pirarucu como predador topo de cadeia e prioritariamente piscívoro, mas crustáceos e moluscos também fazem parte da sua dieta. No entanto, mais recentemente, Watson et al. (2013) concluíram por meio da metodologia de análise isotópica de $\delta^{15} \mathrm{~N}$ no tecido muscular e com análise do trato digestivo, que o pirarucu dos lagos das Guianas é consumidor secundário e onívoro. Ambos os trabalhos descrevem que o adulto se alimenta de pequenos peixes detritívoros e onívoros.

O pirarucu apresenta características fisiológicas singulares, possuindo um duplo sistema respiratório com modificações na bexiga natatória para realizar trocas gasosas 
obrigatórias com a atmosfera, bem como com a respiração pelas brânquias. Assim, quando o peixe sobe a superfície para respirar é pescado nas épocas de vazante do rio. O grupo é classificado como conjunto de espécies sedentárias, oportunistas, de crescimento rápido e rústicas ao manejo (WWF, 2011).

\subsubsection{Manejo da pesca}

O manejo do pirarucu no Amazonas começou em 2000, quando a primeira pesca manejada de forma experimental foi liberada na RDS Mamirauá, de domínio estadual. As pesquisas voltadas ao manejo começaram em 1992 devido à urgente necessidade de conservação desta espécie pela sua relevância social, política e econômica. O manejo é participativo e realizado em ambientes de várzea por pescadores ribeirinhos, com apoio de técnicos e pesquisadores. Este sistema de manejo consolidado se multiplicou pelo Médio Solimões entre 2002 e 2008, constituindo um exemplo para cadeias produtivas sustentáveis na Amazônia (Figueiredo, et al., 2013).

A base do sistema de manejo desenvolvido pioneiramente na RDS Mamirauá é o método do "sistema de contagem", condicionante principal para manejo e parâmetro para autorização da pesca pelo Ibama (Figueiredo, et al., 2013). Esta técnica aliou o conhecimento tradicional dos pescadores no desenvolvimento de uma metodologia para contagem de indivíduos de uma população de A. gigas nos lagos da reserva, publicada por Castello (2004). O método consiste na quantificação do número de vezes em que os indivíduos subem à superfície para respirar em 20 minutos em determinada área. Um adulto respira uma única vez neste intervalo de tempo, e um jovem sobe duas vezes. Assim, a partir da quantidade total de peixes adultos, as cotas liberadas pelo Ibama correspondem a $30 \%$ desse total em cada setor ou lago. 
A partir da experiência da Reserva de Desenvolvimento Sustentável de Mamirauá, a permissão da pesca pelo manejo foi expandida para área da RESEX Auati Paraná e áreas adjacentes. Em 2007, o manejo foi realizado em três Reservas Extrativistas federais (RESEX Baixo Juruá; e RESEX Jutaí), duas Reservas de Desenvolvimento Sustentável estaduais (RDS Mamirauá /RDS Amanã), uma reserva municipal (RM Fonte Boa / RESEX Auati-Paraná) e duas áreas de Acordo de Pesca (Acordo de Pesca do rio Arari - Itacoatiara-AM; e Acordo de Pesca do rio Urubu /Lago Canaçari - Silves-AM). Hoje existem muitas outras áreas de manejo participativo das comunidades tradicionais que comercializam o pescado (ribeirinhos, pescadores artesanais, assentados e agricultores familiares) nos estados do Acre, Rondônia, Amapá, e também dentro de territórios indígenas Paumari no estado do Amazonas (IbamaAmazonas, 2008).

No Pará, na região do Médio Amazonas, em Santarém, o manejo comunitário do pirarucu está sendo desenvolvido a partir dos Acordos de Pesca já estabelecidos, nos quais os pescadores negociam e implementam regras de uso dos recursos pesqueiros. Esses acordos envolvem 140 comunidades locais. Nesta região, o pirarucu sofre ameaça de superexploração pela pesca e pela crescente degradação dos hábitats, e consequentemente, os estoques desta espécie foram considerados esgotados pela equipe de trabalho do IPAAM (Castello et al., 2013). O plano de manejo participativo desenvolvido em cinco comunidades, carece de uma política coerente para essa atividade, aliada à falta de fiscalização das regras que precisam ser aplicadas para efetividade das ações realizadas (Castello et al., 2013).

Ações neste sentido também estão sendo realizadas nos países vizinhos, como na Guiana, Peru, Colômbia e na Bolívia, onde o manejo comunitário do pirarucu foi iniciado. Na Bolívia, na bacia do rio Beni, as primeiras experiências de manejo começaram com o objetivo 
de controle da população desta espécie que foi introduzida tornando-se uma espécie invasora (Carvajal-Vallejos et al., 2013).

\subsubsection{Criação em cativeiro}

O pirarucu apresenta viabilidade econômica e alta produtividade para a criação, apesar de ainda haver aspectos de sua reprodução e alimentação em cativeiro que não são bem compreendidos. A criação de pirarucu é uma atividade importante para conter a superexploração causada pela pesca e tem um grande impacto na economia da Amazônia, pois existem altos valores de mercado, alta demanda e alta produtividade de cultivo (Imbirira, 1991 e 1994; Moura Carvalho \& Nascimento, 1992; Imbiriba et al., 1996; Itaissu et al., 2005).

Atualmente, há registros no Ministério da Agricultura, Pecuária e Abastecimento (MAPA) de criações de pirarucu nos estados do Acre, Roraima, Amapá, Para, Amazonas, Rondônia (TABELA 1). Rondônia é o estado que mais possui estabelecimentos de aquicultura de pirarucu credenciados junto ao governo. No entanto, é sabido que existem muitos estabelecimentos sem credenciamento junto ao MAPA, que comercializam a sua produção na região (Comunicação verbal de Aline Vosgrau Fagundes, Secretaria de Monitoramento e Controle da Pesca e Aquicultura - SEMOC, MAPA).

TABELA 1. Registro de aquicultores na região Norte. Fonte: Ministério da Agricultura, Pecuária e Abastecimento (MAPA), 2016

\begin{tabular}{ccc}
\hline Estado & $\begin{array}{c}\text { Número de } \\
\text { Municípios }\end{array}$ & $\begin{array}{c}\text { Número de } \\
\text { produtores }\end{array}$ \\
\hline Acre & 5 & 9 \\
Roraima & 3 & 3 \\
Amapá & 2 & 3 \\
Amazonas & 4 & 4 \\
Pará & 2 & 2 \\
Rondônia & 27 & 70 \\
\hline
\end{tabular}


Em cativeiro, o pirarucu passa pelo treinamento alimentar com três tipos diferentes de rações. Na fase juvenil, o pirarucu não aceita rações secas e balanceadas, por ser um peixe carnívoro. Assim o treinamento é feito com uso de rações comerciais extrusadas ou peletizadas para peixes carnívoros, que contém $45 \%$ de proteína e são compostas de farinha de peixe, farelo de soja, glúten de fubá de milho e complexo vitamínico mineral (ácido fólico, ácido pantôtenico, antioxidade, biotina, $\mathrm{Co}, \mathrm{Cu}, \mathrm{Fe}, \mathrm{Mg} \mathrm{Zn}$, Se, niacina, vitaminas $\mathrm{A}, \mathrm{B} 1$, B12, B2, C, D3 e K) (Itaissu et al., 2005) (Tabela 2).

TABELA 2. Agenda do treinamento alimentar do pirarucu em cativeiro (temperatura $27^{\circ} \mathrm{C}$ $\left.30^{\circ} \mathrm{C}\right)$.

\begin{tabular}{cccc}
\hline Tipo de ração & $\begin{array}{c}\text { Peso dos peixes } \\
(\mathrm{g})\end{array}$ & $\begin{array}{c}\text { Tamanho e \% da } \\
\text { ração }\end{array}$ & Refeição/dia \\
\hline Tipo I & $5-50$ & $0,8-2.5 \mathrm{~mm}(45 \%)$ & 4 \\
Tipo II & $50-700$ & $4 \mathrm{~mm}(42 \%)$ & 3 \\
Tipo III & $700-12.000$ & $10 \mathrm{~mm}(40 \%)$ & 2 \\
\hline
\end{tabular}

\subsection{Traçadores da origem de peixes}

\subsubsection{Traçadores de origem geográfica}

Uma das formas de traçar a origem da pesca do pirarucu é em relação a origem geográfica. Em ambiente natural, os peixes absorvem o Sr dissolvido nas águas, onde a razão ${ }^{87} \mathrm{Sr} /{ }^{86} \mathrm{Sr}$ reflete a geologia das bacias hidrográficas. A acumulação dos isótopos de Sr ocorre nas estruturas calcificadas cronologicamente ao longo da vida do peixe, sem haver fracionamento isotópico entre a água e as estruturas calcificadas. Vários autores aplicaram a razão ${ }^{87} \mathrm{Sr} /{ }^{86} \mathrm{Sr}$ para traçar a origem de espécies de salmão (Kennedy et al., 1997, 2000, 2002, 2005; Martin et al., 2013a, 2013b; Ingran et al., 1999; Barnett- Johnson, 2004, 2005, 2010).

Em regiões tropicais, poucos estudos foram desenvolvidos sobre a origem e padrões de migração de peixes com a finalidade de entender a distribuição espacial das espécies 
(Walther et al., 2011; Pouilly et al., 2014; Garcez et al., 2014; Hegg et al., 2015; Souza et al., 2016; Duponchele et al., 2016; Hermann et al.,2016). Pouilly et al. (2014) combinaram dados geoquímicos da água com dados biogeoquímicos de otólitos e escamas de peixes não migratórios da Amazônia (Hoplias malabarucus e Schizodon fasciatus) (Figura 5). Os autores compararam os espécimes comprados no mercado (círculos fechados) com amostras de coleções (círculos abertos), obtendo como resultado, uma correlação direta entre a razão isotópica de ${ }^{87} \mathrm{Sr} /{ }^{86} \mathrm{Sr}$ nas escamas e otólitos dos peixes e a razão isotópica ${ }^{87} \mathrm{Sr} /{ }^{86} \mathrm{Sr}$ dissolvida na água dos rios Beni, Beni (lagos), Iténez/Guaporé, Solimões e Tapajós. O estudo permitiu assim, determinar a origem geográfica dos peixes por meio das razões isotópicas de $\mathrm{Sr}$, como demostra a Figura 5, adaptada de Pouilly et al. (2014).

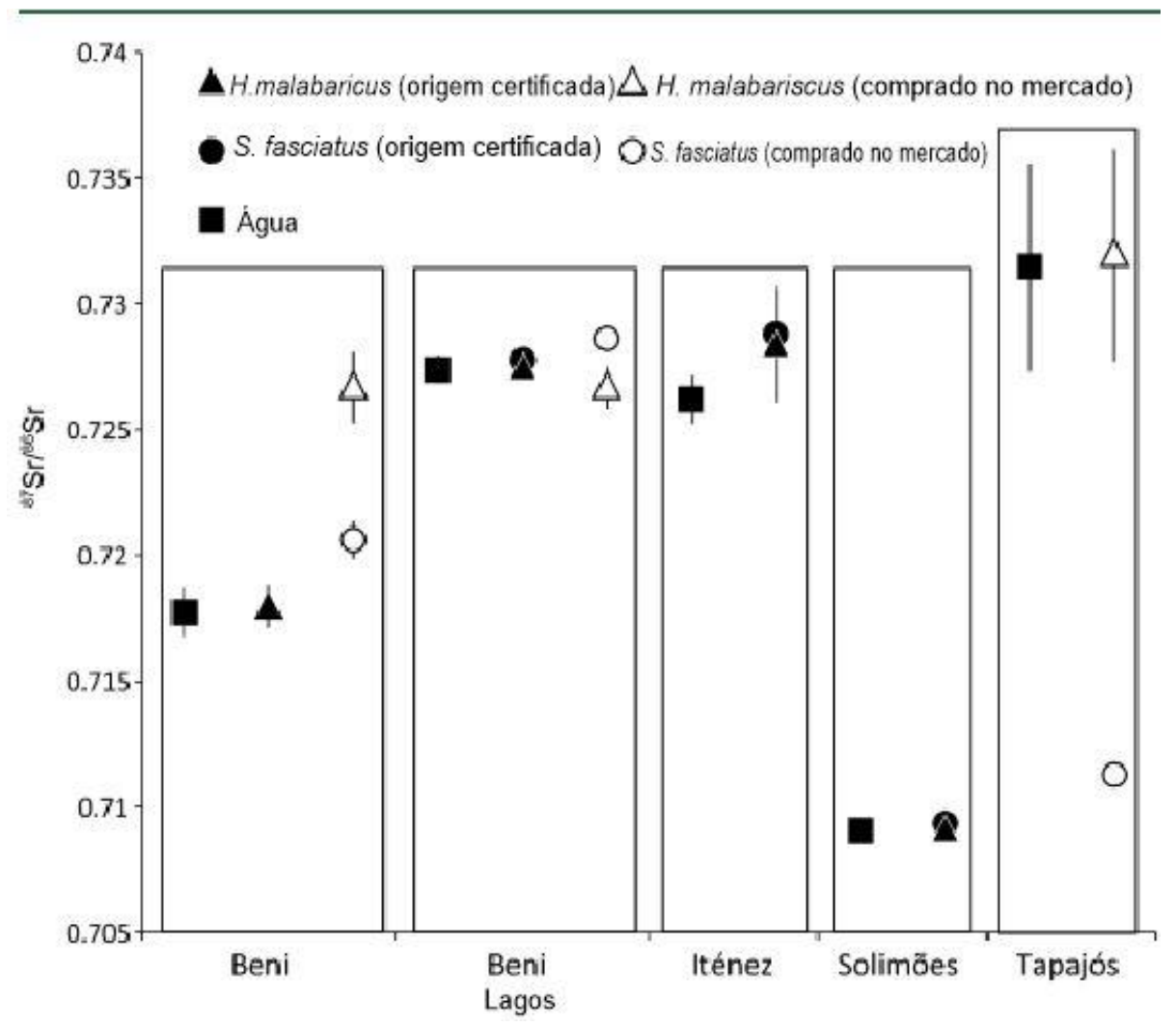

Figura 5, Valores médios das razões isotópicas ${ }^{87} \mathrm{Sr} /{ }^{86} \mathrm{Sr}( \pm \mathrm{SD})$ dissolvidos na água e nas escamas de dois peixes amazônicos sedentários de água doce (Hoplias malabaricus e Schizodon fasciatus) provenientes de cinco regiões amazônicas. Figura adaptada de Pouilly et al., 2014. 


\subsubsection{Otólitos}

Otólitos são estruturas carbonáticas pareadas do ouvido interno dos peixes constituídas por três ossos denominados sagittae, lapillie e asterisci. Esta estruturas são compostas por aragonita $\left(\mathrm{CaCO}_{3}\right)$ e tendem a crescer de forma continua a partir da eclosão do peixe, guardando assim, informações sobre as condições ambientais ao longo de toda a vida de um dado indivíduo. Como não fazem parte do esqueleto e tem como função a audição e o equilíbrio do peixe, os otólitos não são reabsorvidos e seus elementos são permanentemente retidos durante o ciclo de vida dos peixes, mesmo durante períodos de escassez de alimento, sendo metabolicamente inertes (Campana, 1999; Kerr e Campana, 2014) É importante enfatizar que o mesmo não ocorre com outras estrutura carbonáticas, como escamas, que pondem ser reabsorvidas em periodos de escassez de alimento. (Pouilly et al., 2014; Kerr e Campana, 2014)

As variações nas composições química e isotópica ao longo da linha de crescimento do otólito dependem principalmente das variações na composição da água em que o peixe viveu. A depender do elemento, a dieta também pode contribuir para a composição do otólito. Os elementos como carbono e oxigênio,constituintes principais da aragonita, e o estrôncio, elemento traço (concentrção em ppm) são incorporados ao otólito juntamente com o cálcio. A formação do otólito é regulada por células maculares que secretam cálcio no fluido endolinfático que envolve o otólito (Campana \& Nelson, 1985). Os elementos são absorvidos até o plasma sanguíneo, pelas brânquias ou pelos intestinos. Após a absorção, os elementos são transportados para endolinfa e finalmente incorporados aos otólitos (Campana \& Nelson, 1985; Campana, 1999; Kerr e Campana, 2014). Enquanto, fatores como a temperatura, salinidade, a fisiologia do peixe e diferenças genéticas entre as populações podem influenciar na composição química e isotópica de carbono e oxigênio dos otólitos, o mesmo não ocorre 
com isótopos de Sr. Em outras palavras, não há fracionamento isotópico de desse elemento mediado por processos biológicos.

Os pressupostos para aplicação da metodologia isotópica na distinção de estoques pesqueiros são: 1) a assinatura isotópica dos grupos estudados devem ser diferente e; 2) a taxa de mobilização do elemento no tecido analisado deve ser pequena para que o elemento possa ser usado como traçador (Pouilly et al., 2014; Kerr e Campana, 2014; Pracheil et al., 2014). Já as limitações do método são: 1) em estudos de longo tempo, a análise de elementos que estão sob regulação fisiológica deve ser feita com cuidado e; 2) cautela com a contaminação na análise de elementos menos abundantes (<100 ppm) (Kerr e Campana, 2014).

Além do uso da razão ${ }^{87} \mathrm{Sr} /{ }^{86} \mathrm{Sr}$ em otólitos na discriminação de estoques pesqueiros, Campana \& Thorrold (2001) citam trabalhos que analizaram isótopos estáveis de carbono em otólitos. As possíveis fontes de carbono para os otólitos são a dieta e o carbono inorgânico dissolvido na água (DIC) (Kalish, 1991; Schwarcz et al., 1998; Newman et al., 2000; Solomon et al., 2006; Nonogaki et al., 2007). O carbono metabolizado é oriundo da dieta, enquanto o carbono do DIC proveniente da água. Ambos são incorporados ao otólito durante a deposição do $\mathrm{Ca}^{+2}$ (Kalish, 1991; Solomon et al., 2006). O enriquecimento isotópico líquido entre as fontes de C e o otólito é baixo de -3,6\%o (Solomon et al., 2006).

No entanto,de forma geral, o $\delta^{13} \mathrm{C}$ dos otólitos não está em equilibrio com o DIC da água que o peixe vive, pois efeitos metabólicos geram um grande desequilibrio isotópico do carbono dos otólitos em relação à este isótopo da água, e portanto,o carbono dissolvido na água tem pouca contribuição para a formação do otólito. Logo, na maioria dos estudos, esta assinatura isotópica está relacionada às fontes alimentares e de nutrientes do peixe. (Kalish, 1991; Schwarcz et al., 1998; Newman et al., 2000; Nonogaki et al., 2007). 
Porém, Solomon et al. (2006) apresentaram que $17 \%$ do C do otólito é oriundo do C metabólico, enquanto $80 \%$ é proveniente do DIC, em um experimento de manipulação do DIC e da dieta do Oncorhynchus mykiss, uma espécie de truta do Canadá. No entanto, esses autores observam que podem existir variações das fontes de carbono para otólitos dos peixes de acordo com o táxon, a ontogenia e o hábitat. (Solomon et al., 2006). De forma que várias pesquisas indicam que existe um desequilíbrio entre o $\delta^{13} \mathrm{C}$ oriundo do DIC e o $\delta^{13} \mathrm{C}$ do otólito, (Kalish, 1991; Schwarcz et al., 1998; Newman et al., 2000), com a dieta sendo a principal fonte de C para o otólito.

Por sua vez, Nonogaki et al. (2007) analisaram a assinatura isotópica $\delta^{13} \mathrm{C}$ nos otólitos dos peixes herbívoros Panaque nigrolineatus e Hypostomus sp., coletados em ambiente natural, e também realizaram manipulação do $\delta^{13} \mathrm{C}$ da dieta em experimentos laboratoriais, a fim de compreender as fontes de carbono dos otólitos em peixes de água doce de ambiente tropical. Os autores concluiram que o $\delta^{13} \mathrm{C}$ dos otólitos dos peixes reflete o $\delta^{13} \mathrm{C}$ o histórico alimentar tanto em ambiente natural, quanto nos experimentos de manipulação.

\subsubsection{Traçadores de origem de peixes em relação à dieta}

Assim, a dieta dos peixes nos diferentes ambientes está relacionada às fontes alimentares autotróficas de carbono nas cadeias tróficas. Na fotossíntese, a maioria das plantas arbóreas (C3) produz uma molécula com três átomos de carbono, enquanto que as gramíneas (C4) produzem em geral uma mólecula de quatro carbonos. Essas duas rotas fotossintéticas produzem efeitos bastante distintos na razão ${ }^{13} \mathrm{C} /{ }^{12} \mathrm{C}$ das plantas $\mathrm{C} 3$ e $\mathrm{C} 4$. Enquanto as plantas C3 são significantemente enriquecidas em ${ }^{12} \mathrm{C}$ e possuem uma assinatura isotópica entre $-24 \%$ e $-32 \%$, as plantas C4 apresentam uma menor seletividade em relação aos isótopos de carbono, apresentando valores de $\delta^{13} \mathrm{C}$ entre $-14 \%$ e $-9 \%$ (Figura 6) (Fry, 
2008). Os consumidores assimilam isótopos de carbono em seus tecidos oriundos da dieta e suas assinaturas isotópicas representam um equílibrio dinâmico do consumo de alimentos ao longo do tempo e geralmente o sangue é enriquecido em menos de um por mil em relação a sua dieta (DeNiro e Epstein, 1978), já o otólito em 3,6 \%o (Solomon et al., 2006). Assim a assinatura isotópica de carbono serve como traçador do ciclo do carbono nos ecossistemas e indica as fontes alimentares das espécies nos diferentes níveis tróficos (Fry, 2008).

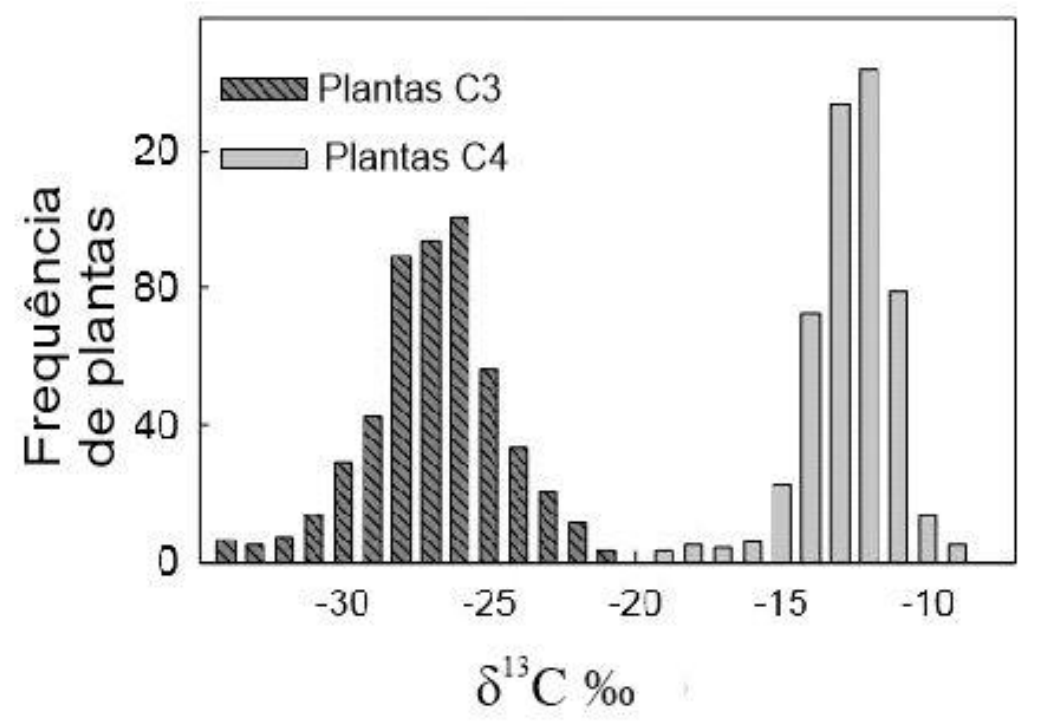

Figura 6. Histograma de distribuição da assinatura isotópica de carbono $\delta^{13} \mathrm{C}$.

$\mathrm{Na}$ Amazônia, somente um estudo analisou o $\delta^{13} \mathrm{C}$ em tecidos carbonáticos. Domingues et al. (2002) analisou as camadas óssea e cartilagenosa de escamas, no começo e no fim da vida dos peixes de duas espécies (Osteoglossum sp. e Arapaima gigas) com o objetivo de compreender seus históricos alimentares. Este estudo revelou que o carbono das camadas cartilagenosa e de carbonato de cálcio das escamas de A. gigas não apresentaram diferenças na composição isotópica de $\delta^{13} \mathrm{C}$ e que a fonte de carbono da camada mineraliza é a dieta. Também não houve mudança ontogenética nos padrões alimentares das duas espécies. 
No entanto, foi encontrado que o $\delta^{13} \mathrm{C}$ das escamas de $A$. gigas variou de $-18,1$ a $-29,2 \%$ e que as mudanças na composição isotópica de $\delta^{13} \mathrm{C}$ nesta espécie podem ser um indicador de padrão de dispersão, possivelmente associados à heterogeneidade de hábitats explorados pelo pirarucu.

Neste contexto, a maioria dos estudos sobre a fonte alimentar de $\delta^{13} \mathrm{C}$ em peixes na Amazônia foi realizado em tecido muscular, a fim de entender a dieta dos peixes em um curto intervalo de tempo (meses) anterior às análises (Forsberg et al., 1993; Jepsen \& Winemiller, 2007; Watson et al., 2013; Mortillato et al., 2014; Marshall et al. 2007).

Porém é importante levar em consideração que podem existir diferenças entre a assinatura de $\delta^{13} \mathrm{C}$ do carbono orgânico que compõe os músculos e o carbono inorgânico incorrporado ao otólito (Radke et al., 1996). Radke et al. (1996) compararam o $\delta^{13} \mathrm{C}$ dos otólitos com o dos músculos num experimento com condições controladas de dieta, composição isotópica da água e temperatura para a espécie de bacalhau Gadus morhua. Estes autores encontraram uma diferença de $-15,91 \%$ entre a composição isotópica de carbono dos otólitos e tecido muscular, onde os peixes tiveram uma dieta de plantas C3 a um temperatura de $16^{\circ} \mathrm{C}$. Ambas as assinaturas de $\delta^{13} \mathrm{C}$ do otólito e do tecido muscular foram relativas à dieta e não apresentaram relação com a composição da água. Também, houve o fracionamento fisiológico entre a fonte alimentar e composição dos diferentes tecidos analisados, no entanto o fracionamento foi menor nos otólitos do que nos músculos devido aos diferentes mecanismos fisiológicos de incorporação de carbono nestes dois tecidos.

Neste sentido, ao buscar compreender a fonte alimentar de carbono para peixes amazônicos, Forsberg et al. (1993) detalharam que a contribuição de diferentes grupos de plantas para os peixes na Amazônia varia dependendo da importância relativa dos produtores primários, da qualidade nutricional, disponibilidade relativa e da preferência de produtores 
primários na cadeia trófica dos peixes. Assim, os autores descreveram quatro grupos principais de plantas que contribuem para a produtividade primária na Amazônia, que servem de fontes de carbono para 35 espécies de peixes. O grupo mais importante em relação a produtividade primária foram as herbácias macrófitas com 52\%, consideradas $\mathrm{C} 4$, seguido das árvores da floresta com 32\%, o perifiton com $8 \%$, e o fitoplânquiton com $8 \%$, todas C3. A média encontrada por Forberg et al. (1993) para valores de $\delta^{13} \mathrm{C}$ da plantas C3 foi de $-29,1 \%$, enquanto que para as plantas $\mathrm{C} 4$ essa média foi de $-12,8 \%$. Com um modelo de mistura da contribuição relativa dos grupos $\mathrm{C} 3$ e C4 na contribuição de carbono para os peixes, estimouse que as plantas $\mathrm{C} 4$ representaram 2,5 a 17,6\% de carbono enquanto que as $\mathrm{C} 3$ refletiram 82,4 a $97,5 \%$ de carbono para todas as espécies.

Em um estudo similar, Araujo-Lima et al. (1986) demonstraram que peixes detritívoros de diferentes ordens (Characiformes e Siluriformes) são isotopicamente distintos em relação ao $\delta^{13}$ C. Da mesma maneira que Mortillaro et al. (2015) argumentaram que podem existir diferenças espaciais na utilização das fontes alimentares C3 e C4 para algumas espécies, como por exemplo para $S$. fasciatus. Mortillaro et al. (2015) encontraram assinaturas $\delta^{13} \mathrm{C}$ mais enriquecidas $(-26,8 \pm 3,1 \%$ em relação aos indivíduos da mesma espécie $(-33,1 \pm$ 2,1\%o) em localidades diferentes de várzea no rio Solimões, em Manaus. Os autores atribuíram esta diferença espacial nas fontes alimentares à alta contribuição e disponibilidade de macrófitas C4 na dieta desta espécie. Desta forma, as oscilações do ciclo hidrológico nos ambientes de várzea amazônicos levam a variabilidade espacial e temporal dos recursos, o que faz com que as espécies possam apresentar adaptabilidade e flexibilidade na dieta e uso do hábitat.

A assinatura $\delta^{13} \mathrm{C}$ também é discutida em relação às guildas tróficas de peixes na Amazônia. Os grupos analisados são os herbívoros, detritívoros, onívoros e piscívoros. 
(Forsberg et al. 1993; Jepsen \& Winemiller, 2007; Mortillato et al., 2014). A maioria dos herbívoros, os detritívoros, onívoros e piscívoros apresentam fonte de carbono com $\delta^{13} \mathrm{C}$ relativos ao grupo $\mathrm{C} 3$, no entanto existem espécies herbívoras com maior contribuição de macrófitas C4. (Forsber et al., 1993; Jepsen \& Winemiller, 2007; Mortillato et al., 2014).

Nesta dissertação o grupo de espécies estudado é caracterizado como piscívoro. A média de $\delta^{13} \mathrm{C}$ encontrada para peixes piscívoros foi de $-29,1 \%$ na bacia do Orinoco, Venezuela (Jepsen \& Winemiller, 2007); nos rios Negro e Solimões em Manaus o $\delta^{13} \mathrm{C}$ variou de $-35 \%$ a $-27 \%$ (Mortillato et al., 2014) e nos afluentes dos rios Solimões e Negro e nos rios Amazonas, Negro e Solimões o $\delta^{13} \mathrm{C}$ variou de -35,9 a -24,1\%o (Forsberg et al., 1993).

\subsection{Estudos isotópicos anteriores sobre o pirarucu}

Os poucos estudos isotópicos sobre o pirarucu restringem-se a sua dieta e posição trófica na cadeia alimentar (Forsberg et al., 1993; Domingues et al., 2002; Watson et al., 2013). Desta forma, em relação ao $\delta^{13} \mathrm{C}$ da dieta do pirarucu, tanto nos trabalhos com tecido muscular de Watson et al. (2013) e Forsberg et al. (1993), quanto no trabalho de Domingues et al. (2002) com escamas de pirarucu, a assinatura isotópica média de $\delta^{13} \mathrm{C}$ foi compatível com às plantas $\mathrm{C} 3\left(\delta^{13} \mathrm{C}\right.$ de $\left.-28,9 \pm 1,2 \%\right)$. A exceção foi um exemplar de Santarém apresentado por Domingues et al. (2002) que apresentou $\delta^{13} \mathrm{C}$ de-18,9 $\pm 0,4 \%$, indicando uma dieta com maior contribuição de plantas C4.

Neste sentido, Forsberg et al. (1993) também estimou que 23,4\% da dieta do Arapaima gigas pode ter contribuição de plantas C4. Domingues et al. (2002) encontraram que o $\delta^{13} \mathrm{C}$ das escamas de $A$. gigas variaram entre $-18,01 \%$ a $-29,2 \%$ e argumentaram que este longo intervalo é consistente com a heterogeneidade espacial e temporal no escossistema Amazônico, visto que $0,3 \times 10^{6}$ de $\mathrm{Km}^{2}$ de floresta são inundados anualmente (Junk, 1997). 


\section{MATERIAL E MÉTODOS}

\subsection{Amostragem}

Foram coletadas amostras de água em diferentes pontos da bacia Amazônica, otólitos de peixes de cativeiro e de ambiente natural, bem como amostras de ração utilizadas na alimentação dos peixes de cativeiro. Nesta seção, são apresentados os pontos de coleta de água, a proveniência dos otólitos e da ração dos peixes de cativeiro. Ao final dessa seção será apresentado um detalhamento da coleta de amostras de água e otólito em Mamirauá.

Foram coletados dezessete pontos de água: nove pontos representativos das fontes isotópicas de $\mathrm{Sr}, \mathrm{O}$ e D dos rios e de água subterrânea na Reserva de Desenvolvimento Sustentável de Mamirauá, situada no município de Tefé-AM (rio Solimões); e em parceria com a doutorando Marília Hauser (UNIR) foram coletados dois pontos na foz do rio Tapajós, próximo a Santarém - PA e um ponto no rio Amazonas; um ponto no cativeiro de AriquemesRO (rio Madeira) e quatro pontos na Bolívia, nos rios Madre Dios, Yata e Beni. (Figura 7). Em Ariquemes - RO, as amostras de água foram coletadas nos tanques de criação de pirarucu em cativeiro, para caracterização do ambiente de cativeiro e da pesca proveniente desta região. Além das amostras de água coletadas, também foram utilizados dados isotópicos de água do trabalho de Santos et al. (2015), onde os autores monitoraram os principais tributários do rio Amazonas (Madeira, Solimões, Negro, Tapajós), o rio Amazonas e o rio Beni na Bolívia. 


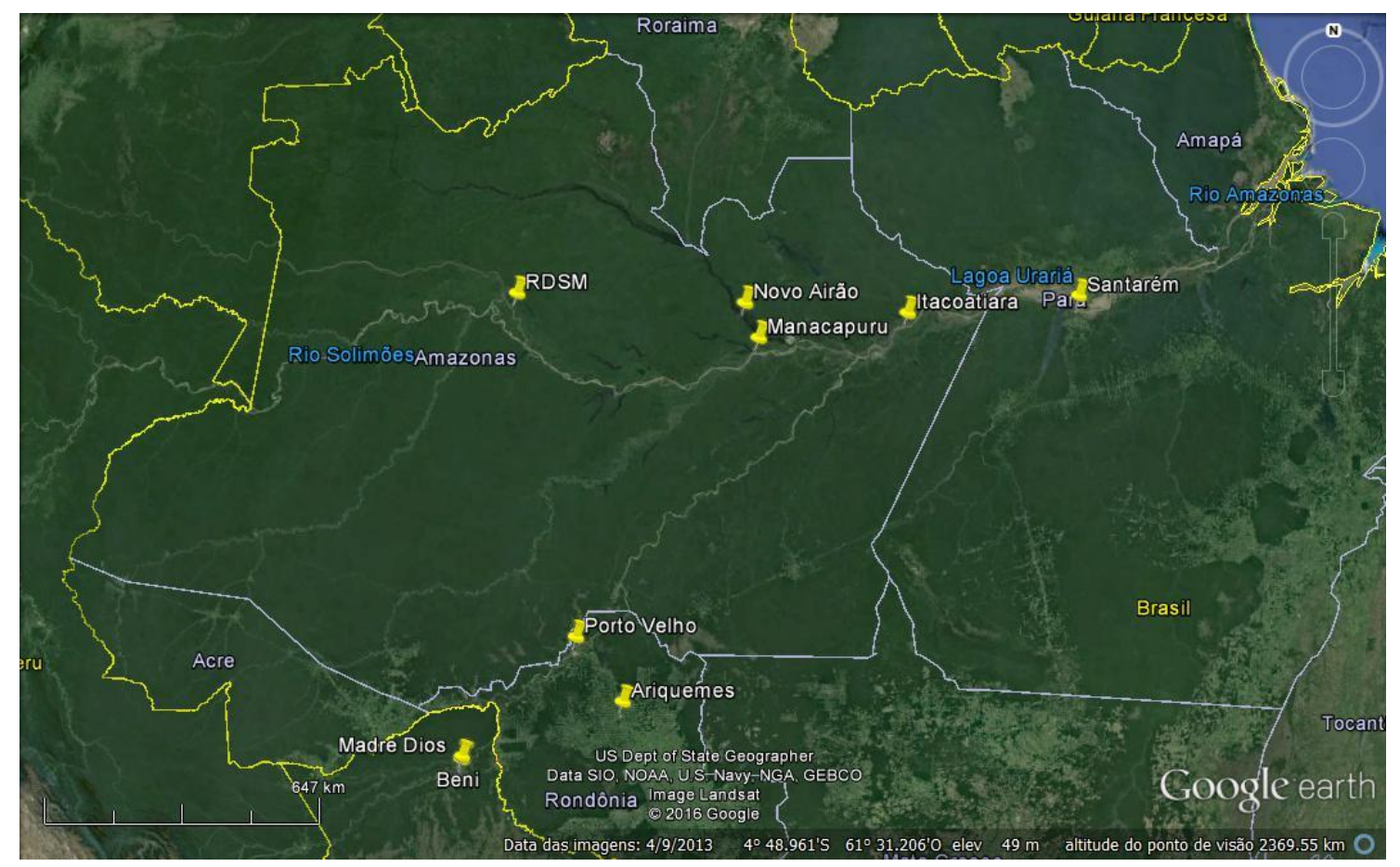

Figura 7 Mapa de localização do estudo. Os marcadores amarelos representam os locais de coleta de água na bacia Amazônica.

Os locais foram selecionados em uma escala espacial ampla para maximizar o contraste da razão ${ }^{87} \mathrm{Sr} /{ }^{86} \mathrm{Sr}$ nas águas entre as diferentes bacias consideradas. Contudo, foram também coletadas águas dentro de uma escala geográfica local, como na Reserva de Desenvolvimento Sustentável de Mamirauá, para verificar se é possível traçar a migração lateral do pirarucu entre o rio principal e os lagos formados na estação de seca.

As amostras de água foram coletadas no meio dos rios, próximo à superfície e longe do motor do barco, em recipientes de polietileno lavados com ácido ultrapuro para as análises da razão isotópica de ${ }^{87} \mathrm{Sr} /{ }^{86} \mathrm{Sr}$. As amostras foram filtradas em campo através de filtros 0.47 $\mu \mathrm{m}$ MilliporeDURAPORE ${ }^{\mathrm{R}}$, armazenadas em garrafas de polietileno lavadas com ácido ultrapuro, e acondicionadas em um isopor com gelo até as análises em laboratório. 
Os otólitos de Arapaima sp. foram coletados em sete locais para análises isotópicas de $\delta^{13} \mathrm{C}, \delta^{18} \mathrm{O},{ }^{87} \mathrm{Sr} /{ }^{86} \mathrm{Sr}$. Amostras de ração utilizadas na alimentação dos peixes do cativeiro em Ariquemes foram coletadas para análises $\delta{ }^{13} \mathrm{C}$ e ${ }^{87} \mathrm{Sr} /{ }^{86} \mathrm{Sr}$ (Tabela 5). As amostras de ração foram utilizadas como padrão na alimentação destes peixes na piscicultura.

O pirarucu é encontrado facilmente nos mercados locais. No entanto o acesso aos otólitos nem sempre é fácil quando adquiridos diretamente com os responsáveis pelo manejo ou cativeiro. Os peixes foram coletados no período permitido em cada região pelos pescadores locais e suas cabeças foram adquiridas de quatro formas: 1) diretamente com os manejadores na RDSM após submissão e aprovação de projeto de pesquisa; 2) com o responsável pelo cativeiro de Ariquemes-RO; 3) nos mercados locais de Santarém-PA, Itacoatiara-AM, Novo Airão-AM e Manacapuru-AM e 4) diretamente com os pescadores do rio Beni, no município de Riberalta. Assim, os otólitos sagittae de cativeiro e ambiente natural foram obtidos nos estados do Amazonas e Pará. Em Rondônia, foram coletadas apenas amostras de cativeiro, já que a pesca está proibida em ambiente natural. Por sua vez, foram obtidos otólitos de espécimes de ambiente natural de três pontos de pesca dos rios Beni, Madre Dios e Yata.

Em Santarém-PA, os cativeiros, indicados pelos fornecedores, situam-se próximos à cidade, bem como a área de pesca no rio Amazonas, que não foi exatamente especificada pelos pescadores. A informação obtida foi que a área de pesca de ambiente natural é uma área aonde se realiza o manejo da espécie e fica próxima à cidade. No estado do Amazonas, as amostras de cativeiro foram obtidas nos mercados de Manaus e são relatadas como oriundas dos municípios de Novo Airão-AM (rio Amazonas), Manacapuru-AM (rio Solimões), e Tefé AM (rio Solimões). As amostras de otólitos de ambientes naturais do estado do Amazonas são 
provenientes da Reserva de Desenvolvimento Sustentável de Mamirauá e de Itacoatiara-AM, onde os peixes são pescados por pescadores que realizam o manejo do pirarucu.

A Tabela 3 apresenta a lista com a origem das amostras coletadas, ressaltando que nem sempre há garantia sobre a origem das mesmas, uma vez que os fornecedores nem sempre as informam com certeza.

TABELA 3. Origem do material biológico (município e tipo de ambiente).

\begin{tabular}{|c|c|c|c|}
\hline Código do indivíduo & Estado/ Pais & $\begin{array}{c}\text { Local } \\
\text { indicado da } \\
\text { pesca }\end{array}$ & $\begin{array}{l}\text { Origem (tipo de } \\
\text { ambiente) }\end{array}$ \\
\hline CAT-COOP-AM-01 & Amazonas & Manacapuru & Cativeiro \\
\hline NAT-ITA-01 & Amazonas & Itacoatiara & Ambiente natural \\
\hline NAT-ITA-02 & Amazonas & Itacoatiara & Ambiente natural \\
\hline NAT-ITA-03 & Amazonas & Itacoatiara & Ambiente natural \\
\hline NAT-ITA-04 & Amazonas & Itacoatiara & Ambiente Natural \\
\hline CAT-N.AIRAO-01 & Amazonas & Novo Airão & Cativeiro \\
\hline CAT-N.AIRAO-02 & Amazonas & Novo Airão & Cativeiro \\
\hline CAT-N.AIRAO-03 & Amazonas & Novo Airão & Cativeiro \\
\hline CAT-N.AIRAO-04 & Amazonas & Novo Airão & Cativeiro \\
\hline CAT-FEIRA-MAM-01 & Amazonas & Mamirauá & Cativeiro \\
\hline CAT-FEIRA-MAM-02 & Amazonas & Mamirauá & Cativeiro \\
\hline CAT-FEIRA-MAM-03 & Amazonas & Mamirauá & Cativeiro \\
\hline NAT-MAM-01 & Amazonas & Mamirauá & Ambiente natural \\
\hline NAT-MAM-02 & Amazonas & Mamirauá & Ambiente natural \\
\hline NAT-MAM-03 & Amazonas & Mamirauá & Ambiente natural \\
\hline NAT-MAM-04 & Amazonas & Mamirauá & Ambiente natural \\
\hline NAT-MAM-05 & Amazonas & Mamirauá & Ambiente natural \\
\hline CAT-SAT-01 & Para & Santarém & Cativeiro \\
\hline CAT-SAT-02 & Para & Santarém & Cativeiro \\
\hline CAT-SAT-03 & Para & Santarém & Cativeiro \\
\hline CAT-SAT-04 & Para & Santarém & Cativeiro \\
\hline CAT-SAT-05 & Para & Santarém & Cativeiro \\
\hline NAT-SAT-01 & Para & Santarém & Ambiente natural \\
\hline NAT-SAT-02 & Para & Santarém & Ambiente natural \\
\hline NAT-SAT-03 & Para & Santarém & Ambiente natural \\
\hline NAT-SAT-04 & Para & Santarém & Ambiente natural \\
\hline NAT-SAT-05 & Para & Santarém & Ambiente natural \\
\hline CAT-ROD-01 & Rondônia & Ariquemes & Cativeiro \\
\hline
\end{tabular}




\begin{tabular}{cccc}
\hline CAT-ROD-02 & Rondônia & Ariquemes & Cativeiro \\
CAT-ROD-03 & Rondônia & Ariquemes & Cativeiro \\
CAT-ROD-04 & Rondônia & Ariquemes & Cativeiro \\
CAT-ROD-05 & Rondônia & Ariquemes & Cativeiro \\
YA-1 & Bolívia & Riberalta & Ambiente natural \\
YA-12 & Bolívia & Riberalta & Ambiente natural \\
YA-13 & Bolívia & Riberalta & Ambiente natural \\
FL-1 & Bolívia & Riberalta & Ambiente natural \\
FL-2 & Bolívia & Riberalta & Ambiente natural \\
FL-20 & Bolívia & Riberalta & Ambiente natural \\
TOTAL & 4 & 7 & 38 \\
\hline
\end{tabular}

\subsubsection{Estudo de caso da Reserva de Desenvolvimento Sustentável de Mamirauá}

A Reserva de Desenvolvimento Sustentável de Mamirauá (RDSM) está localizada no município de Tefé-AM, situada a aproximadamente $600 \mathrm{~km}$ a oeste de Manaus, na planície de inundação dos rios Japurá e Solimões, e abrange uma área de 1.124.000 hectares (Figura 8). A RDSM foi criada em 1999 pelo governo do estado do Amazonas e tem como objetivos promover o desenvolvimento sustentável das comunidades rurais e a conservação da biodiversidade. Como ressaltou Queiroz (2000), a RDSM juntamente com a Reserva de Desenvolvimento Sustentável Amanã e o Parque Nacional Jaú formam a maior unidade de conservação oficial de floresta tropical do mundo.

A RDSM possui representatividade do mosaico de várzea, com a formação de lagos, os quais estão conectados aos rios principais, de acordo com as variações sazonais de seca e de cheia das águas. Esta sazonalidade do regime hidrológico influencia toda a dinâmica da ciclagem de nutrientes no ecossistema e do uso do habitat pelo Arapaima sp. (Queiroz, 2000; Figueiredo et al., 2013). 


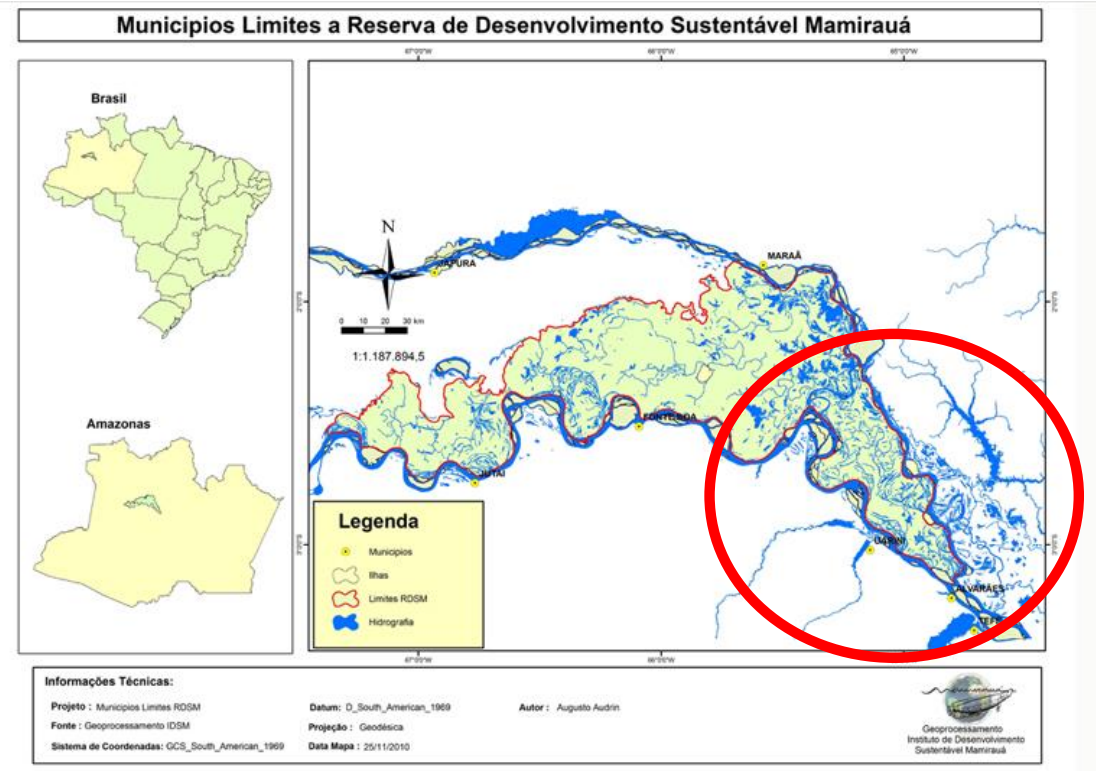

Figura.8 Localização da Reserva de Desenvolvimento Sustentável de Mamirauá (RDSM) (Fonte: www.mamiraua.org.br)

A coleta de água na RDSM foi realizada em dezembro de 2014 nos seguintes pontos: 1) rio Japurá; 2) rio Solimões; 3) rio Aranapu (mistura entre o Japurá e Solimões); 4) subterrânea; 5) lagos Tefé, Tucuxi, Arapaima, que compõe os hábitats utilizados pelo Arapaima sp. e, onde ocorre o manejo nos lagos e sua pesca no período permitido. A Figura 9 ilustra o mapa de coleta.

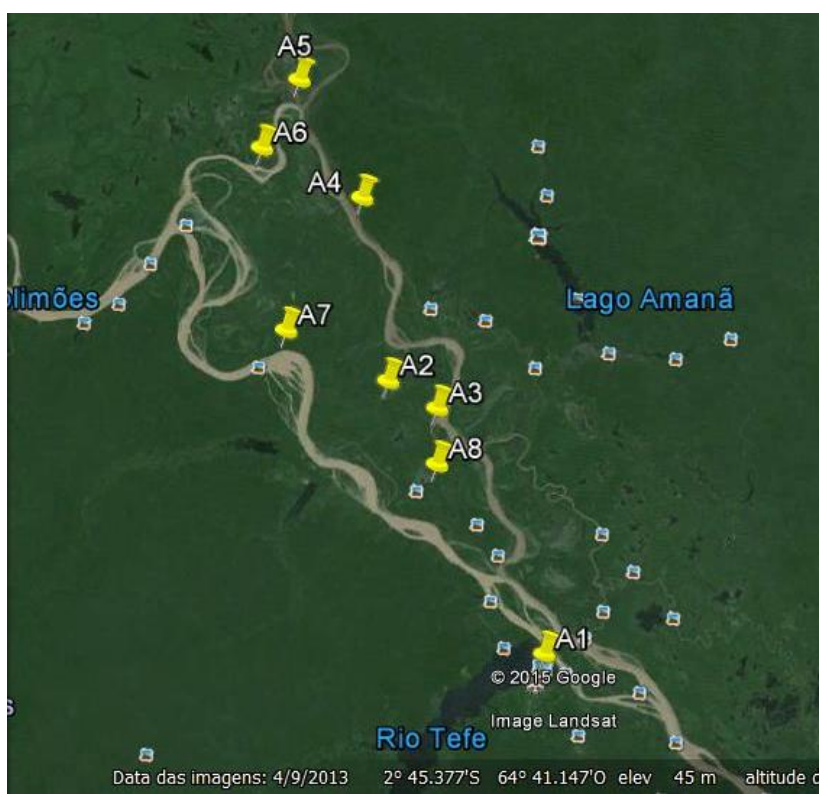

Figura 9. Mapa de coleta de água na RDSM. As amostras foram coletadas nos lagos Tefé (A1), Tucuxi (A2) e Arapaima (A8) e nos rios Japurá (A3, A4 e A5), Aranapu (A6), e Solimões (A7). 
A coleta dos otólitos ocorreu em novembro de 2015 mediante aprovação de projeto de pesquisa. A coordenadora de pesca da RDSM intermediou o contato com os pescadores para aquisição das cabeças.

\subsection{Métodos analíticos}

\subsubsection{Preparação e análise das amostras de água}

As razões isotópicas de ${ }^{87} \mathrm{Sr} /{ }^{86} \mathrm{Sr}, \delta^{18} \mathrm{O}, \delta \mathrm{D}$ das amostras de água foram realizadas no Laboratório de estudos Geocronologia, do Instituto de Geociências da Universidade de Brasília (UnB). Os processos de separação e digestão foram realizados em sala limpa de ISO classe 2. Para as análises de ${ }^{87} \mathrm{Sr} /{ }^{86} \mathrm{Sr}$ das águas, $500 \mathrm{~mL}$ de amostra de água filtrada foram evaporadas, obtendo cerca de 50ng de Sr. O resíduo da evaporação foi então dissolvido em $1 \mathrm{~mL}$ de $2 \mathrm{~N}$ de ácido nítrico e os isótopos de $\mathrm{Sr}$ foram separados através de resinas de troca (Eichrom Sr-Spec $\left.{ }^{\circledR}\right)$. As razões isotópicas foram medidas no espectrômetro de massa por termo-ionização (N-TIMS) THERMO SCIENTIFIC TRITON do Laboratório de Geocronologia do Instituto de Geociência na Universidade de Brasília. O procedimento analítico foi validado a partir das análises do padrão NBS987 que possui valor médio de $0,71027 \pm 1$.

Os valores isotópicos $\delta^{18} \mathrm{O}$ e $\delta \mathrm{D}$ das amostras de água foram determinados a partir de uma alíquota de $2 \mathrm{~mL}$ de água em um espectrofotômetro de cavidade ressonante, marca PICARRO. Nesse equipamento, a água é vaporizada e o vapor introduzido, com arraste de gás nitrogênio seco, numa câmara onde as razões isotópicas são determinadas por meio da interação com um feixe de laser. O padrão utilizado para determinação das razões isotópicas é o V-SMOW de valores de $\delta \mathrm{D}$ e $\delta^{18} \mathrm{O}$ de $0 \%$ (Erro associado: $\delta \mathrm{D}= \pm 1 \%$, $\delta^{18} \mathrm{O}= \pm 0,2 \%$ ).

\subsubsection{Preparação e análise dos otólitos}


Os otólitos foram retirados da cavidade auricular dos peixes por meio da dissecação das cabeças com o uso de pinças de plástico. Eles foram lavados com três gotas de hipoclorito de sódio diluídas em água e colocados no ultrassom por cinco minutos. O emblocamento dos otólitos foi feito com a imersão destas estruturas em resina epóxi e solução catalizadora, na proporção de $60 \%$ de resina para $40 \%$ de catalizador, com a obtenção de placas resistentes após vinte e quatro horas. Após o emblocamento, as amostras foram cortadas transversalmente com o auxílio de um micrótomo digital com serra metalográfica de baixa velocidade (Isomed Buehler, Düsseldorf, Alemanha, 2009).

Estes cortes foram polidos com lixas de papel e lavados com água ultrapura até que o centro pudesse ser visto (Figura 8). Estas preparações foram realizadas no laboratório de Geocronologia da Universidade de Brasília (UnB), no laboratório de Ictiologia e Pesca da Universidade Federal de Rondônia e no laboratório de MARBEC da Universidade de Montpellier (França).

As análises de isótopos de $\mathrm{Sr}$ nos otólitos foram realizadas no Laboratoire de Chimie Analytique Bio-inorganique et Environnement (LCABIE) do Institut Pluridisciplinaire de Recherche sur l'Environnement et les Matériaux (IPREM) na Université de Pau et des Pays de l'Adour, França. O espectrômetro utilizado para as análises isotópicas foi o $\mathrm{Nu}$ Plasma HR-MC-ICPMS (Nu instruments, Wrexham, Reino Unido) acoplado a um Alfamet femtosecond (fs) sistema de ablação a laser (Nexeya SA, Canejan, França). Este laser é equipado com um diodo YB:KGW, fonte de laser de cristal (HP1, Amplitude Systèmes, Pessac, France), que fornece 360-fs pulsos em $1030 \mathrm{~nm}$. A fonte do laser opera com alta energia e baixa repetição, dentro de uma faixa de taxa de repetição de $1-100.000 \mathrm{~Hz}$ e com uma baixa energia (pulso $<25 \mu \mathrm{J}-1$ a $100.000 \mathrm{~Hz}$, até um pulso de $1,000 \mu \mathrm{J}$ abaixo de 
1,000Hz). Estas condições analíticas permitem a ablação a laser do otólito, maximizando a intensidade de sinal.

O feixe do laser é focado com uma lente de $25 \mathrm{~mm}$, resultando numa abertura de feixe (tamanho do spot) de 50-200 $\mu \mathrm{m}$ de diâmetro em alta velocidade (acima de $0,5 \mu \mathrm{m} / \mathrm{s}$ ). O campo óptico gerado pelo feixe de laser é de $25 \mathrm{~mm}^{2}$. Esta metodologia foi aplicada e descrita com mais detalhes em (Claverie et al., 2009; Tabouret et al., 2010). No presente trabalho, o laser operou em $20 \mathrm{~Hz}$ nos otólitos, com um pulso de energia de $500 \mu \mathrm{J}$ até o limite da profundidade de ablação enquanto que o scanner fazia $200 \mu \mathrm{m}$ de largura em um movimento de ida e volta com uma velocidade de $5-10 \mu \mathrm{m} / \mathrm{s}$, resultando em uma ablação aparente de $15 \times 200 \mu \mathrm{m}$ da amostra ao longo do eixo maior do otólito que é paralelo às suas marcas de crescimento. Esta forma de ablação permite a melhora da intensidade de sinal no MC-ICPMS enquanto mantem a alta resolução espacial.

Os primeiros dez otólitos foram analisados desde o centro até o fim da vida dos peixes, para avaliar a variação da razão ${ }^{87} \mathrm{Sr} /{ }^{86} \mathrm{Sr}$ ao longo do otólito, uma vez que, uma variação pode indicar uma migração ao longo da vida dos peixes. Devido a constância da razão ${ }^{87} \mathrm{Sr} /{ }^{86} \mathrm{Sr}$ ao longo de todas as amostras, foi padronizado que somente os últimos $30 \%$ da vida do peixe apresentavam informações suficientes para caracterizar o ambiente de vida dos pirarucus. Nestes casos, a ablação foi realizada com uma velocidade de 5-10 $\mu \mathrm{m} \cdot \mathrm{s}^{-1}$, com uma profundidade de ablação que não excedeu $30 \mu \mathrm{m}$ (Figura 10). 


\section{Medial}

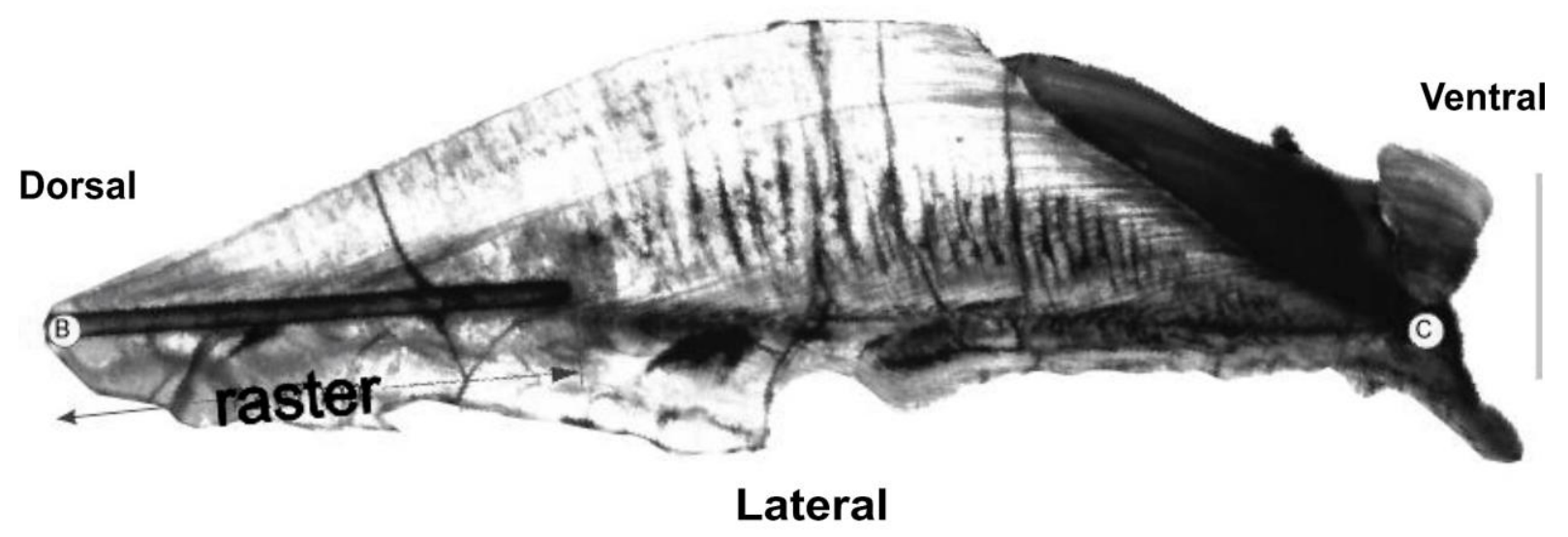

Figura 10. Ablação a laser no otólito de Arapaima sp. O centro e a borda estão representados como C e B, respectivamente.

O acoplamento do laser com o MC-ICPMS foi feito com um longo tubo antiestético de 2 m, 6 mm de diâmetro externo e 4 mm de diâmetro interno (Legris SA, Rennes, França) dentro do ICP, usando o gás de carregamento hélio (He). Uma tocha de duas entradas foi usada para misturar o aerossol gerado pelo laser com o aerossol líquido (solução de $2 \%$ HNO 3 em água ultrapura) antes da introdução no plasma (Barats et al., 2007). Este sistema de introdução de duplo fluxo permite a otimização do MC-ICPMS pela nebulização adequada da solução para o ajuste. As condições de medida foram ajustadas para a máxima sensibilidade e estabilidade do plasma. A interferência do ${ }^{87} \mathrm{Rb}$ na intensidade de sinal do ${ }^{87} \mathrm{Sr}$ foi medida pelo sinal do ${ }^{85} \mathrm{Rb}$ (Barnett-Johnson et al., 2010). A intensidade de ${ }^{83} \mathrm{Kr}$ foi monitorada para controlar as interferências de ${ }^{84} \mathrm{Kr}$ e ${ }^{86} \mathrm{Kr}$ no ${ }^{84} \mathrm{Sr}$ e ${ }^{88} \mathrm{Sr}$, respectivamente. A razão invariável ${ }^{86} \mathrm{Sr} /{ }^{88} \mathrm{Sr}$ foi usada para corrigir a razão ${ }^{87} \mathrm{Sr} /{ }^{86} \mathrm{Sr}$ e o efeito de massa (mass bias) usando a lei exponencial (Walther et al., 2008). No começo e no fim de cada sessão de quatro horas, a razão ${ }^{87} \mathrm{Sr} /{ }^{86} \mathrm{Sr}$ do otólito interno do laboratório certificado em pó (NIES22, material certificado de referência produzido pelo Instituto Nacional de Estudos Ambientais do Japão) 
foi analisado para checar a confiabilidade das medidas de ${ }^{87} \mathrm{Sr} /{ }^{86} \mathrm{Sr}$. (Martin et al., 2013). Em todos os casos os valores ${ }^{87} \mathrm{Sr} /{ }^{86} \mathrm{Sr}$ do fs-LA-MC-ICPMS (média +-2DP $=0,7137+-0,0017$, $\mathrm{n}=38$ ) estavam em um ajuste muito bom com os valores certificados pelo laboratório (média +- $2 \mathrm{DP}=0,7092+-0,0001, n=54)$.

No laboratório de estudos Geocronologia da Universidade de Brasília (UnB), os cortes transversais dos otólitos com 1,5 mm de espessura foram perfurados no Microdrill nos mesmos $30 \%$ final da vida do peixe, onde foram realizados o raster na ablação a laser para análise de ${ }^{87} \mathrm{Sr} /{ }^{86} \mathrm{Sr}$, a fim de obter a assinatura isotópica de carbono $\left(\delta^{13} \mathrm{C}\right)$ e de oxigênio $\left(\delta^{18} \mathrm{O}\right)$ no período equivalente. $\mathrm{O}$ material foi coletado utilizando uma linha de aproximadamente $200 \mu \mathrm{m}$ de comprimento e $0,8 \mu \mathrm{m}$ de profundidade, ao longo do eixo de crescimento do otólito. O material perfurado foi retirado com papel de pesagem de amostras, e colocado diretamente em micro tubos para as análises isotópicas.

As análises isotópicas de carbono e oxigênio foram realizadas a partir do $\mathrm{CO}_{2}$ produzido pela reação das amostras com ácido fosfórico concentrado $\left(\mathrm{H}_{3} \mathrm{PO}_{4}\right)$. As razões isotópicas foram determinadas por espectrometria de massa de fonte gasosa utilizando-se o equipamento Delta Plus V Thermo-Fisher. Os resultados analíticos foram validados utilizando-se os padrões internacionais NBS $18\left(\delta^{13} \mathrm{C}=-5,014 ; \delta^{18} \mathrm{O}=-23,2\right)$, NBS $19\left(\delta^{13} \mathrm{C}=\right.$ 1,$\left.95 ; \delta^{18} \mathrm{O}=-2,20\right)$, IAEA CO-08 $\left(\delta^{13} \mathrm{C}=-5,764 ; \delta^{18} \mathrm{O}=-22,7\right)$ e IAEA CO-09 $\left(\delta^{13} \mathrm{C}=-47,321\right.$; $\delta^{18} \mathrm{O}=-15,6$ para calibração do gás de referência e durante a análise das amostras. Para o cálculo do $\delta^{13} \mathrm{C}$ o padrão utilizado foi o $\operatorname{PDB}\left(\delta^{13} \mathrm{C}=0\right)$ e V-SMOW $\left(\delta^{18} \mathrm{O}=0\right)$.

\subsection{Análises Estatísticas}

Atendidos os pressupostos de normalidade com o teste estatístico de Shapiro-Wilk, aplicou-se uma ANOVA para avaliar as diferenças da média da razão ${ }^{87} \mathrm{Sr} /{ }^{86} \mathrm{Sr}$ dos: 1) rios das 
diferentes bacias hidrográficas; 2) entre os indivíduos das mesmas bacias coletadas em ambiente natural e 3) entre os indivíduos das mesmas bacias coletadas em cativeiro. Depois, foi realizada uma análise de discriminante quadrática (QDA), (Barnett- Johnson, 2008) com os dados avaliados após a identificação de procedência indicada pelas análises isotópicas, para determinar se a razão ${ }^{87} \mathrm{Sr} /{ }^{86} \mathrm{Sr}$ e as assinaturas de $\delta^{13} \mathrm{C}$ podem ser usadas corretamente como classificadores da origem da pesca do pirarucu. A função quadrática foi usada para estimar a matriz resposta variância-covariância e foi aplicada para todos os indivíduos. O procedimento de teste de acurácia, tipo Jackknife (Barnett- Johnson, 2008) foi aplicado ao modelo de classificação da QDA. No teste de acurácia simples do modelo da QDA, todas as amostras são usadas para a construção do modelo e todas são testadas. No entanto, não há independência entre o modelo e sua predição. Assim, no teste de acurácia Jackknife, um modelo é construído com todas as amostras menos uma (n-1) e a predição é feita apenas com as amostras que não entraram no modelo, o que garante a independência entre o modelo e a predição. Todas as análises estatísticas foram feitas no programa de estatístico freeware $\mathrm{R}$ (http://www.rproject.org/). 


\section{RESULTADOS}

Nesta seção, serão apresentados: 1) os resultados das análises isotópicas de $\mathrm{Sr}$ da coleta de água dos rios; 2) as razões ${ }^{87} \mathrm{Sr} /{ }^{86} \mathrm{Sr}$ ao longo dos últimos $30 \%$ da vida dos peixes de ambiente natural e de cativeiro, agrupados por sub-bacias hidrográficas; 3) composições isotópicas de $\mathrm{Sr}$ e $\mathrm{C}$ das rações utilizadas na alimentação dos peixes criados em cativeiro; 4) as assinaturas isotópicas de $\delta^{13} \mathrm{C} e \delta^{18} \mathrm{O}$ dos pirarucus; 5) média das razões ${ }^{87} \mathrm{Sr} /{ }^{86} \mathrm{Sr}$ e assinatura $\delta^{13} \mathrm{C}$ de todos os indivíduos e resultados da QDA e do teste de acurácia Jackknife; e por fim os 6) resultados da caracterização físico-química e isotópica da água da RDSM e composição isotópica dos peixes da reserva.

\section{1. $\operatorname{Raz} \tilde{a} o^{87} \mathrm{Sr} /{ }^{86} \mathrm{Sr}$ dos rios}

Os rios da bacia Amazônica apresentaram razões ${ }^{87} \mathrm{Sr} /{ }^{86} \mathrm{Sr}$ variáveis de acordo com a geologia da sub-bacia amostrada, foram significativamente diferentes entre si (ANOVA, $\mathrm{F}=11,36, \mathrm{p}<0,01)$ e estão de acordo com a descrição de Santos et al. (2015). As razões isotópicas ${ }^{87} \mathrm{Sr} /{ }^{86} \mathrm{Sr}$ ratificam a heterogeneidade geológica da bacia Amazônica (Figura 11). 


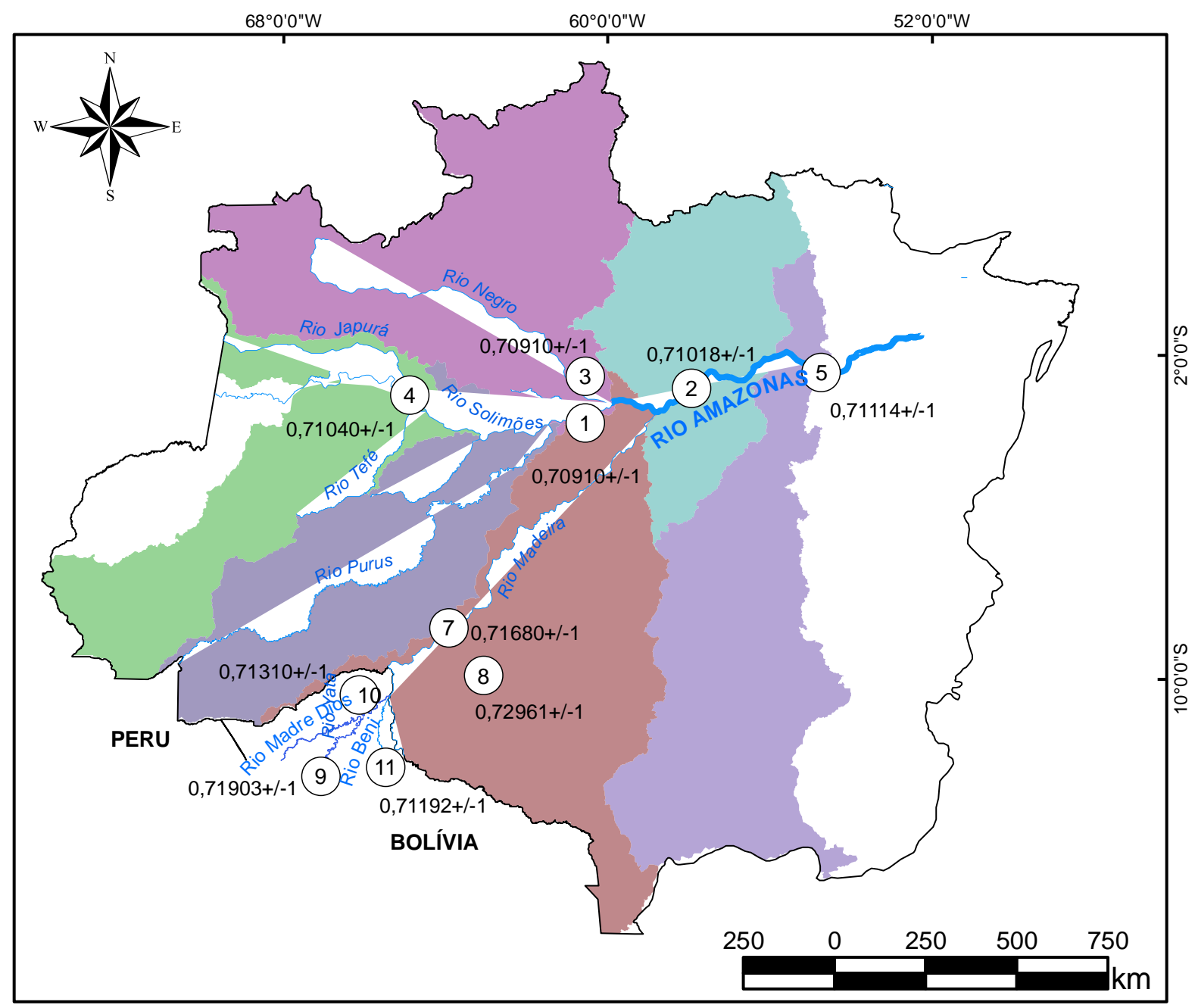

Figura 11. Mapa das razões isotópicas de ${ }^{87} \mathrm{Sr} /{ }^{86} \mathrm{Sr}$ na bacia Amazônica. Os números correspondem aos pontos de coleta de água com suas respectivas razões ${ }^{87} \mathrm{Sr} /{ }^{86} \mathrm{Sr}$. A localização dos pontos de coleta é: 1) Manacapuru; 2) Itacoatiara; 3) Novo Airão; 4) RDSM; 5) Santarém; 7) Porto Velho; 8) Ariquemes; 9) rio Beni; 10) confluência do rio Beni e Madre Dios; 11) rio Yata.

\section{2. $\mathrm{Raz} \tilde{a} \mathrm{o}^{87} \mathrm{Sr} /{ }^{86} \mathrm{Sr}$ dos otólitos}

Nesta seção estão apresentadas as razões ${ }^{87} \mathrm{Sr} /{ }^{86} \mathrm{Sr}$ ao longo do terço final da vida dos pirarucus de ambiente natural, agrupados em sub-bacias, bem como dos indivíduos criados em cativeiro. Os dados cronológicos em alta resolução espacial destes indivíduos estão representados nos gráficos com as respectivas faixas de variação da razão ${ }^{87} \mathrm{Sr} /{ }^{86} \mathrm{Sr}$ dos rios da 
bacia Amazônica descritas por Santos et al. (2015), Pouilly et al. (2014) e Duponchelle et al. (2016).

\subsubsection{Peixes de ambiente natural}

As médias das razões isotópicas ${ }^{87} \mathrm{Sr} /{ }^{86} \mathrm{Sr}$ dos peixes de ambiente natural foram significativamente diferentes nas diferentes sub-bacias (ANOVA, $F=18,397, p<0,01$ ). Os resultados cronológicos em alta resolução espacial dos últimos $30 \%$ da vida dos peixes de ambientes naturais das sub-bacias do Baixo Amazonas (Santarém), do Médio Amazonas e Solimões (Itacoatiara e Mamirauá) e do rio Beni, Madre Dios e Yata (Bolívia) estão descritas nas Figuras 12,13 e 14, respectivamente.

A Figura 12 apresenta a variação da composição isotópica de Sr dos otólitos de peixes coletados na região de Santarém. As amostras apresentam pequena variação na composição isotópica ao longo dos otólitos, mesmo considerando os diferentes indivíduos. Quanto à média da composição isotópica dos indivíduos de Santarém (média das razões ${ }^{87} \mathrm{Sr} /{ }^{86} \mathrm{Sr}=$

$0,70895+/-1)$, ressalta-se que essa é inferior à razão isotópica média de ${ }^{87} \mathrm{Sr} /{ }^{86} \mathrm{Sr}$ do Amazonas $(0,71114+/-1)$. 


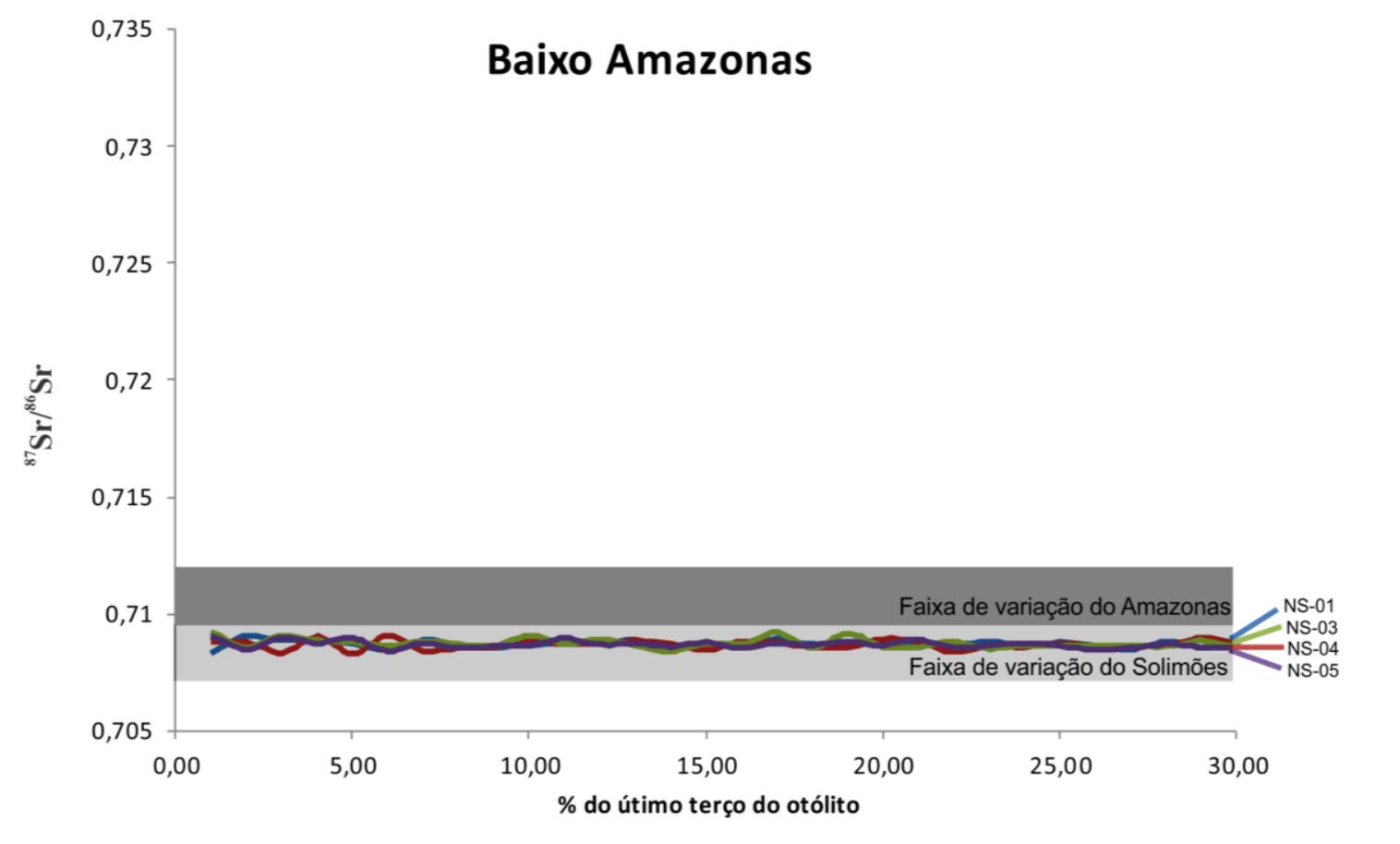

Figura 12. Razão ${ }^{87} \mathrm{Sr} /{ }^{86} \mathrm{Sr}$ dos indivíduos de pirarucu de Santarém. As faixas representam a variação do rio Solimões (cinza claro e a do rio Amazonas (cinza escuro) de acordo com Santos et al. (2015).

Os resultados encontrados para os exemplares do rio Solimões na RDSM e em Itacoatiara apresentaram variações significativas entre os indivíduos (Figura 13). De uma maneira geral, as análises dos exemplares de Mamirauá possuem valores médios compatíveis com as razões isotópicas de Sr do rio Solimões na RDSM (0,70900+/-1), enquanto que os valores médios dos exemplares de Itacoatiara estão de acordo com a razão ${ }^{87} \mathrm{Sr} /{ }^{86} \mathrm{Sr}$ do rio Amazonas nessa mesma localidade $(0,71018+/-1)$. Os dados revelam ainda uma maior dispersão da razão isotópica entre os indivíduos da RDSM (rio Solimões) quando comparados aos exemplares de Itacoatiara. Esta variação encontrada para os peixes do rio Solimões é compatível com a faixa de variação isotópica natural do Sr nesta sub bacia (Santos et al., 2015), assim como a menor variação dos indivíduos de Itacoatiara corrobora as flutuações isotópicas do rio Amazonas, com exceção do espécime NAT-ITA-02. 
O indivíduo NAT-ITA-02 apresentou um pico de variação da razão ${ }^{87} \mathrm{Sr} /{ }^{86} \mathrm{Sr}$ relativo ao rio Madeira no começo do período de vida analisado. O município de Itacoatiara está situado na confluência do rio Madeira com rio Amazonas, onde na época de seca, quando o nível das águas está baixo, há a formação de lagos compostos de águas dos dois rios. Assim, este pico de variação da razão ${ }^{87} \mathrm{Sr} /{ }^{86} \mathrm{Sr}$ do indivíduo NAT-ITA-02 indica que o espécime esteve em hábitats formados por águas do rio Madeira neste período da vida.

Todavia, as análises cronológicas dos exemplares estão de acordo com a razão ${ }^{87} \mathrm{Sr} /{ }^{86} \mathrm{Sr}$ do rio Amazonas em Itacoatiara de 0,71018+/-1 e em Mamirauá no rio Solimões de 0,70900+/-1 (Figura 13).

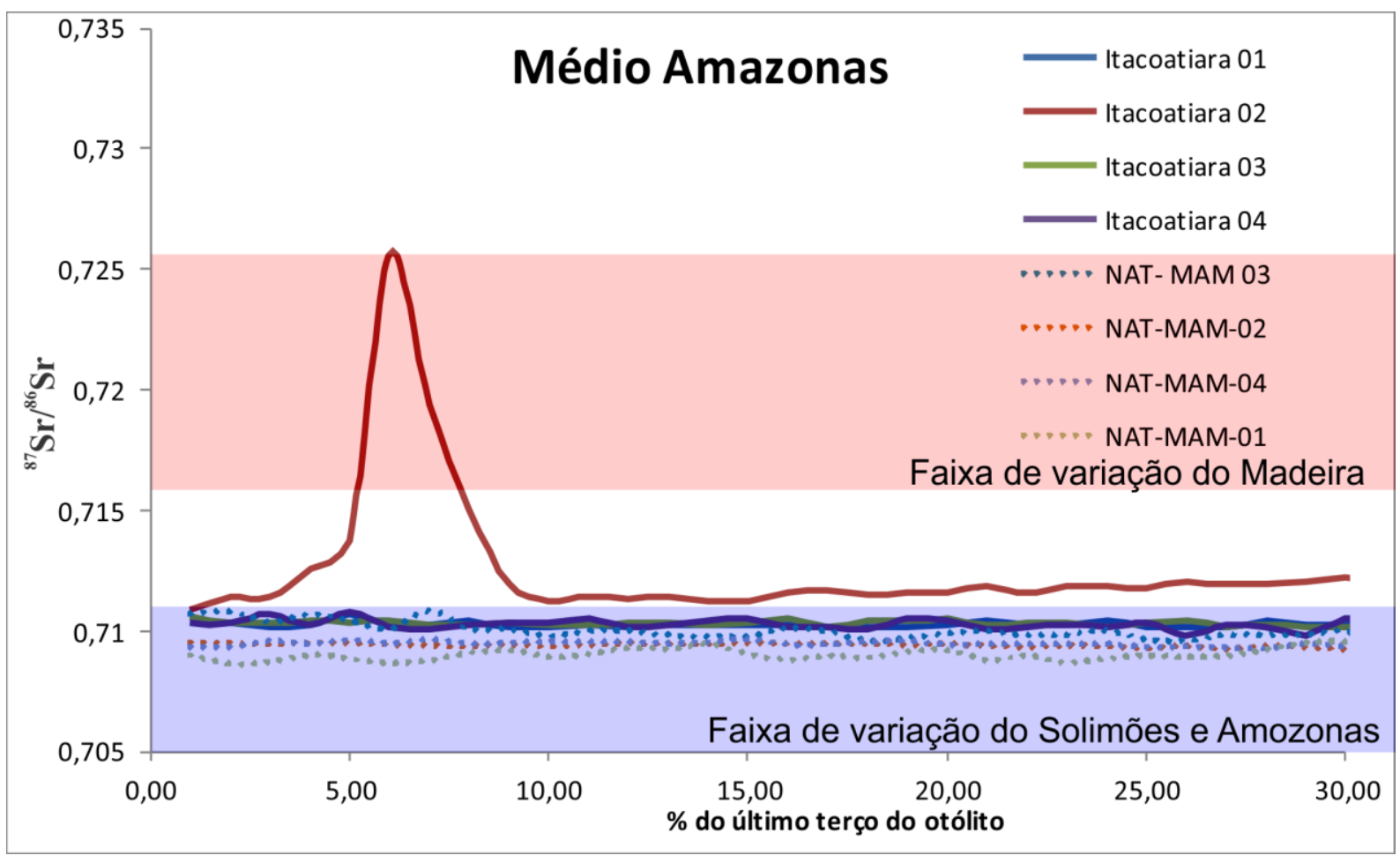

Figura 13. Razão ${ }^{87} \mathrm{Sr} /{ }^{86} \mathrm{Sr}$ dos indivíduos de pirarucu do Solimões e Médio Amazonas. A faixa azul representa a variação da razão ${ }^{87} \mathrm{Sr} /{ }^{86} \mathrm{Sr}$ dos rios Solimões e Amazonas, e a faixa rosa representa a variação da razão ${ }^{87} \mathrm{Sr} /{ }^{86} \mathrm{Sr}$ do rio Madeira de acordo com Santos et al. (2015). 
A Figura 14 apresenta as razões ${ }^{87} \mathrm{Sr} /{ }^{86} \mathrm{Sr}$ dos indivíduos oriundos de três regiões da bacia do Beni na Bolívia. Os indivíduos LV apresentam a razão ${ }^{87} \mathrm{Sr} /{ }^{86} \mathrm{Sr}$ média de $0,71459+/-$ 1 e foram indicados como provenientes da pesca na laguna média no rio Madre Dios. Já os indivíduos FL apresentam razão ${ }^{87} \mathrm{Sr} /{ }^{86} \mathrm{Sr}$ média de 0,72285 +/-1 e foram informados como procedentes do município de Riberalta, onde ocorre a confluência do rio Madre Dios e o Beni. Por fim os indivíduos YA exibiram as razões mais altas (média de 0,72862 +/-1) e são indicados como procedentes do rio Yata.

Todos os indivíduos da bacia do Beni-Madeira apresentaram variações isotópicas na razão ${ }^{87} \mathrm{Sr} /{ }^{86} \mathrm{Sr}$ muito maiores do que os indivíduos dos rios Solimões e Amazonas. Esta variação corrobora a descrição de variação temporal da razão ${ }^{87} \mathrm{Sr} /{ }^{86} \mathrm{Sr}$ desta bacia descrita por Santos et al. (2015) e Duponchelle et al. (2016). Também é possível observar que existe uma variação local entre os rios que compõem a sub-bacia do Beni - Madeira, onde os indivíduos do rio Yata apresentam oscilações maiores do que aqueles da confluência entre o rio Beni e o Madre Dios (Figura 14). 


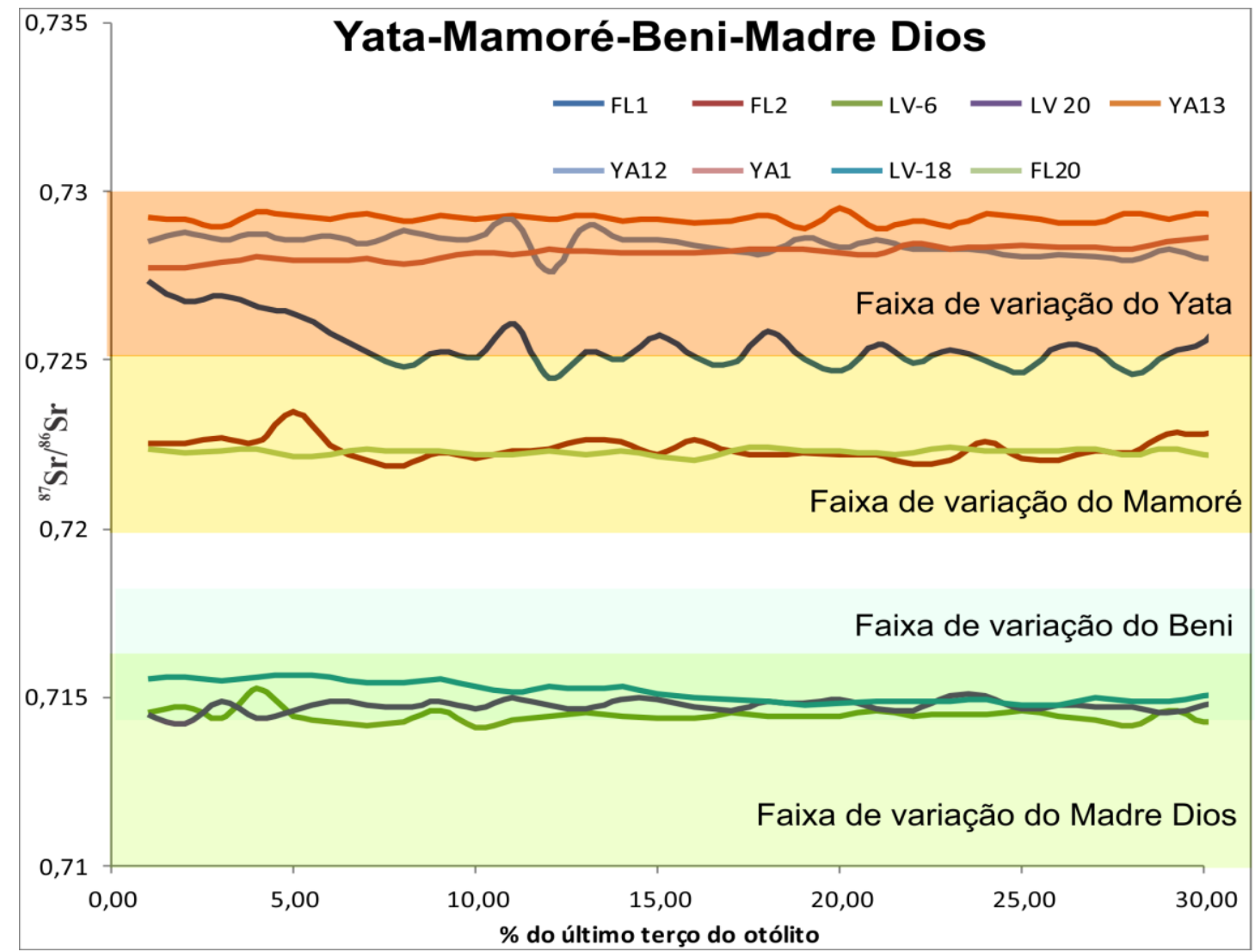

Figura 14. Razão ${ }^{87} \mathrm{Sr} /{ }^{86} \mathrm{Sr}$ dos indivíduos de pirarucu da Bolívia nos rios Beni, Madre Dios e Yata. As faixas representam a variação da razão ${ }^{87} \mathrm{Sr} /{ }^{86} \mathrm{Sr}$ nos rios Yata (rosa), Mamoré (laranja), Beni (verde) e Madre Dios (cinza) de acordo com Pouilly et al. (2014) e Duponchelle et al (2016).

\subsubsection{Peixes de cativeiro}

O padrão encontrado para os peixes de cativeiro é diferente dos peixes de ambiente natural. A média das razões ${ }^{87} \mathrm{Sr} /{ }^{86} \mathrm{Sr}$ dos peixes de cativeiro nas diferentes sub-bacias em estudo foram significativamente diferentes (ANOVA, $\mathrm{F}=5.614, \mathrm{p}=0.0161$ ). Os resultados da razão isotópica dos peixes de cativeiro das diferentes áreas de amostragem são apresentados nas Figuras 15 (Amazonas e Solimões), 16 (Baixo Amazonas em Santarém) e 17 (Rondônia). Em geral, as razões isotópicas de $\mathrm{Sr}$ permanecem relativamente constante ao longo do intervalo analisado do otólito, sugerindo que indivíduo permaneceu praticamente no mesmo ambiente. 
Os indivíduos coletados na feira de Manaus e do cativeiro de Novo Airão exibiram a razão ${ }^{87} \mathrm{Sr} /{ }^{86} \mathrm{Sr}$ com valores médios de 0,710 , ou seja, compatíveis com os valores observados para o rio Solimões. Já o indivíduo proveniente da Cooperativa de pescadores de Manacapuru apresenta razão ${ }^{87} \mathrm{Sr} /{ }^{86} \mathrm{Sr}$ média de 0,720 , que é um valor situado no intervalo inferior observado para o rio Negro (Figura 15). Ao contrário dos demais indivíduos, o exemplar coletado em Manacapuru apresenta maiores flutuações na razão isotópica de $\mathrm{Sr}$ ao longo das linhas de crescimento do otólito.

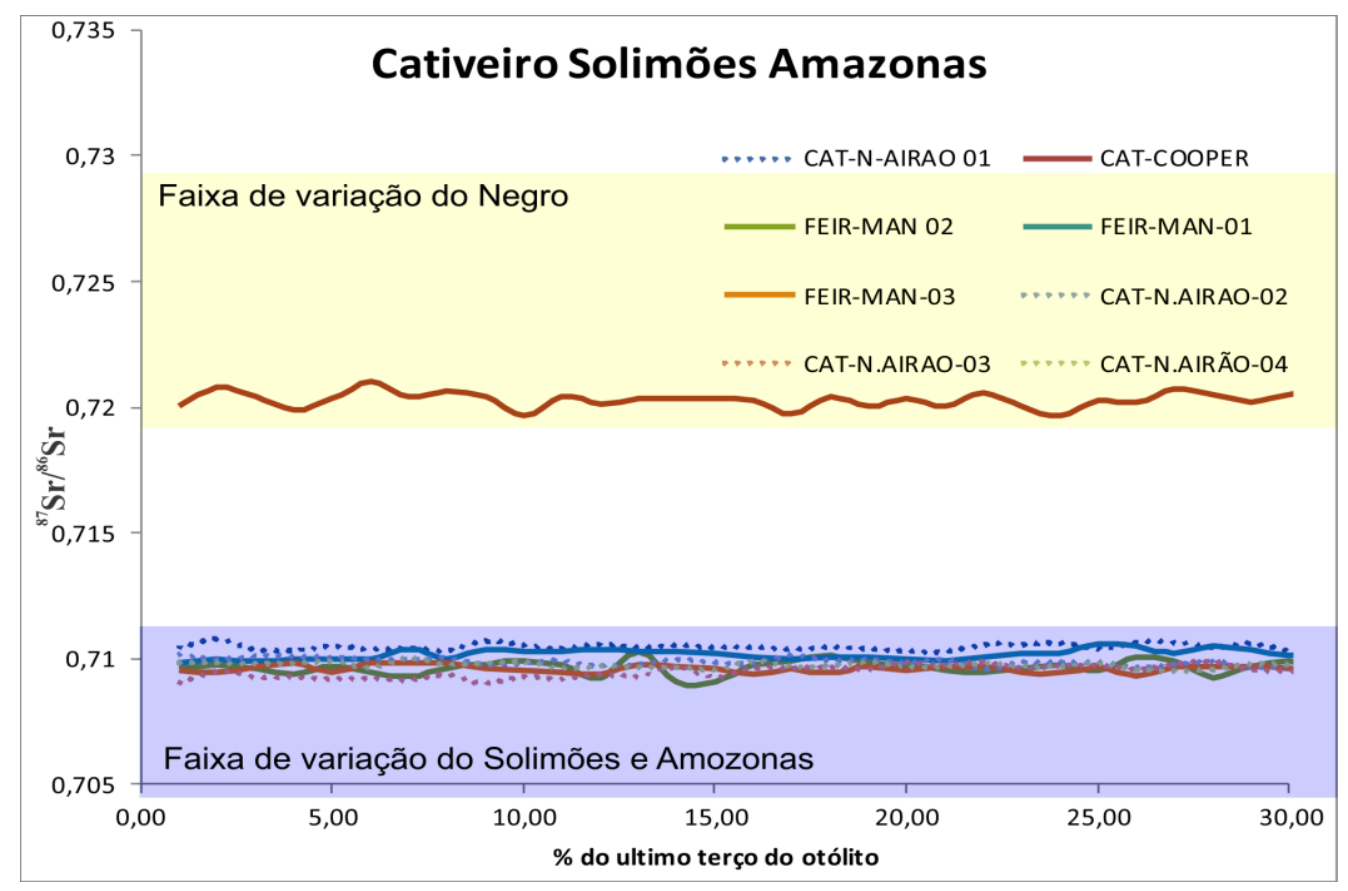

Figura 15. Razão ${ }^{87} \mathrm{Sr} /{ }^{86} \mathrm{Sr}$ dos peixes de cativeiro do Solimões e Amazonas. As Faixas representam a variação da razão ${ }^{87} \mathrm{Sr} /{ }^{86} \mathrm{Sr}$ dos rios Solimões e Amazonas (azul) e negro (laranja) de acordo com Santos et al. (2015).

Os indivíduos de cativeiro de Santarém no baixo Amazonas apresentam padrão de variação de $\mathrm{Sr}$ ao longo da linha de crescimento do otólito muito diferente do observados nas demais amostras (Figura 16). O exemplar CAT-SAT-05 apresentou razão isotópica média de 0,7129 e uma constância da razão ${ }^{87} \mathrm{Sr} /{ }^{86} \mathrm{Sr}$ ao longo do período de vida analisado. Já o indivíduo CAT-SAT-02 apresentou uma razão isotópica média de 0,725 durante a maior parte 
do último terço do otólito e depois uma brusca mudança para razões de ${ }^{87} \mathrm{Sr} /{ }^{86} \mathrm{Sr}$ em torno de 0,710. Por sua vez, o indivíduo CAT-SAT-01 apresentou grandes oscilações na composição isotópica ao longo do período de vida analisado conforme mostra a Figura 16.

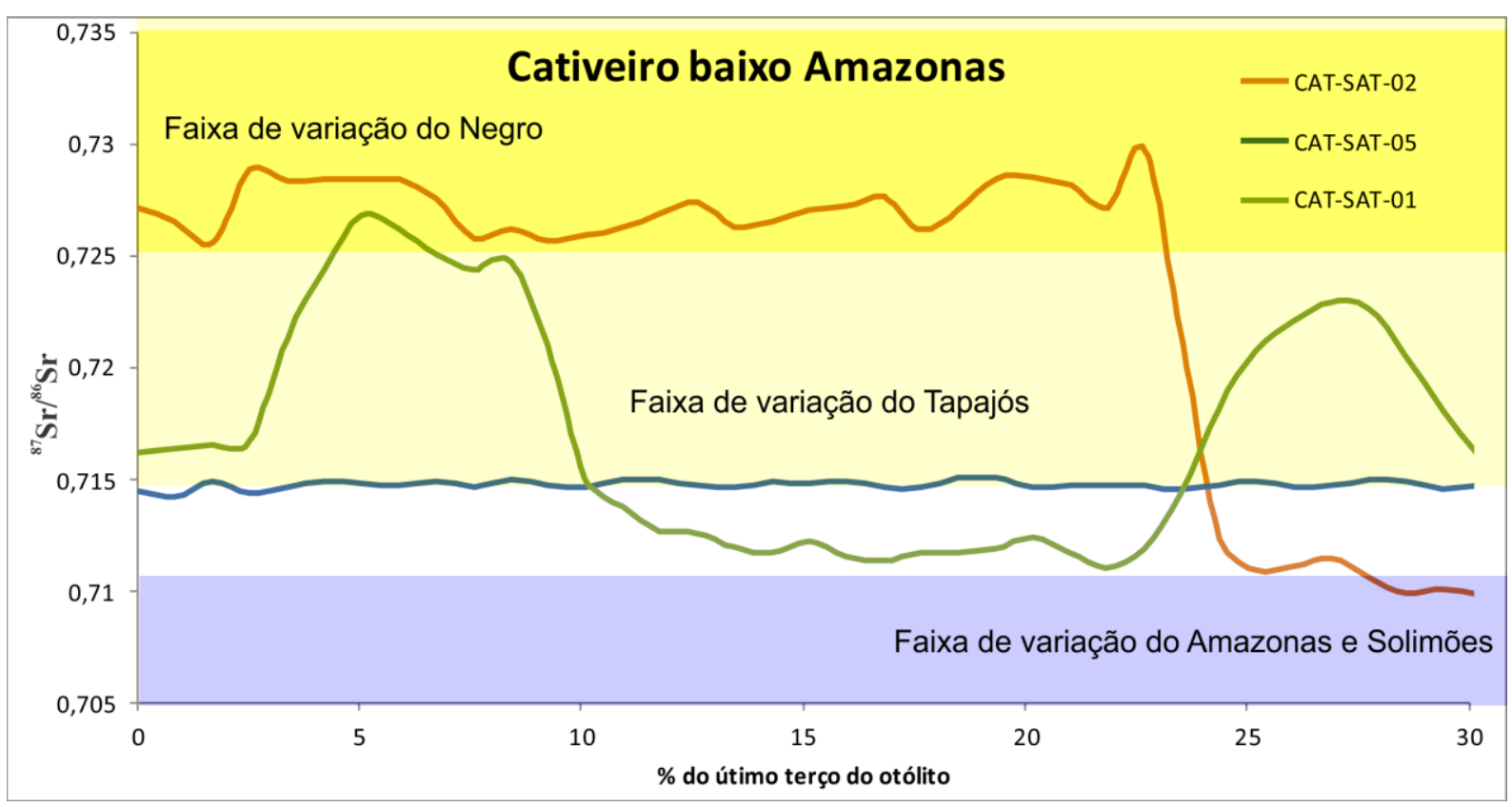

Figura 16. Razão ${ }^{87} \mathrm{Sr} /{ }^{86} \mathrm{Sr}$ dos peixes de cativeiro do baixo Amazonas. As faixas representam a variação da razão ${ }^{87} \mathrm{Sr} /{ }^{86} \mathrm{Sr}$ nos rios Negro (laranja), Tapajós (amarelo) e Amazonas (azul) de acordo com Santos et al. (2015).

E por fim, a Figura 17 apresenta os resultados dos indivíduos provenientes de Ariquemes-RO. Três dentre os quatro peixes apresentam pequena variação na razão isotópica ${ }^{87} \mathrm{Sr} /{ }^{86} \mathrm{Sr}$ ao longo do período de vida analisado. Estes exemplares exibiram razões ${ }^{87} \mathrm{Sr} /{ }^{86} \mathrm{Sr}$ relativas a Porto Velho (média 0,7168). Apenas o indivíduo CAT-ROD 01 apresentou variação significativa na razão isotópica de $\mathrm{Sr}$ ao longo da linha de crescimento do otólito, apresentando valores médios de ${ }^{87} \mathrm{Sr} /{ }^{86} \mathrm{Sr}=0,72961+/-1$, compatível com a razão ${ }^{87} \mathrm{Sr} /{ }^{86} \mathrm{Sr}$ do tanque de criação 


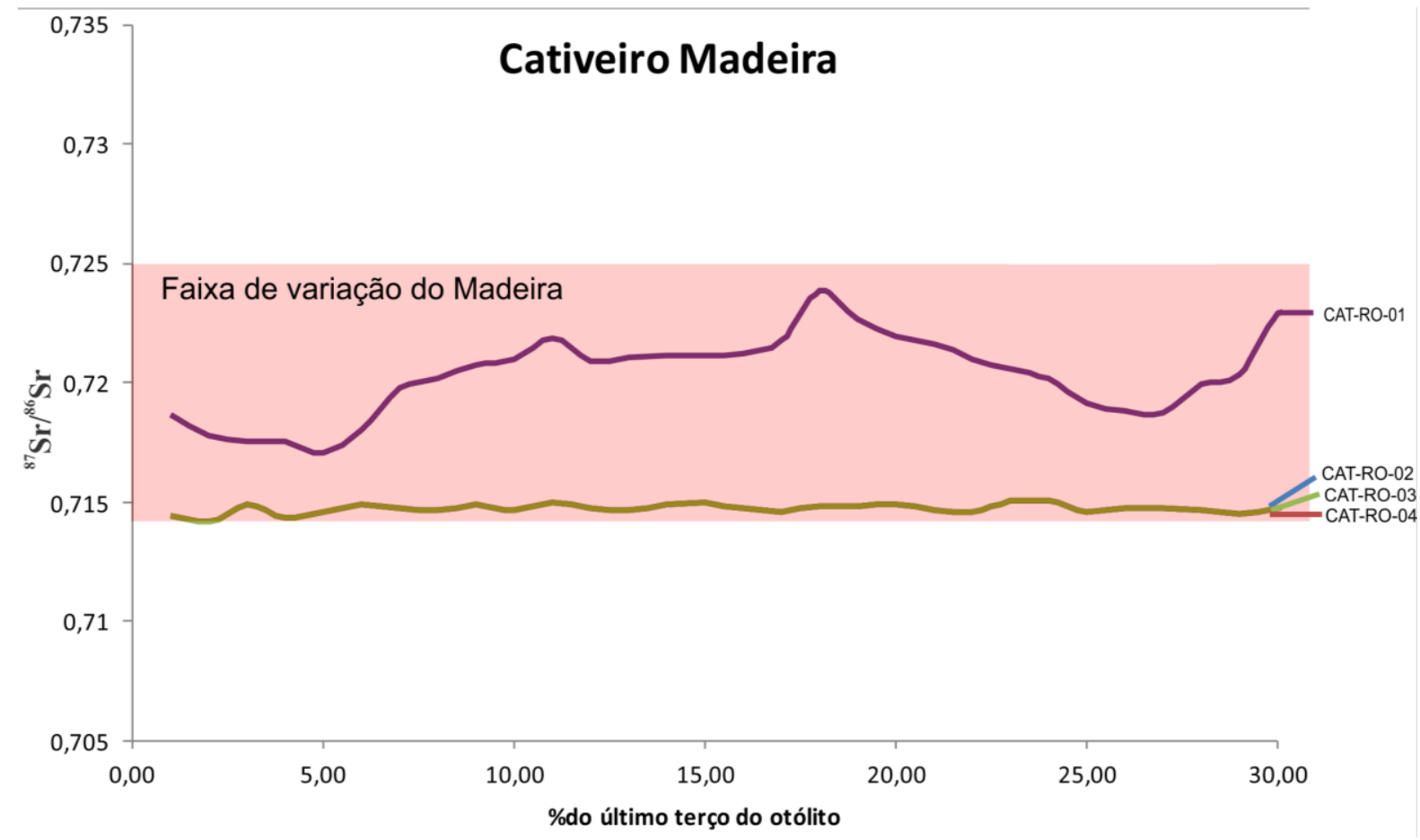

Figura 17. Razão ${ }^{87} \mathrm{Sr} /{ }^{86} \mathrm{Sr}$ dos indivíduos de pirarucu de cativeiro do rio Madeira. A faixa rosa representa a variação da razão ${ }^{87} \mathrm{Sr} /{ }^{86} \mathrm{Sr}$ do rio Madeira de acordo com Santos et al. (2015) e Duponchelle et al. (2016). 
A Tabela 4 apresenta a variação da razão ${ }^{87} \mathrm{Sr} /{ }^{86} \mathrm{Sr}$ dos peixes de ambiente natural e cativeiro agrupados de acordo com os rios de origem. Houve diferença significativa entre a origem dos peixes quanto ao rio de procedência (ANOVA, $\mathrm{F}=19.566 ; \mathrm{p}=<0.01$ ).

TABELA 4. Variação dos isótopos de $\mathrm{Sr}$ nos pirarucus de cativeiro e ambiente natural indicando os: rios de origem, número de indivíduos, média da razão ${ }^{87} \mathrm{Sr} /{ }^{86} \mathrm{Sr}$ do otólito, desvio padrão, razão ${ }^{87} \mathrm{Sr} /{ }^{86} \mathrm{Sr}$ mínima do otólito e razão ${ }^{87} \mathrm{Sr} /{ }^{86} \mathrm{Sr}$ máxima do otólito. $($ ANOVA, $\mathrm{F}=19.566 ; \mathrm{p}<0,01)$

\begin{tabular}{cccccc}
\hline Rio & $\begin{array}{c}\mathbf{N}^{\mathbf{o}} \text { de } \\
\text { indivíduo } \\
\mathbf{S}\end{array}$ & $\begin{array}{c}\text { Média da } \\
\text { razão } \\
{ }^{87} \mathbf{S r} /{ }^{86} \mathbf{S r} \text { do } \\
\text { otólito }\end{array}$ & $\begin{array}{c}\text { Desvio } \\
\text { Padrão }\end{array}$ & $\begin{array}{c}\text { Razão } \\
{ }^{87} \mathbf{S r} /{ }^{86} \mathbf{S r} \\
\text { mínima do } \\
\text { otólito }\end{array}$ & $\begin{array}{c}\text { Razão } \\
{ }^{\mathbf{8 7}} \mathbf{S r} /{ }^{86} \mathbf{S r} \\
\text { máxima do } \\
\text { otólito }\end{array}$ \\
\hline $\begin{array}{c}\text { Amazonas } \\
\text { Baixo- }\end{array}$ & 4 & 0.71089 & 0.00119 & 0.71020 & 0.71267 \\
Amazonas & 6 & 0.71126 & 0.00288 & 0.70865 & 0.71479 \\
Beni & 8 & 0.72294 & 0.00588 & 0.71441 & 0.72885 \\
Madeira & 3 & 0.71734 & 0.00442 & 0.71479 & 0.72245 \\
Solimões & 13 & 0.70989 & 0.00169 & 0.70894 & 0.71543 \\
\hline
\end{tabular}

\subsubsection{Composição isotópica da ração dos indivíduos de cativeiro}

Considerando que para algumas amostras de peixe de cativeiro há diferenças significativa entre a composição média do otólito e a média da razão ${ }^{87} \mathrm{Sr} /{ }^{86} \mathrm{Sr}$ da água da subbacia em que os mesmos foram criados, investigou-se a possibilidade dessa diferença está relacionada à dieta de cativeiro. Assim, as razões ${ }^{87} \mathrm{Sr} /{ }^{86} \mathrm{Sr}$ e as assinaturas $\delta^{13} \mathrm{C}$ das rações utilizadas na alimentação dos pirarucus em cativeiro estão apresentadas na Tabela 5.

TABELA 5. Tipos de ração e assinatura $\delta^{13} \mathrm{C}\left(\%\right.$ ) (Erro associado: $\delta^{13} \mathrm{C}=0,05 \%$ ) e razão ${ }^{87} \mathrm{Sr} /{ }^{86} \mathrm{Sr}$

\begin{tabular}{ccc}
\hline Tipo da ração & $\mathbf{\delta}^{\mathbf{1 3}} \mathbf{C}(\% \mathbf{)})$ & ${ }^{\mathbf{8 7}} \mathbf{S r} \mathbf{~}^{\mathbf{6}} \mathbf{S r}$ \\
\hline Tipo I & $-19,31$ & 0,723617 \\
Tipo II & $-15,09$ & 0,729315 \\
Tipo III & $-14,95$ & 0,719627 \\
\hline
\end{tabular}


Neste sentido, a Figura 18 apresenta a relação entre as razões dos otólitos de cativeiro, da água e das rações utilizadas na alimentação destes peixes. Observa-se que na maioria dos indivíduos a composição média da razão ${ }^{87} \mathrm{Sr} /{ }^{86} \mathrm{Sr}$ situa-se entre a composição média da bacia e da ração. Para os indivíduos CAT-FEIRA-MAM, indicados como provenientes de Tefé, observa-se que não é possível explicar a composição isotópica dos indivíduos a partir dos valores da água dos rios e da ração. O exemplar CAT-ROD-01 é o único onde a razão isotópica do otólito situa-se no mesmo intervalo composicional da ração.

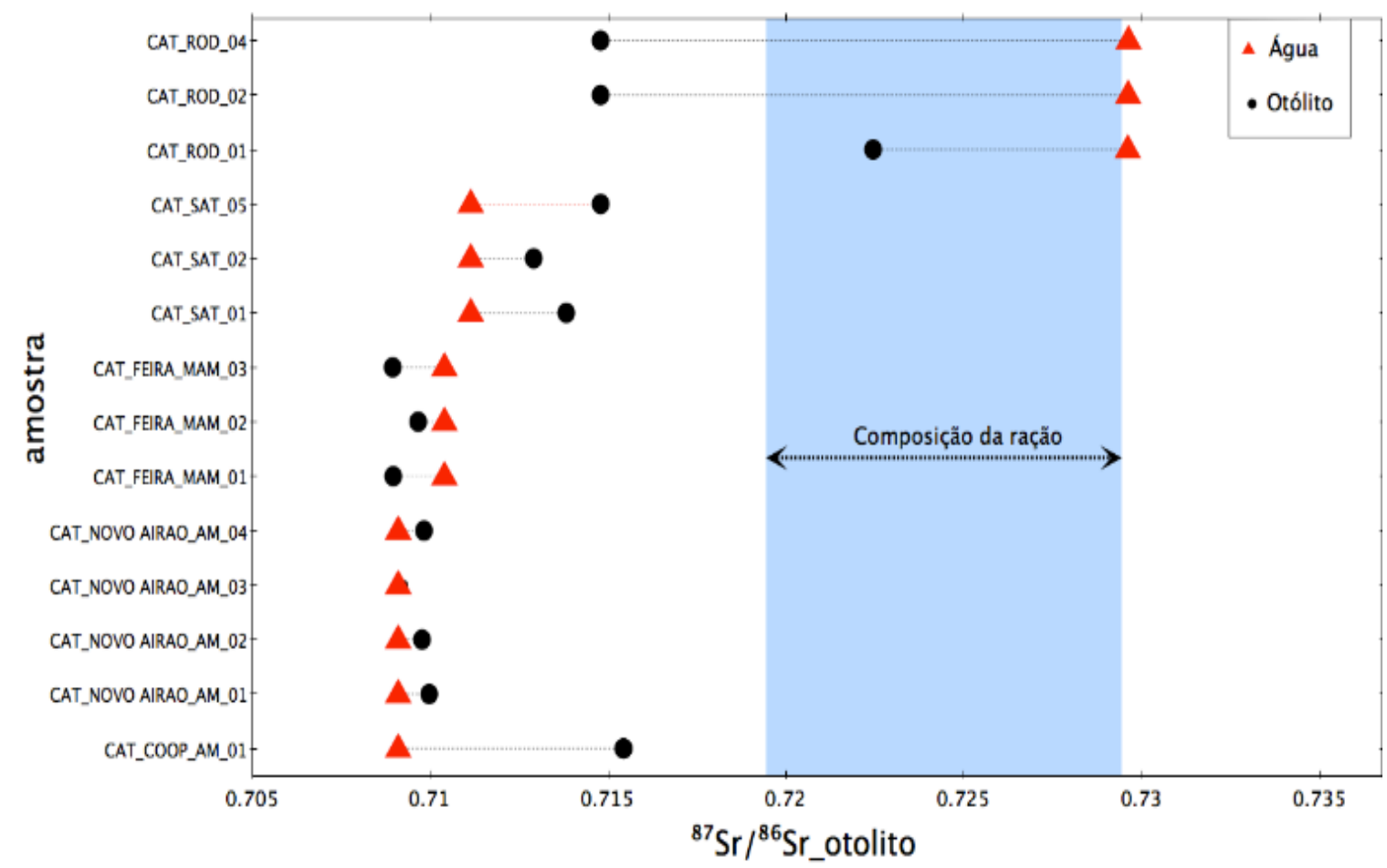

Figura 18. Razão ${ }^{87} \mathrm{Sr} /{ }^{86} \mathrm{Sr}$ dos otólitos dos peixes de cativeiro, da média das águas das respectivas bacias e das rações utilizadas na alimentação em cativeiro. A faixa azul representa a variação da razão ${ }^{87} \mathrm{Sr} /{ }^{86} \mathrm{Sr}$ das rações utilizadas na alimentação dos peixes. 


\subsection{Assinaturas $\delta^{13} \mathrm{C} e \delta^{18} \mathrm{O}$ dos peixes}

As assinaturas isotópicas de $\delta^{13} \mathrm{C}$ dos otólitos dos peixes de ambiente natural e de cativeiro foram significativamente diferentes (ANOVA, $\mathrm{F}=124.44, \mathrm{p}<0,01$ ). A maioria dos pirarucus de ambiente natural apresentaram assinaturas $\delta^{13} \mathrm{C}$ compatível com o intervalo de variação da composição isotópica de plantas C3, com média de $-28.9 \pm 1.2$ (Forsberg, et al., 1993; Watson et al., 2013; Domingues et al., 2002) (Figura 19). Dentre os indivíduos de ambiente natural, apenas nos de Itacoatiara observou-se valores de $\delta^{13} \mathrm{C}(-15,34 \%$ a $-20,06 \%$ o intermediários entre uma dieta baseada em plantas C3 e C4.

Já em relação aos indivíduos de cativeiro, apenas os exemplares obtidos diretamente nos cativeiros de Rondônia (Madeira) e três indivíduos de Santarém (Baixo Amazonas) apresentaram a assinatura isotópica de C4, relativa a alimentação das rações peletizadas a base de milho. Todos os peixes obtidos na feira de Manaus, considerados como oriundos de cativeiro (Novo Airão, Tefé e Manacapuru) exibiram baixas assinaturas $\delta^{13} \mathrm{C}$ características dos peixes de ambiente natural do sistema Amazônico (Figura 19). Por sua vez, a maioria dos exemplares dos cativeiros de Santarém apresentaram assinaturas $\delta^{13} \mathrm{C}$ intermediárias entre plantas C3 e C4.

As assinaturas isotópicas de $\delta^{18} \mathrm{O}$ também estão demonstradas na Figura 19. Para alguns peixes de cativeiro (assinatura $\delta^{13} \mathrm{C}$ relativa a $\mathrm{C} 4$ ), as assinaturas de $\delta^{18} \mathrm{O}$ foram maiores do que para aqueles de ambiente natural. No entanto, não houve variação da assinatura $\delta^{18} \mathrm{O}$ na escala espacial da bacia Amazônica. 


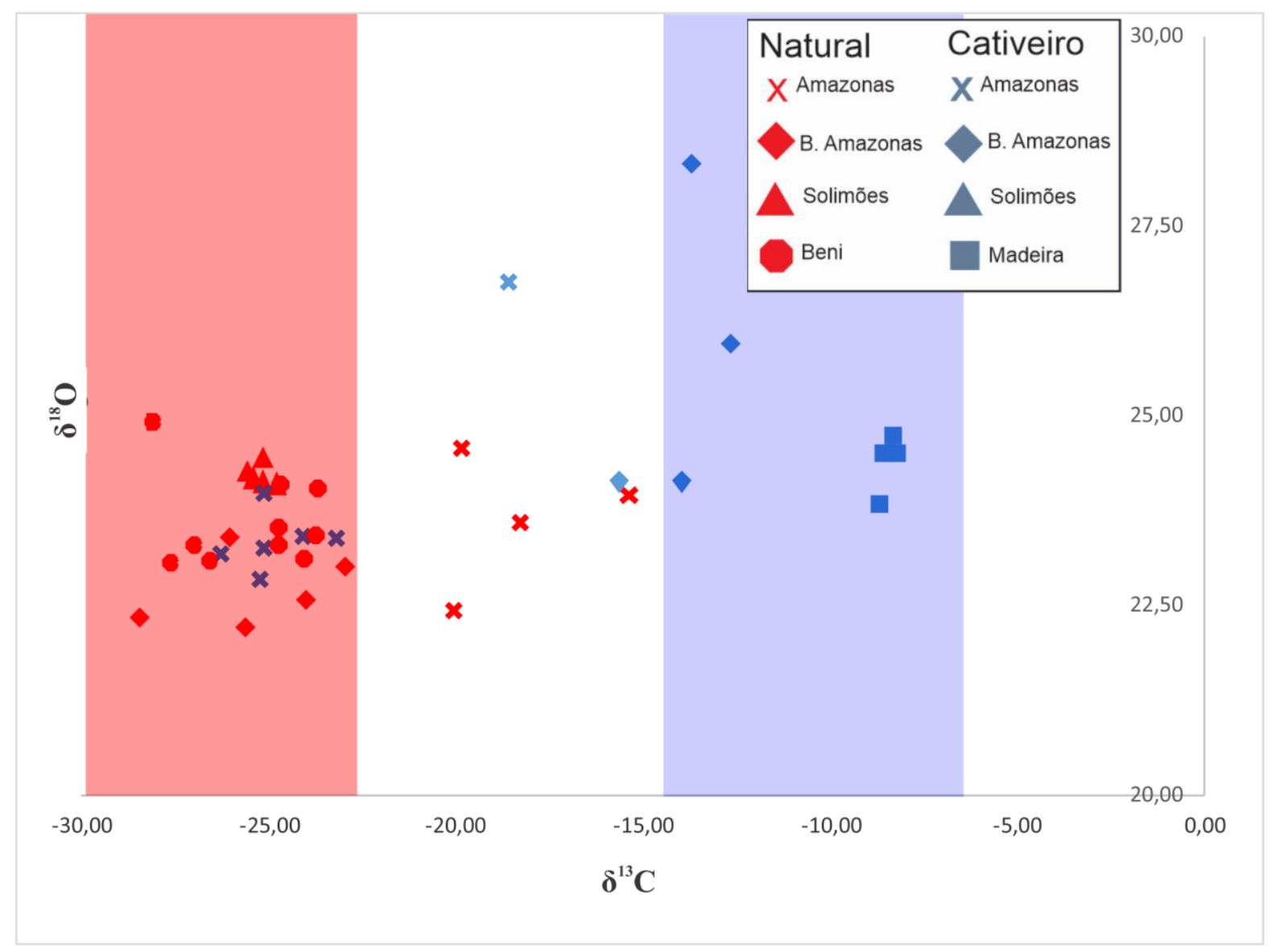

Figura 19. Relação $\delta^{13} \mathrm{C}$ e $\delta^{18} \mathrm{O}$ da pesca do pirarucu na bacia Amazônica. As faixas em azul e rosa representam a faixa de assinatura isotópica $\delta^{13} \mathrm{C}$ das plantas $\mathrm{C} 3$ e $\mathrm{C} 4$, respectivamente.

\subsection{Média da razão ${ }^{87} \mathrm{Sr} /{ }^{86} \mathrm{Sr}$ e assinatura $\delta^{13} \mathrm{C}$ dos peixes}

A média da razão isotópica ${ }^{87} \mathrm{Sr} /{ }^{86} \mathrm{Sr}$ e a assinatura $\delta^{13} \mathrm{C}$ dos otólitos de pirarucu estão apresentadas na Figura 20. As razões ${ }^{87} \mathrm{Sr} /{ }^{86} \mathrm{Sr}$ dos otólitos apresentaram uma grande variação relativas aos diferentes rios da bacia Amazônica. Nos indivíduos da Bolívia observou-se razões ${ }^{87} \mathrm{Sr} /{ }^{86} \mathrm{Sr}$ maiores, o que reflete as rochas antigas presentes na região. Já os exemplares de Rondônia apresentaram as razões relativas ao Madeira e ao tanque de criação. E os peixes do Amazonas e Solimões exibiram razões mais baixas relativas à geologia de suas bacias. 
Em relação a assinatura $\delta^{13} \mathrm{C}$, os otólitos também apresentaram a variação entre plantas $\mathrm{C} 3$ e $\mathrm{C} 4$, com indivíduos de ambiente natural exibindo assinaturas correspondentes às plantas C3. Entretanto, a maior parte dos peixes informados como de cativeiro apresentaram assinaturas relativas a áreas de ambiente natural. Somente nos indivíduos de Rondônia e um indivíduo de Santarém observou-se assinaturas correspondentes a plantas C4.

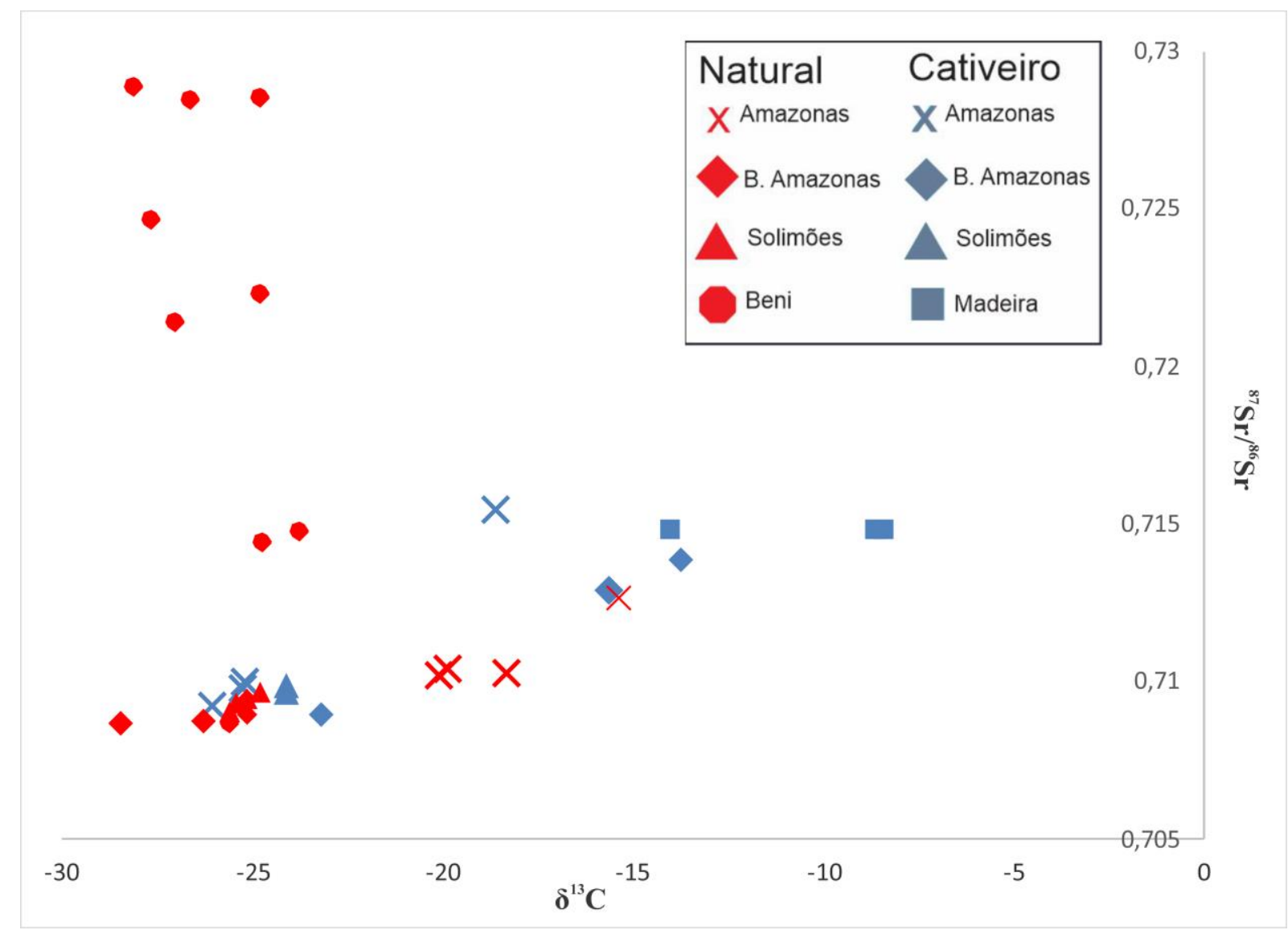

Figura 20. Razão ${ }^{87} \mathrm{Sr} /{ }^{86} \mathrm{Sr}$ média e assinatura $\delta^{13} \mathrm{C}$ dos pirarucus da bacia Amazônica

\subsection{Análise discriminante}

Os resultados da QDA e do teste de acurácia Jackknife estão apresentados na Tabela 6. A QDA discriminou a origem da pesca do pirarucu quanto a origem geográfica pela razão ${ }^{87} \mathrm{Sr} /{ }^{86} \mathrm{Sr}$ com probabilidade total de classificação correta de 70,5\%. A probabilidade de classificação geográfica correta por rio da bacia Amazônica para o pirarucu foi de: $50 \%$ no rio 
Amazonas, $75 \%$ no rio Beni, $75 \%$ no rio Madeira e de $78,5 \%$ no rio Solimões. O teste de acurácia Jackknife não se aplicou para os indivíduos do Amazonas, Beni e Madeira. Já para o Solimões a probabilidade de acurácia foi de $100 \%$ e probabilidade total do teste para estes agrupamentos de dados foi de $50 \%$.

A discriminação total quanto ao método de produção pela assinatura $\delta^{13} \mathrm{C}$ foi de $94,16 \%$, com a probabilidade correta de classificação de $85,71 \%$ para peixes de cativeiro e 92,29\% para peixes de ambiente natural. A predição total do teste Jackknife para este modelo de QDA foi de $100 \%$, de $100 \%$ para peixes de cativeiro e não se aplicou para peixes de ambiente natural.

TABELA 6. Resultados da QDA e do teste de acurácia Jackknife dos indivíduos de pirarucu agrupados por rios segundo a razão ${ }^{87} \mathrm{Sr} /{ }^{86} \mathrm{Sr}$ e por método de produção segundo a assinatura $\delta^{13}$ C. (N.A. significa não se aplica)

\begin{tabular}{ccc}
\hline $\begin{array}{c}\text { Probabilidade de classificação dos } \\
\text { grupos (QDA) }\end{array}$ & ${ }^{{ }^{87} \mathbf{S r} /{ }^{\mathbf{6}} \mathbf{S r}}$ & $\begin{array}{c}\text { Predição do teste } \\
\text { Jackknife }\end{array}$ \\
\hline Amazonas & & N.A \\
Beni & $50 \%$ & N.A \\
Madeira & $75 \%$ & N.A. \\
Solimões & $75 \%$ & $100 \%$ \\
Probabilidade de classificação total & $79 \%$ & $50 \%$ \\
\hline Probabilidade de classificação dos & $70,50 \%$ & Predição do teste \\
grupos (QDA) & \multirow{2}{*}{$\mathbf{C}$} & $100 \%$ \\
Cativeiro & $86 \%$ & N.A \\
Ambiente natural & $92 \%$ & $100 \%$ \\
\hline Probabilidade de classificação total & $94,16 \%$ &
\end{tabular}

4.6. Estudo de Caso Mamirauá- Uso de marcadores isotópicos em uma escala local

Os resultados das amostras de água da RDSM estão nas Figuras 21, 22 e 23. Os dados de condutividade da Figura 21 estão representados de acordo com as características das águas. 
As águas do rio Solimões são mais condutivas devido à maior concentração de íons. Já as águas do rio Japurá são menos condutivas, visto que há menor quantidade de matéria orgânica dissolvida em comparação com o rio Solimões. E por fim, o rio Aranapu é caracterizado pela mistura destas duas fontes de água.

Os lagos possuem condutividade mais elevada do que os rios, com exceto o rio Solimões e Aranapu, já que as taxas de evaporação são maiores. Esse padrão é também observado nos resultados isotópicos de $\delta^{18} \mathrm{O}$ e $\delta \mathrm{D}$ observado nas Figuras 22 e 23, respectivamente. As águas dos lagos são mais enriquecidas no isótopo mais pesado, do que a água dos rios, devido as diferentes taxas de evaporação.

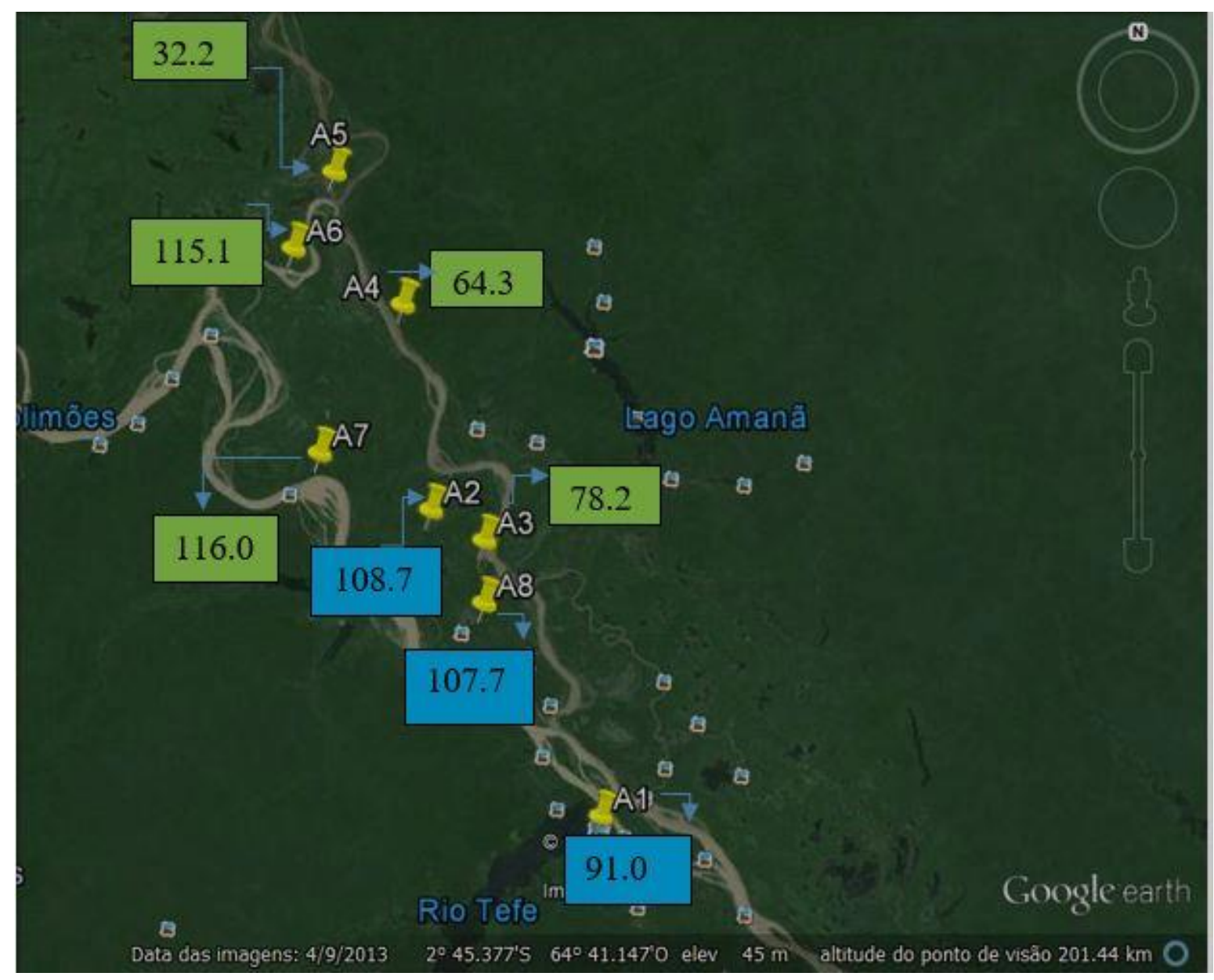

Figura 21. Mapa da condutividade dos rios Japurá (A3, A4 e A5), Aranapu (A6), Solimões (A7), e lagos Tefe (A1), Tucuxi (A2) e Arapaima (A8). Os lagos estão em azul e os rios em verde. 


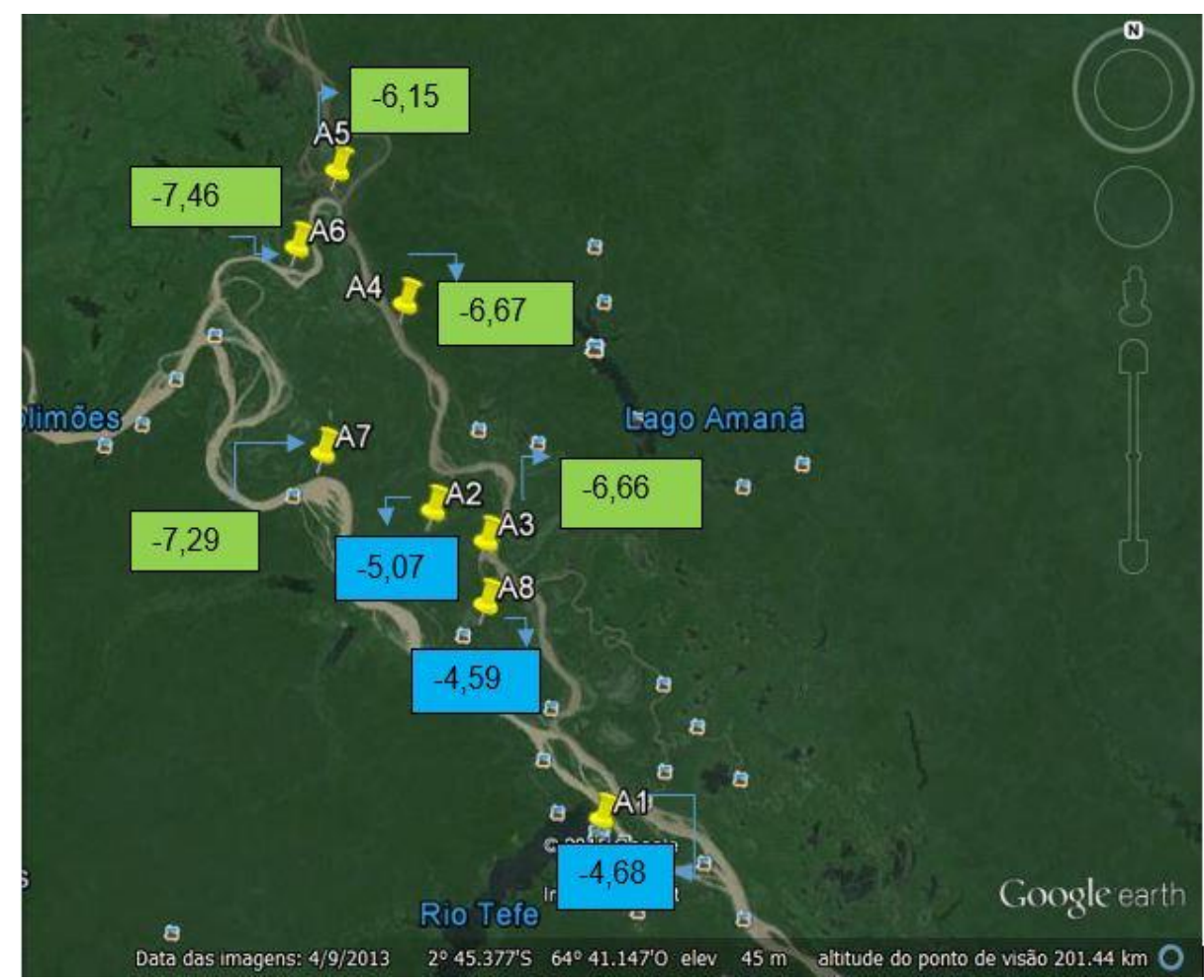

Figura 22. Mapa da razão isotópica $\delta^{18} \mathrm{O}$ dos rios Japurá (A3, A4 e A5), Aranapu (A6), Solimões (A7), e lagos Tefé (A1), Tucuxi (A2) e Arapaima (A8). Os lagos estão em azul e os rios em verde.

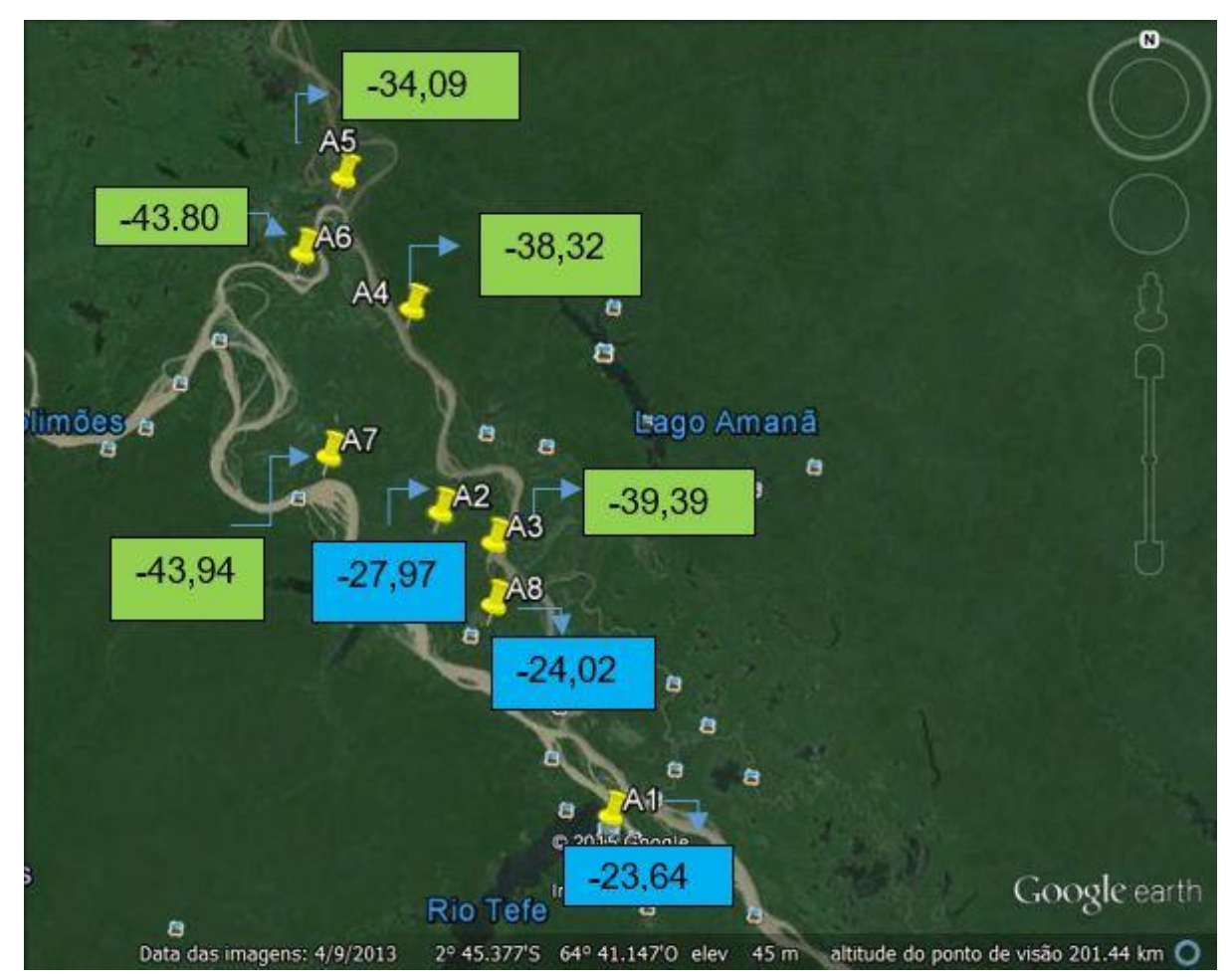

Figura 23. Mapa da razão isotópica $\delta \mathrm{D}$ dos rios Japurá (A3, A4 e A5), Aranapu (A6), Solimões (A7), e lagos Tefé (A1), Tucuxi (A2) e Arapaima (A8). Os lagos estão em azul e os rios em verde. 
Para a interpretação dos resultados isotópicos de $\delta \mathrm{D}$ e $\delta^{18} \mathrm{O}$ das águas da RDSM, os dados foram inseridos em um gráfico juntamente com a Linha de Água Meteórica Global (GMWL) para avaliar o padrão de evaporação e precipitação da água na RDSM.

As águas meteóricas são as águas de precipitação e vapor de ar atmosférico que influenciam a composição isotópica das águas superficiais dos rios. A composição isotópica de $\delta \mathrm{D}$ e $\delta^{18} \mathrm{O}$ dessas águas possui uma forte relação linear, que pode ser representada por uma reta chamada Linha de Água Meteórica Global (GMWL). Sua equação é dada por: $\delta \mathrm{D}=$ $8 \delta^{18} \mathrm{O}+10 \%$ (IEAE \& UNESCO) e as variações associadas a esta curva são relativas ao fracionamento isotópico durante a evaporação e condensação no ciclo hidrológico.

A Figura 24 representa a relação entre $\delta^{18} \mathrm{O}$ e $\delta \mathrm{D}$ com Linha de água meteórica global (GMWL) e as amostras de água da RDSM. É possível perceber as diferenças entre rios e lagos, sendo que esses últimos apresentam valores isotópicos mais elevados em função de fracionamento isotópico por evaporação. Estes resultados sugerem que a assinatura isotópica da água de poço da cidade de Tefé (A9) está sendo influenciada pela água superficial dos corpos de água da região, pois as assinaturas isotópicas parecem ser resultado de uma mistura das assinaturas das águas de rios e lagos. É possível também inferir que todas as águas (lago, rios e poço) são fortemente influenciadas pela precipitação local, já que os pontos de coleta estão próximos à linha de agua meteórica global. 


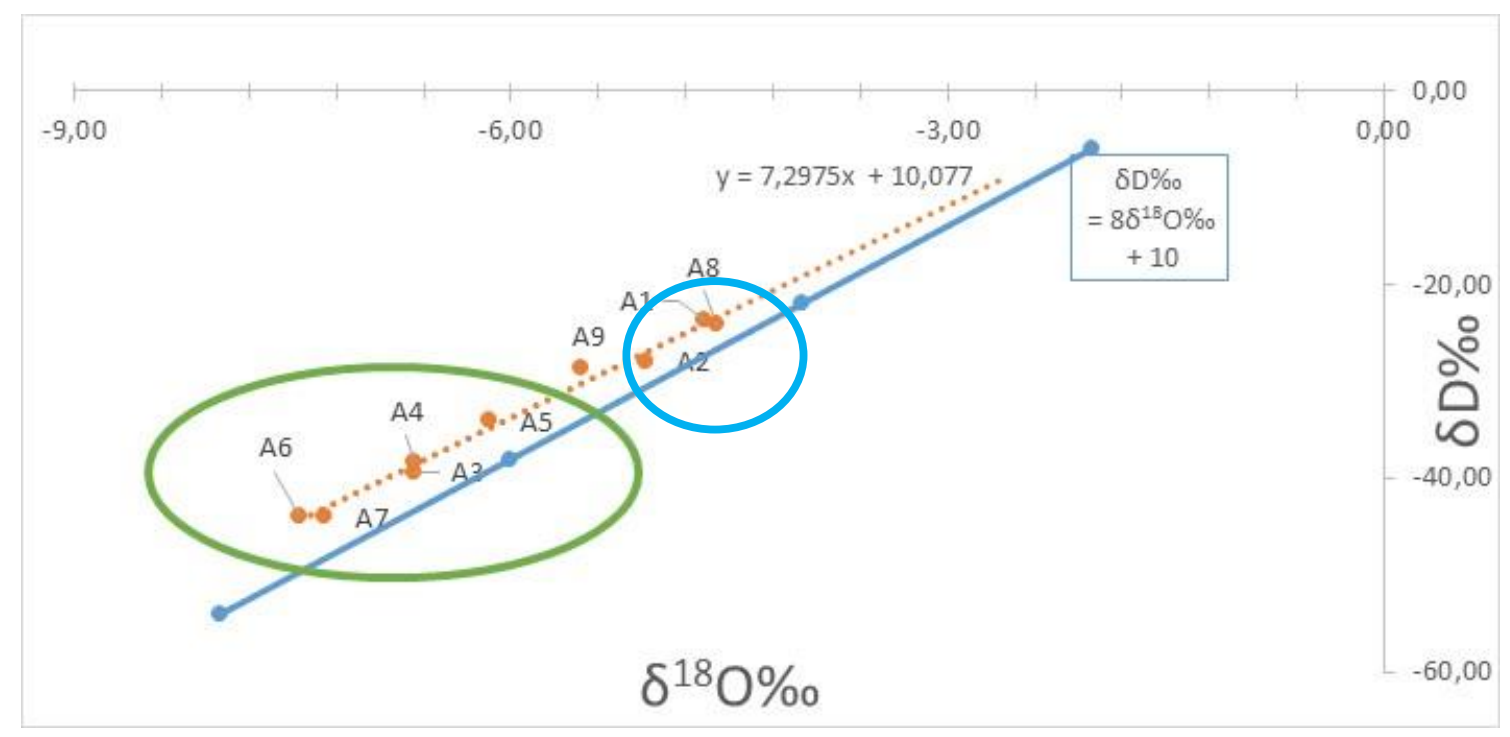

Figura 24. Relação entre $\delta^{18} \mathrm{O}$ e $\delta \mathrm{D}$. A linha contínua azul representa a reta de água meteórica global (GMWL) e a linha tracejada laranja representa as águas coletadas na RDSM. No círculo azul estão as águas dos lagos Tefé, Tucuxi e Arapaima e no círculo verde as águas dos rios Japurá, Aranapu e Solimões. O ponto A9 representa a água subterrânea.

Ao comparar os resultados médios obtidos neste estudo $\left(\delta^{18} \mathrm{O}=-6,01 \pm 1 \%\right.$; $\delta \mathrm{D}=-33,77$ $\pm 0,2 \%$ ) com os dados médios do período 1976 e 1977 de Tefé (Matsui et al., 1977), oriundos do programa de monitoramento Global Network of Isotopes in Rivers (GNIR) da IAEA $\left(\delta^{18} \mathrm{O}\right.$ $=-6.63 \pm 0.05$ e $\delta \mathrm{D}=-45.35 \pm 0.35)$, podemos perceber que ao aplicar o teste estatístico $\mathrm{T}$, não há diferença significativa entre as assinaturas isotópicas de $\delta^{18} \mathrm{O}$ e $\delta \mathrm{D}(\mathrm{p}$-value $=0.109)$ nos dois estudos nesta região, mesmo com o passar de mais de 40 anos.

A Figura 25 mostra o mapa da razão isotópica de ${ }^{87} \mathrm{Sr} /{ }^{86} \mathrm{Sr}$ dos rios Japurá, Aranapu e Solimões, e de três lagos Tucuxi, Arapaima e Tefé. Neste último lago, o aporte de águas do Solimões é maior do que do rio Japurá, então a razão isotópica referente ao lago Tefé $\left({ }^{87} \mathrm{Sr} /{ }^{86} \mathrm{Sr}=0.7105\right)$ é próxima à do rio Solimões $\left({ }^{87} \mathrm{Sr} /{ }^{86} \mathrm{Sr}=0.7091\right)$. Apesar de não haver diferença significativa entre rios e lagos de acordo com o teste $t(t=-0.3486, d f=3.8954$, $p$ value $=0.7454)$, é possível observar a diferença nesta escala espacial, na época da seca, 
relativa aos diferentes pontos de coleta de água da RDSM de acordo com a razão ${ }^{87} \mathrm{Sr} /{ }^{86} \mathrm{Sr}$.

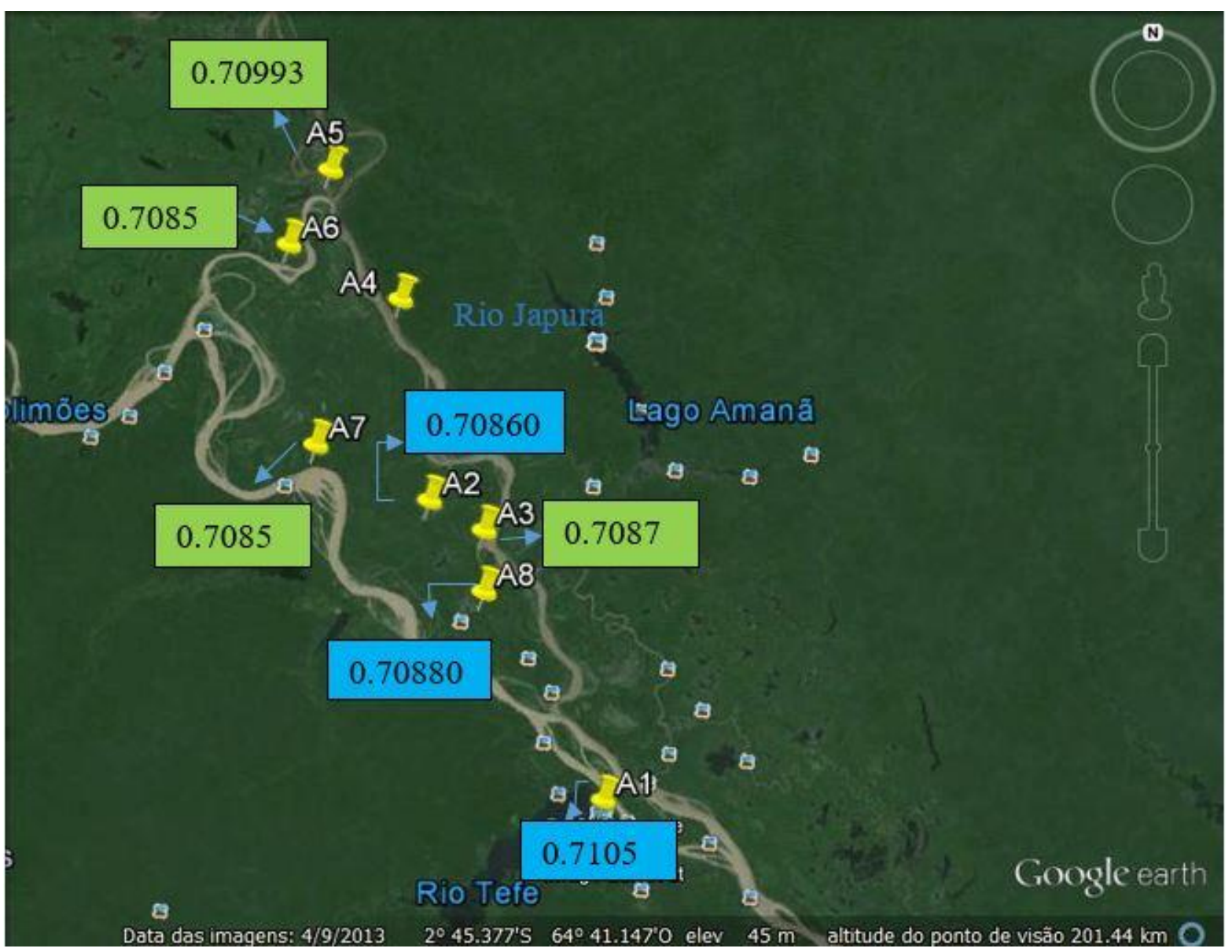

Figura 25. Razão isotópica ${ }^{87} \mathrm{Sr} /{ }^{86} \mathrm{Sr}$ dos rios Japurá (A3, A4 e A5), Aranapu (A6), Solimões (A7), e lagos Tefé (A1), Tucuxi (A2) e Arapaima (A8). Os lagos estão em azul e os rios em verde.

E por fim, a Figura 26 apresenta as razões ${ }^{87} \mathrm{Sr} /{ }^{86} \mathrm{Sr}$ dos indivíduos obtidos da RDSM, por meio da submissão de projeto de pesquisa. 


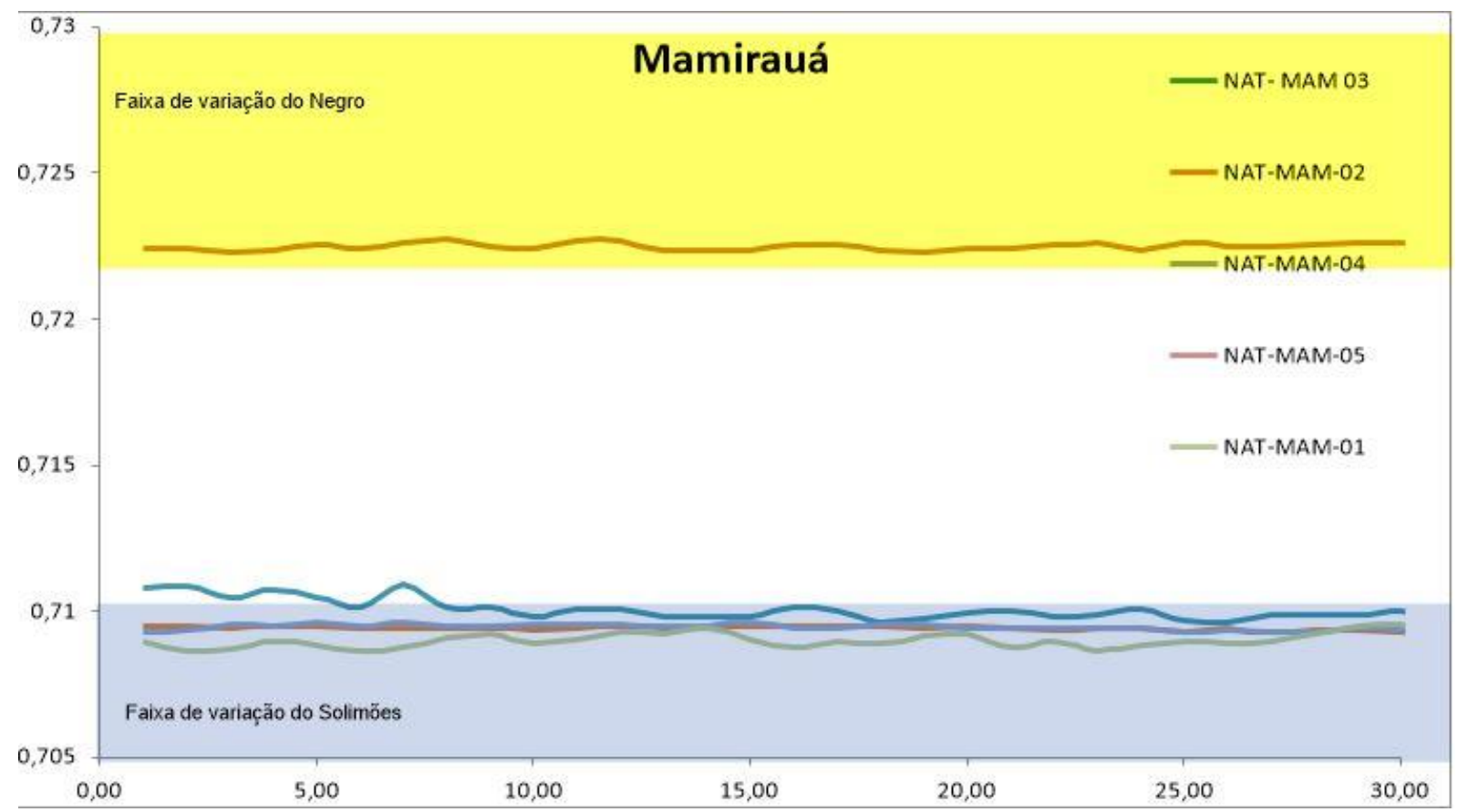

Figura 26. Razão ${ }^{87} \mathrm{Sr} /{ }^{86} \mathrm{Sr}$ dos pirarucus da RDSM. As faixas representam as variações nas razões ${ }^{87} \mathrm{Sr} /{ }^{86} \mathrm{Sr}$ dos rios Negro (amarelo) e Solimões (azul).

Na figura 26, o único indivíduo que não apresentou a razão ${ }^{87} \mathrm{Sr} /{ }^{86} \mathrm{Sr}$ relativa ao rio Solimões foi o NAT-MAM-02, os demais apresentaram razões ${ }^{87} \mathrm{Sr} /{ }^{86} \mathrm{Sr}$ coerentes com a coleta de água na região. Este indivíduo apresenta uma razão ${ }^{87} \mathrm{Sr} /{ }^{86} \mathrm{Sr}$ relativa à afluentes do Negro (média 0,7223), onde as rochas da região são mais antigas dos que as do Solimões. 


\section{DISCUSSÃO}

De forma geral, a variação isotópica de ${ }^{87} \mathrm{Sr} /{ }^{86} \mathrm{Sr}$ dos peixes demostra as diferenças nas faixas de variação natural isotópica relativas a cada sub-bacia amazônica descritas por Santos et al. (2015). Estas diferenças ficam evidentes ao compararmos as médias das razões ${ }^{87} \mathrm{Sr} /{ }^{86} \mathrm{Sr}$, os desvios padrão por agrupamento, bem como o intervalo entre as razões mínima e máxima de ${ }^{87} \mathrm{Sr} /{ }^{86} \mathrm{Sr}$ dos peixes (Tabela 4). Os indivíduos do Amazonas apresentaram o menor desvio padrão, enquanto os indivíduos do Beni e Madeira apresentaram os maiores desvios padrões, indicando assim, o padrão hidrogeoquímico dos seus rios de origem.

\subsection{Variações naturais e os registros isotópicos dos peixes de ambiente natural}

A análise cronológica dos isótopos de ${ }^{87} \mathrm{Sr} /{ }^{86} \mathrm{Sr}$ dos indivíduos de ambiente natural ratificou o uso da ferramenta para determinação de origem do pescado de pirarucu na bacia Amazônica. A origem geográfica dos indivíduos pode ser identificada em relação às subbacias que compõem o sistema amazônico (Pouilly et al., 2014; Hegg et al., 2015; Duponchelle et al., 2016). Além da relação entre a razão ${ }^{87} \mathrm{Sr} /{ }^{86} \mathrm{Sr}$ da água e dos indivíduos, a análise cronológica em alta resolução permitiu a observação dos padrões de variação de fundo geológico das sub-bacias registradas nos organismos.

Para os indivíduos indicados como de áreas de manejo de Santarém no baixo Amazonas, a variação na razão isotópica ${ }^{87} \mathrm{Sr} /{ }^{86} \mathrm{Sr}$ encontrada ao longo do período da vida analisado dos peixes está dentro de uma pequena faixa de variação sazonal do rio Solimões descrita por Santos et al. (2015), a qual está relacionada às oscilações no ciclo hidrológico, que afetam as razões de ${ }^{87} \mathrm{Sr} /{ }^{86} \mathrm{Sr}$ da água.

A falta de variação da razão ${ }^{87} \mathrm{Sr} /{ }^{86} \mathrm{Sr}$ característica do rio Amazonas e a baixa variação da razão ${ }^{87} \mathrm{Sr} /{ }^{86} \mathrm{Sr}$ do rio Solimões descrita por Santos et al. (2015) também são 
observadas nos pirarucus indicados como de Itacoatiara e de Mamirauá (Figura 13). A maioria dos indivíduos do rio Amazonas em Itacoatiara, com exceção do indivíduo NATITA-02, apresentam uma constância da razão ${ }^{87} \mathrm{Sr} /{ }^{86} \mathrm{Sr}$ ao longo do período de vida analisado. Já os indivíduos de Mamirauá apresentaram razões ${ }^{87} \mathrm{Sr} /{ }^{86} \mathrm{Sr}$ relativas a sazonalidade da variação de 0,705 - 0,710, descrita por Santos et al. (2015) para o rio Solimões.

Por outro lado, a ampla variação da razão ${ }^{87} \mathrm{Sr} /{ }^{86} \mathrm{Sr}$ nos rios Beni-Madeira descritas por Pouilly et al. (2014), Santos et al. (2015) e Duponchelle et al. (2016), estão registradas nos otólitos dos peixes dos ambientes naturais desta região (Figura 14). As oscilações nas razões ${ }^{87} \mathrm{Sr} /{ }^{86} \mathrm{Sr}$ são maiores quando comparadas com os peixes do rio Amazonas e Solimões. Estes resultados indicam que o registro temporal da razão ${ }^{87} \mathrm{Sr} /{ }^{86} \mathrm{Sr}$ em otólitos de pirarucu reflete as variações locais das bacias onde os peixes habitam, caracterizando a integração temporal sazonal existente nos compartimentos geológicos, hidrológicos e biológicos em relação aos isótopos de estrôncio na bacia Amazônica.

\subsection{Padrão de Sedentarismo e migração lateral}

A pequena variação temporal das razões isotópicas de $\mathrm{Sr}$ para a maior parte dos indivíduos estudados indica que o pirarucu tem pouca mobilidade durante sua vida. Considerando que os diferentes rios da Amazônia apresentam diferenças isotópicas significativas, inclusive durante o ciclo hidrológico (Santos et al., 2015), os dados revelam que os indivíduos estudados permaneceram a maior parte de sua vida em águas com mesma composição isotópica de Sr. Essa observação é compatível com a ecologia do gênero Arapaima sp., que define esse grupo de peixes como espécies sedentárias, podendo, no máximo, migrar lateralmente durante os períodos de reprodução (Queiroz, 2000; Castello, 2008; Arantes et al., 2013; Hermann et al., 2016). Hermann et al. (2016) reiteraram o padrão 
de sedentarismo de Arapaima sp. por meio da análise de multi elementos ( $\mathrm{Sr}$ : $\mathrm{Ca}, \mathrm{Zn}: \mathrm{Ca}$ ) em baixa resolução de LA-ICPMS e SXFM. No entanto os autores não puderam verificar a migração lateral do pirarucu, pois os diferentes hábitats utilizados pelo peixe possuem composições químicas muito similares.

Dentre os indivíduos estudados, o NAT-ITA-02 apresenta clara evidência de migração lateral ou mudança para ambientes com diferentes características isotópicas de Sr. Em menor escala, variações isotópicas ao longo dos otólitos podem ser observadas também nos indivíduos da região do Beni, Madre de Dios e Yata, onde as variações isotópicas ambientais de Sr ocorrem.

O exemplar NAT-ITA-02 de Itacoatiara apresentou uma variação no começo do período de vida analisado, o que pode indicar um período de migração lateral para lagos da região ou mudança na composição isotópica da água onde o indivíduo esteve (Figura 13). O município de Itacoatiara fica próximo ao encontro do rio Madeira $\left({ }^{87} \mathrm{Sr} /{ }^{86} \mathrm{Sr}\right.$ varia de 0,715 a 0,726) com as águas do rio Amazonas (Duponchelle et al., 2016). O pico com alta razão isotópica ${ }^{87} \mathrm{Sr} /{ }^{86} \mathrm{Sr}$ nesse indivíduo indica que possivelmente o mesmo viveu esse período de sua vida em águas com características isotópicas do rio Madeira num dos lagos formados por águas de mistura do rio Madeira com o Amazonas, assim como sugeriu Pouilly et al. (2014) ao comparar os peixes de rios e lago na região do rio Beni.

O conjunto de dados isotópicos do pirarucu de ambiente natural ratifica a descrição do gênero como sedentária. Os dados relativos ao indivíduo de Itacoatiara (NAT-ITA-02), são importantes, pois embora indique que as populações de pirarucu são sedentárias, pode haver migração lateral de acordo com o ciclo reprodutivo do gênero (Castello, 2008; Queiroz 2000; Araripe et al., 2013; Hermann et al., 2016). Castello (2008) observou a migração lateral do pirarucu entre os rios e a planície de inundação de acordo com a dinâmica de pulso do nível 
das águas, por meio da contagem dos peixes no momento da respiração obrigatória do peixe. A contribuição desenvolvida nesta dissertação é importante para a construção do conhecimento sobre aspectos de história de vida, sobre a dinâmica de populações do pirarucu e áreas prioritárias para o manejo desta (Pracheil et al., 2014), pois corrobora o padrão de migração lateral em outro local da distribuição do gênero na bacia Amazônica.

Variações isotópicas significativas foram observadas também em indivíduos da região dos rios Beni, Madre de Dios e Yata. Conforme relatados por Pouilly et al. (2014), rios e lagos dessa região apresentam maior diversidade na composição isotópica de $\mathrm{Sr}$, de forma que as variações observadas nos otólitos dos peixes refletem também essa variabilidade ambiental.

Em função da complexidade hidrológica das diferentes áreas que compõem a bacia Amazônica, nem sempre a razão isotópica de ${ }^{87} \mathrm{Sr} /{ }^{86} \mathrm{Sr}$ pode ser utilizada como parâmetro indicativo de migração lateral. Essa feição só pode ser observada quando as composições isotópicas do rio e do lago diferem significativamente (Pracheil et al., 2014), como no caso do encontro do Amazonas com o Madeira (Duponchelle et al., 2016). Assim, não é possível com este delineamento amostral, concluir se as variações na razão ${ }^{87} \mathrm{Sr} /{ }^{86} \mathrm{Sr}$ dos demais indivíduos analisados neste estudo correspondem às migrações laterais para lagos locais, uma vez que as composições são próximas aos valores isotópicos dos rios amostrados (Duponchelle, et al., 2016; Herman et al., 2016).

\subsection{Variações no registro isotópico dos peixes de cativeiro}

Em contraste com os peixes de ambiente natural, os peixes de cativeiro podem ser submetidos à diferentes ambientes ao longo de sua vida, bem como a uma dieta com características distintas em relação às áreas naturais (SEBRAE, 2013). Desta forma, tendo por base as variações isotópicas é possível tecer considerações sobre o modo de criação e o tipo 
de alimento fornecido aos peixes. Quanto ao modo de criação, pode-se avaliar por exemplo, se um dado indivíduo foi capturado em ambiente natural e posteriormente mantido em cativeiro, ou se durante sua vida ele viveu em águas com diferentes composições isotópicas de Sr. Os relatos sobre as formas de criação mencionam que indivíduos adultos podem ser transportados de um cativeiro para outro, principalmente para compor matrizes reprodutoras (SEBRAE, 2013). Os dados podem ainda, validar parte das informações fornecidas pelos fornecedores quanto à origem e dieta do pescado.

Os peixes de cativeiro apresentam uma ampla variação de padrões de variação isotópica de Sr. Por exemplo, a maior parte dos peixes dos cativeiros do Amazonas e Solimões apresentam valores constantes da razão isotópica de Sr (Figura 15), e comparáveis aos valores observados para os peixes de ambiente natural da mesma região (Figura 27). Esses peixes possuem ainda composição isotópica de carbono semelhante a indivíduos de ambientes natural, conforme mostrado na Figura 19. A exceção é o indivíduo proveniente da Cooperativa de Peixes de Manacapuru no qual os valores de ${ }^{87} \mathrm{Sr} /{ }^{86} \mathrm{Sr}$ são semelhantes ao do rio Negro $(0,720)$. Esse mesmo exemplar apresenta também valores mais elevados de $\delta^{13} \mathrm{C}(-$ $18,58 \%)$. 


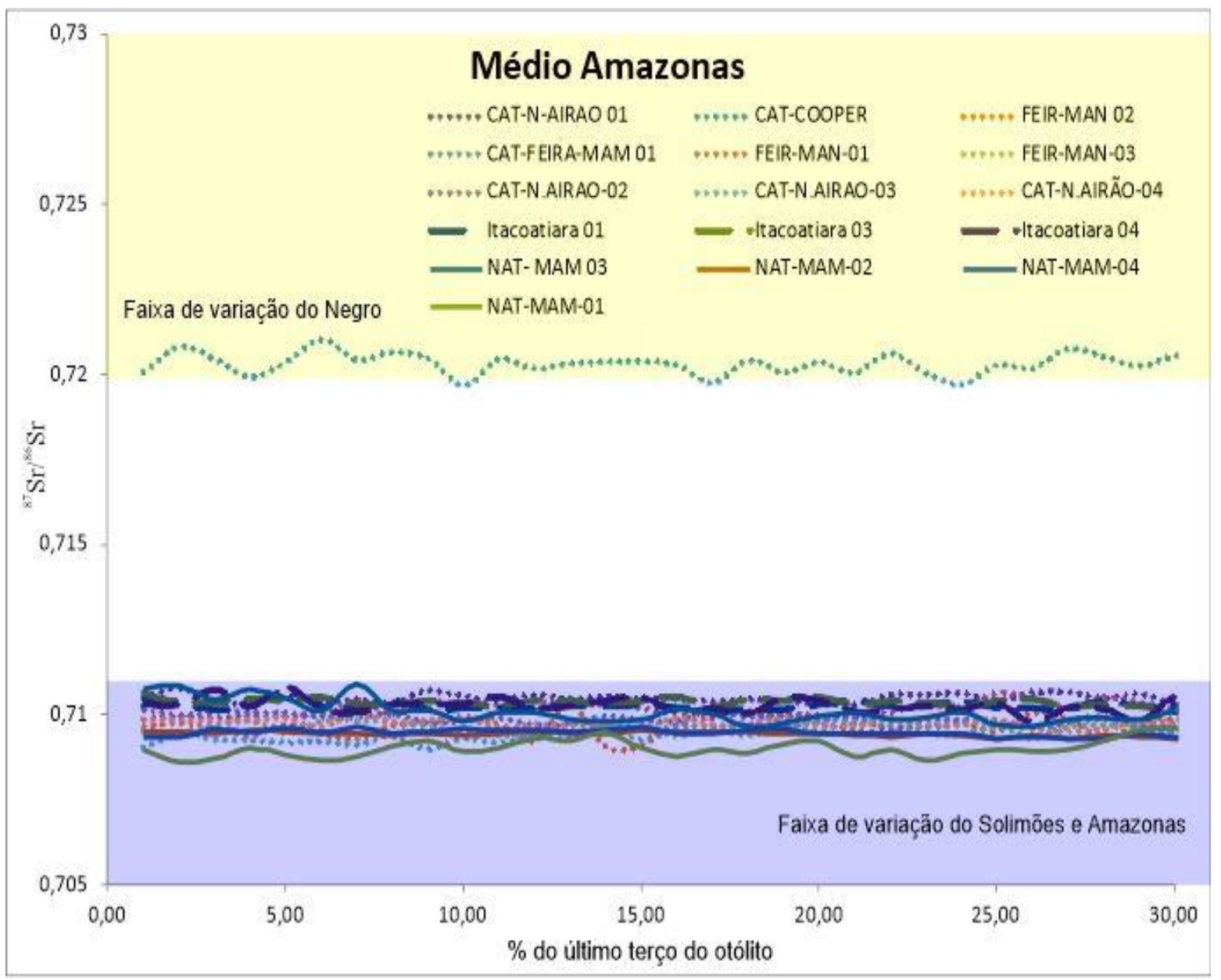

Figura 27. Comparação entre as razões ${ }^{87} \mathrm{Sr} /{ }^{86} \mathrm{Sr}$ dos indivíduos de ambiente natural e de cativeiro do médio Amazonas. As faixas representam o intervalo de variação dos rios Solimões e Amazonas (azul) e do rio Negro (laranja) de acordo com Santos et al. (2015).

Em contraste com os indivíduos de cativeiro do Amazonas e Solimões, os peixes de cativeiro de Santarém apresentam padrões diversificados de variação na razão ${ }^{87} \mathrm{Sr} /{ }^{86} \mathrm{Sr}$ ao longo dos intervalos dos otólitos analisados (Figura 16). Esses padrões são também distintos dos observados nos peixes de ambiente natural como demonstrado na Figura 28. Por exemplo, enquanto o pirarucu CAT-SAT-05 apresenta valores isotópicos de Sr relativamente constantes ao longo do intervalo do otólito analisado, os dois outros indivíduos apresentam variações significativas na razão isotópica. O indivíduo CAT-SAT-02 apresenta razão isotópica compatível com rios de águas escuras (i.e., rio Negro/Tapajós, que drenam regiões cratônicas 
descritas por Santos et al., 2015) durante grande parte do período analisado, e depois varia bruscamente para valores menores, semelhantes aos observados em águas no baixo Amazonas. Por outro lado, o indivíduo CAT-SAT-01 também apresenta flutuações comparáveis aos rios Negro, Tapajós e baixo Amazonas, mas com padrões distintos de variação ao longo da vida do indivíduo.

As variações isotópicas observadas nos indivíduos CAT-SAT-01 e CAT-SAT-02 revelam mudanças bruscas de ambiente, que podem estar associadas tanto à processos naturais, quanto condições de criação dos peixes. Considerando que a composição isotópica de carbono desses indivíduos é bem mais positiva do que os valores observados para peixes de ambiente natural (Figuras 19 e 20), é mais provável que as variações de ${ }^{87} \mathrm{Sr} /{ }^{86} \mathrm{Sr}$ reflitam condições de criação de cativeiro. Segundo os produtores, peixes já adultos podem ser movimentados entre pisciculturas especializadas para compor matrizes reprodutoras. Em outras ocasiões, indivíduos adultos podem ser capturados em ambiente natural para também compor essas matrizes. A duas situações acima poderiam explicar as bruscas variações observadas nesses indivíduos. 


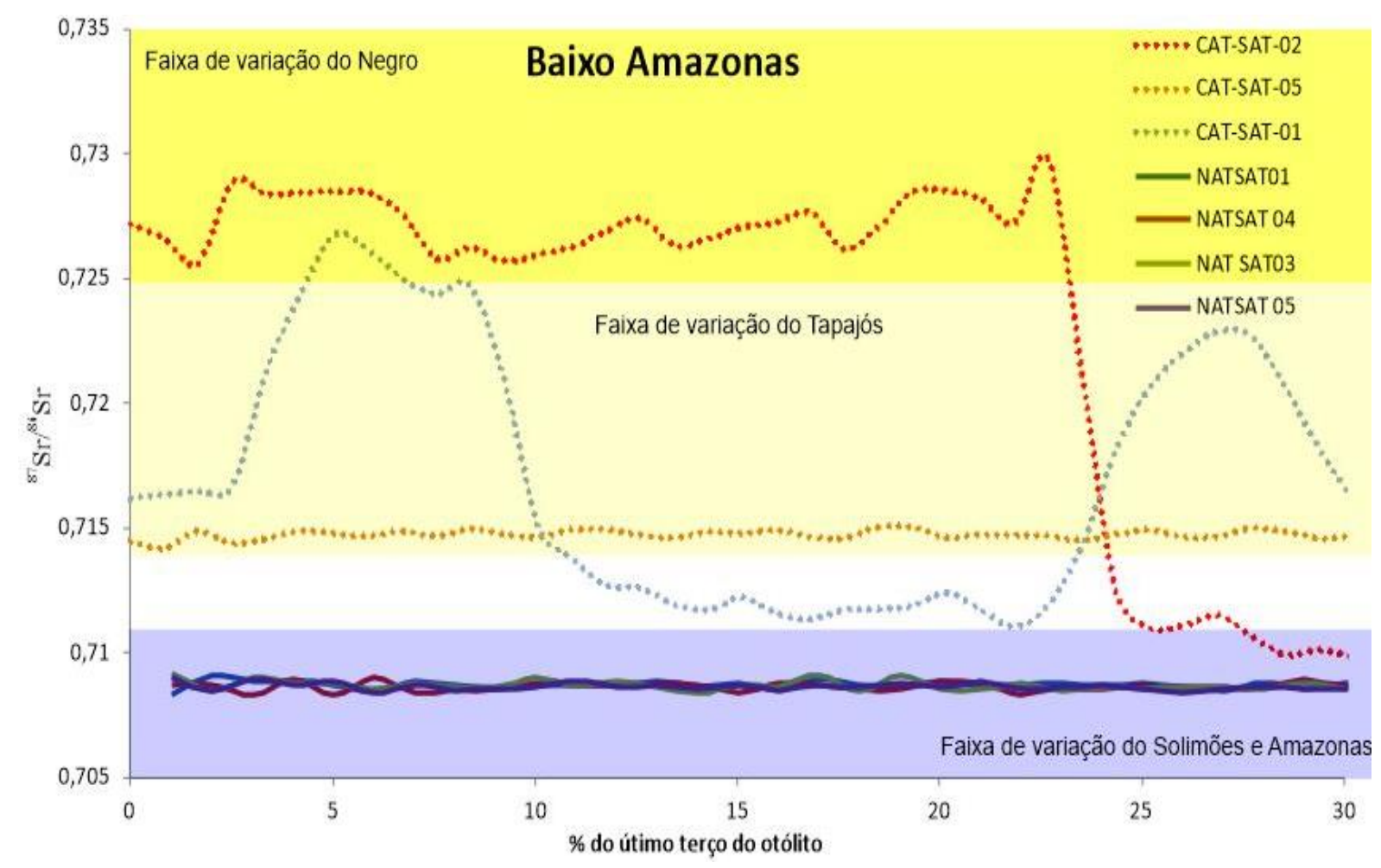

Figura 28. Comparação entre as razões ${ }^{87} \mathrm{Sr} /{ }^{86} \mathrm{Sr}$ dos indivíduos de ambiente natural e de cativeiro do baixo Amazonas. As faixas representam o intervalo de variação dos rios Solimões e Amazonas (azul), do Tapajós (laranja) e do Negro (amarelo) de acordo com Santos et al. (2015).

Por último, dentre os quatro indivíduos oriundos do cativeiro de Ariquemes - RO, três apresentam pequena variação na razão isotópica ${ }^{87} \mathrm{Sr} /{ }^{86} \mathrm{Sr}$ no período de vida analisado (Figura 17). A exceção foi o indivíduo CAT-ROD-01 que apresenta oscilações na razão ${ }^{87} \mathrm{Sr} /{ }^{86} \mathrm{Sr}$. Cabe enfatizar que dentre os vários indivíduos estudados, os pirarucus de cativeiro da região do Rondônia são os que apresentam as mais elevadas razões isotópicas de carbono, sugerindo, portanto, maior contribuição de plantas C4 na dieta relativa às rações.

\subsection{Confiabilidade da amostragem}

Um dos desafios quando se compara indivíduos provenientes de cativeiro e de ambiente natural reside na qualidade das informações fornecidas sobre a origem dos peixes 
amostrados. Essa questão é particularmente sensível quando se aborda recursos naturais em que a comercialização é restrita a indivíduos de cativeiro ou de áreas de manejo. Neste sentido, a ferramenta desenvolvida neste trabalho foi útil e precisa, como indicou a QDA e o teste Jackknife realizado com a classificação feita com a análise dos dados e não com a informação dada pelos vendedores ou pescadores (Tabela 6). Esta análise estatística apresentou alta probabilidade de classificação dos peixes em relação aos rios da bacia Amazônica e ao método de produção. No entanto, a análise discriminante juntamente com o teste de acurácia Jackknife não se aplicaram para os indivíduos agrupados pela razão ${ }^{87} \mathrm{Sr} /{ }^{86} \mathrm{Sr}$ relativas aos rios Amazonas, Beni, Madeira e para peixes de ambiente natural discriminados pela assinatura $\delta^{13} \mathrm{C}$. A não aplicação do teste para estes dados não indica que o fator de classificação do conjunto de dados é duvidoso, mas que os fatores de classificação utilizados para separar os grupos podem apresentar sobreposições para alguns indivíduos, como é o caso do Beni- Madeira (Tabela 4), e dos indivíduos de Santarém e Itacoatiara de ambiente natural que apresentaram assinaturas de $\delta^{13} \mathrm{C}$ relativos a mistura.

As características isotópicas do local de procedência dos indivíduos estudados nem sempre foram compatíveis com resultados obtidos. A razão ${ }^{87} \mathrm{Sr} /{ }^{86} \mathrm{Sr}$ dos indivíduos de ambiente natural de Santarém no baixo Amazonas (Figura 12) não foi coerente com a razão ${ }^{87} \mathrm{Sr} /{ }^{86} \mathrm{Sr}$ da coleta de água na região, nem com as razões ${ }^{87} \mathrm{Sr} /{ }^{86} \mathrm{Sr}$ descritas na literatura. O que indica que provavelmente estes peixes não foram pescados no baixo Amazonas e sim na bacia do rio Solimões, cuja razão isotópica é mais baixa (média de ${ }^{87} \mathrm{Sr} /{ }^{86} \mathrm{Sr}$ de $0,70907+/-25$; Santos et al., 2015).

No entanto, existe outra interpretação, que não se pode descartar com o conhecimento atual. A variação de fundo geoquímico da região em uma escala local pode gerar variações nos peixes que não podemos interpretar atualmente, pois os dados de ${ }^{87} \mathrm{Sr} /{ }^{86} \mathrm{Sr}$ de água em 
escala local são escassos. Este problema é mais provável nos pirarucus que vivem essencialmente em lagos, que podem apresentar variações importantes em escala local (Pouilly et al., 2014)

Já na bacia do rio Beni, os indivíduos foram indicados como sendo procedentes de Riberalta, onde ocorre a confluência dos rios Madre Dios e Beni (Figura 14). A razão isotópica ${ }^{87} \mathrm{Sr} /{ }^{86} \mathrm{Sr}$ da confluência desses rios é de $0,71310+/-1$, uma vez que a razão do rio Beni é de 0,71903+/-1 e do Madre Dios de 0,71192+/-1. Entretanto, esses indivíduos apresentam razões isotópicas mais radiogênicas (i.e. compatíveis com rochas mais antigas) como as águas do rio Mamoré e do rio Yata, também afluentes do Beni. Essa interpretação é ainda mais evidente para o indivíduo FL1, que apresentou uma razão ${ }^{87} \mathrm{Sr} /{ }^{86} \mathrm{Sr}$ ao longo do período de vida analisado um pouco maior do que os demais da mesma região, correspondendo a confluência dos rios Yata e Mamoré.

Peixes de cativeiro também podem apresentar composição isotópica de $\mathrm{Sr}$ que não seja compatível com as características isotópicas do local informado. O indivíduo da Cooperativa de pescadores de Manacapuru apresenta razão ${ }^{87} \mathrm{Sr} /{ }^{86} \mathrm{Sr}$ relativa ao rio Negro, que não confere com o valor isotópico da região indicada de criação no rio Solimões em Manacapuru (Figura 15). O indivíduo CAT-SAT-05 foi indicado como do baixo Amazonas e apresenta razão do rio Tapajós (Figura 16). O indivíduo CAT-SAT-02, apresentou a razão isotópica dos peixes do rio Negro/Tapajós durante a maior parte do período de vida analisado e depois o valor ${ }^{87} \mathrm{Sr} /{ }^{86} \mathrm{Sr}$ cai abruptamente para os valores relativos ao baixo Amazonas, indicando que aparentemente este indivíduo não foi criado em um cativeiro na região do baixo Amazonas durante grande parte da sua vida.

Dos peixes oriundos do cativeiro de Ariquemes-RO (Figura 17), a maioria apresentou razão ${ }^{87} \mathrm{Sr} /{ }^{86} \mathrm{Sr}$ diferente da água coletada nos tanques de criação. O responsável pelo cativeiro 
relatou que os peixes são trocados de tanques três vezes ao longo da vida e que a mesma fonte de água é usada em todos os tanques. Assim, são precisos mais estudos para entender o porquê desta diferença na razão isotópica entre os indivíduos de cativeiro.

Os pirarucus que tiveram sua procedência geográfica compatíveis quanto aos locais de pesca e cultivo foram: os quatro de Itacoatiara no rio Amazonas (Figura 13), os cinco de Mamirauá no rio Solimões (Figura 13), os três peixes LV da confluência dos rios Madre Dios e Beni (Figura 14), os três do YA do rio Yata, afluente dos rios Mamoré e Beni (Figura 14), e o indivíduo CAT-RO-01 do cativeiro de Ariquemes, na bacia do Madeira.

Já em relação ao método de produção e dieta, apenas os indivíduos obtidos diretamente nos cativeiros de Rondônia (Madeira) e um indivíduo de Santarém (Baixo Amazonas) apresentaram a assinatura isotópica de $\mathrm{C} 4$, relativa a alimentação das rações peletizadas a base de milho. Assim, considerando que o fracionamento líquido entre o $\delta^{13} \mathrm{C}$ do otólito em relação as fontes de carbono é de -3,6\% (Solomon et al.,2006), as fontes de carbono destes peixes estão na faixa $-4,6 \%$ a $-12 \%$., corroborando as fontes $\mathrm{C} 4$ nas dietas destes indivíduos.

Entretanto, a maioria dos indivíduos de cativeiro de Santarém apresentaram assinaturas $\delta^{13} \mathrm{C}$ intermediárias entre plantas $\mathrm{C} 3$ e $\mathrm{C} 4$ (Figura 18). Apesar desses peixes apresentarem assinaturas $\delta^{13} \mathrm{C}$ de mistura, ao observar que o fracionamento líquido entre o carbono do otólito e as fontes de carbono é de 3,6\%o (Solomon et al.,2006), a dieta desses peixes também é relativa às plantas $\mathrm{C} 4$, e está na faixa de $-9,06 \%$ a $-12 \%$.

Assim existem pelo menos duas possibilidades para a composição da dieta C4 dos peixes de cativeiro: A primeira, pode ser a ração a base de milho usada na alimentação dos peixes nesse método de produção. Ou a segunda, estes indivíduos podem ter assimilado a assinatura $\delta^{13} \mathrm{C}$ das comunidades $\mathrm{C} 4$ que contribuem com 2,5-17,6\% das assinaturas dos 
peixes da bacia Amazônica (Forsberg, et al., 1993). Domingues et al. (2002) também relatou um único indivíduo de Santarém com assinatura $\delta^{13} \mathrm{C}$ relativo a mistura, quando analisou escamas de pirarucu para compreender melhor a dieta desta espécie. Por sua vez, Mortillaro et al. (2015) encontraram diferença espacial na utilização das fontes alimentares em S. fasciatus em ambientes de várzea com maior contribuição de macrófitas $\mathrm{C} 4$ na dieta desta espécie em uma das localidades estudadas.

Todavia, todos os indivíduos obtidos na feira de Manaus que são oriundos de cativeiro (Novo Airão, Tefé e Manacapuru) apresentaram assinaturas $\delta^{13} \mathrm{C}$ relativas a peixes de ambiente natural do sistema Amazônico (C3) na faixa de -19\%o a -26\%o, e estão de acordo com as descrições de $\delta^{13} \mathrm{C}$ dos produtores primários C3 de Araujo- Lima et al. (1986), Forsberg et al. (1993) e de Mortillato et al. (2015) (Figura 19).

Neste sentido, a maioria dos pirarucus de ambiente natural apresentaram assinaturas $\delta^{13} \mathrm{C}$ compatíveis com a descrição de Arapaima sp. de Forsberg, et al. (1993) Watson et al. (2013) e Domingues et al. (2002), com fontes de carbono relativas às assinaturas isotópicas das plantas C3 de média $-28.9 \pm 1.2 \%$. (Figura 17). No entanto, o fracionamento entre a assinatura $\delta^{13} \mathrm{C}$ dos otólitos em relação à dieta é de $-3,6 \%$ (Solomon et al., 2006), o que corrobora a fonte C3 de plantas na dieta do gênero Arapaima sp. O grupo C3 representa 82,4 - 97,5\% das assinaturas $\delta^{13} \mathrm{C}$ dos peixes da bacia Amazônica. (Araujo-Lima et al., 1986; Forsberg, et al., 1993).

Ainda assim é preciso ter cautela ao comparar a composição isotópica de $\delta^{13} \mathrm{C}$ entre otólitos e tecido muscular, uma vez que pode existir diferença isotópica entre o carbono orgânico do tecido muscular e o carbono inorgânico do otólito. No bacalhau do Atlântico esta diferença é de 15,9\%o (Radke et al., 1996). Assim, ao comparar as composições de $\delta^{13} \mathrm{C}$ dos otólitos com outras entre estruturas calcificadas como as escamas de Arapaima sp descritas 
por Domingues et al. (2002), existe uma maior contribuição do grupo C3 como fonte de carbono. No entanto Domingues et al. (2002) argumentam que existe uma variação entre 18,01 a $-29,2 \%$ e que este longo intervalo é consistente com a heterogeneidade espacial e temporal no escossistema Amazônico, visto que grande parte da floresta é inundada anualmente (Junk, 1997).

Dos peixes de ambiente natural, apenas os indivíduos de Itacoatiara apresentaram valores intermediários de $\delta^{13} \mathrm{C}$ que variaram de $-15,37$ - a $-20,06 \%$. Considerando que as assinaturas dos otólitos possuem fracionamento de $-3,6 \%$, as fontes de carbono destes peixes se encontram na faixa de $-11,8 \%$ a $-16,5 \%$. Assim os peixes de Itacoatiara também possuem fonte de carbono relativa às plantas $\mathrm{C} 4$.

Entretanto, a heterogeneidade ambiental do ecossistema amazônico, representado por uma variedade de tipos de água (brancas, negras, claras), a formação de muitos canais, além da sazonalidade hidrológica do nível dos rios podem explicar variações nas fontes isotópicas de $\delta^{13} \mathrm{C}$ locais para os peixes em ambiente natural (Domingues et al., 2002), como foi observado nos indivíduos de Itacoatiara. No trabalho de Domingues et al. (2002) foi encontrado um único indivíduo com assinatura de $-18.9 \pm 0.4 \%$, onde os autores discutem como o carbono derivado das comunidades $\mathrm{C} 4$ pode dominar o sistema e ser incorporado na cadeia trófica em alguns locais da Amazônia. Da mesma forma, Mortillaro et al. (2015) encontraram a maior contribuição e disponibilidade de plantas C4 na dieta de $S$. fasciatus devido à maior digestabilidade das macrófitas C4 para essa espécie nos ambientes de várzea, revelando assim, a adaptabilidade e flexibilidade dos peixes em relação ao uso de recursos em ambientes sazonais. Forsberg et al. (1993) também relataram que a espécie Arapaima gigas pode ter contribuição de plantas $\mathrm{C} 4$ em até $23,4 \%$ em sua dieta, o que explica a assinatura $\delta^{13} \mathrm{C}$ mais altas em alguns peixes de Itacoatiara. 
Também é preciso considerar que o grupo Arapaima sp. pertence a guilda dos piscívoros (Sánchez, 1969; Queiroz, 2000; Watson et al., 2013), assim o pirarucu se alimenta de peixes onívoros e detritívoros que podem, por sua vez, se alimentam de ambas as fontes de carbono C3 e C4 (Domingues et al., 2002). Entretanto, é descrito na literatura que a guilda dos piscívoros apresenta o grupo C3 como fonte principal de carbono (Forsberg et al. 1993; Jepsen \& Winemiller, 2007; Mortillato et al., 2014).

Outra maneira de avaliar se os peixes são procedentes do método de produção indicado pode ser por meio da combinação das assinaturas de $\delta^{18} \mathrm{O}$ e $\delta^{13} \mathrm{C}$ (Figura 19). Para alguns peixes de cativeiro (assinatura $\delta^{13} \mathrm{C}$ relativa a $\mathrm{C} 4$ ), as assinaturas de $\delta^{18} \mathrm{O}$ foram maiores do que para os indivíduos de ambiente natural. O motivo desta diferença entre as assinaturas de $\delta^{18} \mathrm{O}$ pode ser a diferente taxa de evaporação entre tanques de criação e rios. $\mathrm{O}$ isótopo mais leves $\left({ }^{16} \mathrm{O}\right)$ tende a evaporar mais rápido que o mais pesado $\left({ }^{18} \mathrm{O}\right)$, o que causa o fracionamento isotópico e resulta em assinaturas diferentes para os tanque e rios.

No entanto, a assinatura de $\delta^{18} \mathrm{O}$ não apresentou um potencial de traçador da origem da pesca do pirarucu em ampla escala na bacia Amazônica, já que a assinatura $\delta^{18} \mathrm{O}$ não variou nesta escala (Figura 19). Para que o fracionamento causado pela evaporação, condensação e precipitação ocorrido no ciclo hidrológico seja suficiente para ser um traçador em larga escala, é preciso haver um gradiente latitudinal para que o efeito da continentalidade possa ser observado (Fry, 2008). No caso da bacia Amazônica a extensão geográfica é longitudinal, característica que não permite o uso desta ferramenta como traçador geográfico da pesca do pirarucu na bacia Amazônica (Fry, 2008). 


\subsection{Pirarucu de Mamirauá e as variações isotópicas}

Na reserva de Desenvolvimento Sustentável de Mamirauá foi possível caracterizar isotopicamente o ambiente físico e amostrar o pirarucu com procedência garantida e sob manejo realizado pelos pescadores em uma escala local (Figuras 21, 22, 23, 25 e 26). Os pirarucus amostrados na RDSM apresentaram resultados interessantes quanto ao uso do habitat (Figura 26). A maioria dos peixes apresentou a razão ${ }^{87} \mathrm{Sr} /{ }^{86} \mathrm{Sr}$ relativo ao rio Solimões e a variação sazonal registrada em seus otólitos é característica da faixa natural de variação desde rio descrita por Santos et al. (2015).

No entanto, o indivíduo NAT-MAM-02 apresentou razão ${ }^{87} \mathrm{Sr} /{ }^{86} \mathrm{Sr}$ relativa ao rio Negro. A RDSM se situa entre os rios Japurá e Solimões. O rio Japurá é afluente andino do Solimões e possui razão ${ }^{87} \mathrm{Sr} /{ }^{86} \mathrm{Sr}$ relativa a rochas desta região de média 0.708 (Duponchelle et al., 2016). Este indivíduo não apresentou razões ${ }^{87} \mathrm{Sr} /{ }^{86} \mathrm{Sr}$ ao longo de todo período analisado nem do rio Japurá, nem do rio Solimões. Este resultado pode indicar que o pirarucu também habita as águas dos afluentes do rio Negro, sem realizar migrações para as águas brancas do Solimões. No entanto, é preciso uma melhor caracterização local das águas da região para compreender a fonte de razão ${ }^{87} \mathrm{Sr} /{ }^{86} \mathrm{Sr}$ mais elevada deste exemplar.

Não foi possível, com este delineamento amostral, afirmar se a variação da razão ${ }^{87} \mathrm{Sr} /{ }^{86} \mathrm{Sr}$ encontrada nestes indivíduos ao longo do período de vida analisado, corresponde ao padrão de migração lateral descrito por Castello, (2008). São necessários estudos em uma escala temporal maior para a caracterização isotópica sazonal do habitat do pirarucu. Bem como, a análise de mais indivíduos para a caracterização isotópica da migração lateral desta espécie na Reserva.

Entretanto, todas as assinaturas isotópicas de $\delta^{18} \mathrm{O}$ dos pirarucus de Mamirauá foram relativas às assinaturas desse isótopo nos lagos da região, corroborando assim a descrição do 
uso do habitat da espécie em ambientes lênticos e com pouca correnteza (Queiroz, 2000; Castello, 2008; Castello et al, 2013). Bem como, as assinaturas $\delta^{13} \mathrm{C}$ de todos os peixes da reserva foram relativas às plantas $\mathrm{C} 3$, indicadoras da procedência de manejo em ambiente natural da bacia Amazônica. A assinatura de $\delta^{13} \mathrm{C}$ integra a ciclagem do carbono no ecossistema indicando as fontes alimentares preferenciais das espécies e a assinatura $\delta^{18} \mathrm{O}$ a ciclagem da água no ecossistema nos diferentes compartimentos (Fry,2008).

\subsection{Comparando espécimes de cativeiro e de ambiente natural}

Os padrões observados para peixes de ambiente natural e de cativeiro são diferentes. Em geral, os peixes de cativeiro apresentam assinatura $\delta^{13} \mathrm{C}$ relativas tanto às plantas $\mathrm{C} 4$ quanto às plantas C3. Já para peixes de ambientes naturais na bacia Amazônica, o padrão de assinatura $\delta^{13} \mathrm{C}$ de plantas $\mathrm{C} 3$ foi confirmado em sua maioria, com exceção de alguns indivíduos de Itacoatiara de ambiente natural que apresentaram valores intermediários entre $\mathrm{C} 3$ e $\mathrm{C} 4$.

Curiosamente, em relação a razão ${ }^{87} \mathrm{Sr} /{ }^{86} \mathrm{Sr}$, os peixes de ambiente natural tiveram a razão ${ }^{87} \mathrm{Sr} /{ }^{86} \mathrm{Sr}$ mais constante em algumas bacias do que os peixes de cativeiro. Em alguns peixes de cativeiros não se observou relação entre a razão ${ }^{87} \mathrm{Sr} /{ }^{86} \mathrm{Sr}$ nos otólitos e a média da razão ${ }^{87} \mathrm{Sr} /{ }^{86} \mathrm{Sr}$ da água das bacias de origem. Para os peixes de ambiente natural essa relação foi observada com relação a todos os exemplares estudados

Entretanto, os resultados da análise de discriminante tiveram uma alta probabilidade de classificação no modelo gerado em relação à origem geográfica e ao método de produção (Tabela 6), alcançando assim, uma boa discriminação com uso da ferramenta analítica desenvolvida neste trabalho. Estes resultados confirmam a eficiência e precisão do uso da ferramenta de análise isotópica na determinação da origem da pesca do pirarucu na bacia 
Amazônica, com possíveis aplicações para a regulação, controle e fiscalização dos órgãos competentes, bem como na definição de rotas de comércio e ainda na certificação da origem dos peixes comercializados oriundos das atividades de manejo e criação em cativeiro.

\subsection{Relação entre composição isotópica da ração e dos peixes de cativeiro}

$\mathrm{Na}$ relação entre a razão ${ }^{87} \mathrm{Sr} /{ }^{86} \mathrm{Sr}$ dos otólitos de cativeiro, da água e das rações utilizadas na alimentação destes peixes (Figura 18), a maioria dos peixes tem a razão ${ }^{87} \mathrm{Sr} /{ }^{86} \mathrm{Sr}$ do otólito entre as razões da água, da ração e os valores estão próximos a razão média da bacia. Este não é o caso dos indivíduos de Santarém, que provavelmente foram pescados no rio Solimões e não no rio Amazonas como indicado, nem do indivíduo CAT-COOPER indicado como de Manacapuru.

Para os indivíduos (CAT-FEIRA-MAM), indicados como provenientes de cativeiros de Tefé, não há uma relação entre a razão ${ }^{87} \mathrm{Sr} /{ }^{86} \mathrm{Sr}$ dos otólitos, tampouco da água, ou da dieta. Nesses casos, os valores encontrados de variabilidade natural na bacia podem não corresponder a variação local da fonte de água usada nos tanques de criação, ou das médias da dieta ingerida por estes indivíduos.

O indivíduo CAT-ROD-01, é o único onde a razão do otólito equivale à razão da ração. Walther and Thorrold (2006) realizaram um trabalho para quantificar a contribuição relativa da água e da comida para $\mathrm{Sr}$ e $\mathrm{Ba}$ nos otólitos do peixe marinho $F$. heteroclitus por meio de ${ }^{86} \mathrm{Sr}$ e ${ }^{137} \mathrm{Ba}$ marcados e concluíram que o $\mathrm{Sr}$ é proveniente da água e não da dieta. Porém, os autores obtiveram que estes elementos são sensíveis a mudanças ambientais, como salinidade. Uma das conclusões foi no sentido de que a importância relativa das fontes de água e de dieta nos otólitos pode depender da disponibilidade de $\mathrm{Ca}^{+2}$ na água, e que possivelmente em peixes de água doce, as baixas concentrações de $\mathrm{Ca}^{+2}$ na água podem ser 
compensadas pela disponibilidade de íons da comida. Assim, é possível que as águas dos tanques dos cativeiros apresentem uma menor concentração de $\mathrm{Ca}^{+2}$ do que as águas dos rios, fato que pode alterar a fisiologia do peixe quanto à fonte de absorção de Sr nos otólitos. 


\section{CONCLUSÕES}

A proposta desta dissertação foi apresentar um estudo isotópico para rastrear a origem da pesca do pirarucu consumido pelas populações locais e comercializado em mercados da Amazônia, considerando, portanto, indivíduos provenientes da criação em cativeiro e da pesca em ambientes naturais. O estudo foi focado nas características isotópicas dos otólitos dos indivíduos estudados, nos quais foi determinada a composição isotópica de carbono e oxigênio, bem com a determinação cronológica das variações isotópicas de $\mathrm{Sr}$ ao longo do eixo de crescimento desses otólitos. É importante salientar que as análises isotópicas de Sr empregadas neste estudo constituem um registro contínuo das características do hábitat do peixe. Além dos dados obtidos nos otólitos, são apresentados também dados isotópicos sobre a água nas diferentes sub-bacias e da ração utilizada na alimentação dos peixes de cativeiro.

Como conclusões gerais deste trabalho, podemos afirmar que a combinação da razão ${ }^{87} \mathrm{Sr} /{ }^{86} \mathrm{Sr}$ com a assinatura $\delta^{13} \mathrm{C}$ permite discriminar indivíduos oriundos de diferentes rios da bacia Amazônica, bem como os diferentes métodos de produção. A identificação da origem da pesca de Arapaima sp. é importante para a construção do conhecimento ecológico em relação a história de vida deste gênero e para os padrões de migração, uso do habitat e dieta, que são necessários para o seu manejo e conservação.

Desta forma, pode-se afirmar que houve compatibilidade entre as razões isotópicas de ${ }^{87} \mathrm{Sr} /{ }^{86} \mathrm{Sr}$ dos peixes com o ambiente de origem por meio do registro contínuo dos hábitats dos peixes nos otólitos. Neste sentido, também é possível afirmar que a pequena variação das composições isotópicas do pirarucu em ambiente natural confirma o caráter sedentário deste gênero e também com observações de variações isotópicas em alguns indivíduos, que podem corresponder à migração lateral ou mudança ambiental na fonte de água. Assim, os resultados 
desta pesquisa fornecem subsídio para estudos de ecologia de populações e, consequentemente, para o manejo e identificação de habitat críticos para a conservação do gênero.

Diante dos resultados apresentados, abrem-se perspectivas para possíveis aplicações da ferramenta desenvolvidas neste trabalho: 1) na regulação, controle e fiscalização realizada pelos órgãos competentes; 2) na definição de rotas de comércio; e 3) na certificação da origem deste peixe, que contribui para todos os elos da cadeia produtiva, fortalecendo os trabalhos de manejo realizado pelas comunidades locais e de criação em cativeiro que vêm contribuindo como alternativa para a manutenção dos estoques de Arapaima sp em ambiente natural.

As questões em aberto nesta dissertação são: a elucidação do padrão de migração lateral em ambiente natural na escala local por meio da razão ${ }^{87} \mathrm{Sr} /{ }^{86} \mathrm{Sr}$, sendo necessários estudos mais detalhados para a caracterização temporal dos rios e lagos em uma escala local nos diferentes rios da bacia Amazônica. Igualmente são necessários mais estudos para compreender as variações das razões ${ }^{87} \mathrm{Sr} /{ }^{86} \mathrm{Sr}$ dos peixes em cativeiro, bem como a possível assimilação de Sr pela ração nestes ambientes. Outra questão para estudos posteriores é em relação a assinatura $\delta^{13} \mathrm{C}$ dos pirarucus do rio Amazonas em Itacoatiara e Santarém.

É possível concluir que a ferramenta isotópica apresenta diversas aplicações no rastreamento da pesca do pirarucu na bacia Amazônia, sendo assim importante para o desenvolvimento tecnológico e ecológico desta espécie no ecossistema Amazônico. Todavia, existe a necessidade de se aprofundar o trabalho para obter uma maior eficiência. Entre outros, é necessário construir um melhor conhecimento sobre o fundo geoquímico e suas variações locais. Além da realização de novos experimentos com foco na Reserva de Desenvolvimento Sustentável de Mamirauá e na bacia de inundação do rio Beni, os quais poderiam resolver algumas perguntas relativas a este tema e testar a hipótese de Castello sobre as migrações laterais. 


\section{REFERÊNCIAS BIBLIOGRÁFICAS}

Allegre, C.J. Isotope Geology. United Stades of America.New York: Cambrige,2008, 534p.

Araujo-Lima C, Forsberg B, Victoria R, Martinelli L (1986) Energy sources for detritivorous fishes in the Amazon. Science 234: $1256-1258$.

Araripe, J; Rêgo, P. S.; Queiroz, H. L.; Sampaio, I.; Schneider, H. Dispersal capacity and genetic structure of Arapaima gigas on different geographic scales using microsatellite markers. PloS One, v. 8, 2013.

Barats, A.; Pecheyran C.; Amouroux, D.; Dubascoux, S.; Chauvaud, L.; Donard, O.F.X. Matrix-matched quantitative analysis of trace-elements in calcium carbonate shells by laser ablation ICP-MS: Application to the determination of daily scale profiles in scallop shell (Pecten maximus) Anal Bioanal. Chem., v. 387, p.1131-1140.2007.

Barnett-Johnson R; Ramos F.C; Grimes C.B; MacFarlane R.B. Validation of Sr isotopes in otoliths by laser ablation multicollector inductively coupled plasma mass spectrometry (LA-MC-ICP-MS): opening avenues in fisheries science applications. Can J Fish Aquat Sci. v.2: p.2425-2430. 2005

Barnett-Johnson R.; Pearson T.E.; Ramos F.C.; Grimes C.B.; MacFerlane R.B. Tracking natal origins of salmon using isotopes, otoliths, and landscape geology. Limnol Oceanogr v.53:1633-1642. (2008)

Barnett-Johnson, R.; Teel, D.; Casillas, E. Genetic and otolith isotopic markers identify salmon populations in the Columbia River at broad and fine geographic scales. Environ. Biol. Fish., v.89, p.533-546. 2010.

Barnett-Johnson R. Determining the importance of stock structure, and production sources to population dynamics of California Chinook salmon using otoliths as geochemical signatures. Coastal Environmental Quality Initiative no. 010.2004. http://repositories.cdlib.org/ucmarine/ceqi/010. Accessed 10 September 2015

Beffi. C.; Trincherini, P.R. Food traceability using the $87 \mathrm{Sr} / 86 \mathrm{Sr}$ isotopic ratio mass spectrometry. Eur Food Res Technol (2016). DOI 10.1007/s00217-016-2712-2

Bell, J.G.; Preston, P.R.; Henderson,J.;James F.S; Bron, E; Cooper,K.; Morrison, D.J. Discrimination of Wild and Cultured European Sea Bass (Dicentrarchus labrax) Using Chemical and Isotopic Analyses. J. Agric. Food Chem.,v. 55,p.5934-5941. 2007 
Brasil. Instrução normativa Ibama n³4, de 18 de junho de 2004. Estabelece normas gerais para o exercício da pesca do pirarucu (Arapaima gigas) na Bacia Hidrográfica do Rio Amazonas.

Brasil. Rondônia. LEI No 1038 DE 22 DE JANEIRO DE 2002. Estabelece diretrizes para proteção à pesca e estímulos à aqüicultura do Estado de Rondônia e dá outras providências.

Campana, S.E; Fowler, A.J. Otolith Elemental Fingerprinting for Stock Identification of Atlantic Cod (Gadus morhua) Using Laser Ablation ICPMS. Can. 9. Fish. Aquar. Sci., vol. 51, p1942-1950. 1994.

Campana, S.E. Chemistry and composition of fish otoliths: pathways, mecanisms and applications. Marine Ecology Progress Series.Vol 188: 263-297, 1999.

Campana, S. E; Thorrold,S.R. Otoliths, increments, and elements: Keys to a comprehensive understanding of fish population? Can. J. Fish. Aquat. Sci. vol. 58,2001. DOI: 10.1139-cjfas-58-1-30

Campana, S.E, Neilson JD. Microstructure of fish otoliths. Can J Fish Aquat Sci 42:1014-1032. 1985

Carvajal-Vallejos, F.; Macnaughton A.; Coca C.; Trujillo,S.; Carolsfeld,J.; Van Damme,P.A. A introdução de Arapaima cf. gigas na Amazônia boliviana: impactos nas pescarias, cadeias de valor emergentes e perspectivas para a gestão comunitária. In: Figueiredo, E. S. A. (Org.). Biologia, conservação e manejo participativo de pirarucus na Pan-Amazônia. Tefé: IDSM, 2013. p. 17-31.

Castello L. A method to count Pirarucu Arapaima gigas: Fishres, Assessment, na Management. North American Journal of Fisheries Management 24:379-389, 2004

Castello L. Lateral migration of Arapaima gigas in floodplains of the Amazon. Ecol Freshwat Fish v.17: p.3846. 2008. doi:10.1111/j.1600-0633.2007.00255x

Castello; L.; Stewart, D.; Arantes, C. C. O que sabemos e precisamos fazer a respeito da conservação de pirarucu (Arapaima spp.) na Amazônia. In: FIGUEIREDO, E. S. A. (Org.). Biologia, conservação e manejo participativo de pirarucus na Pan-Amazônia. Tefé: IDSM, 2013. p. 17-31.

Claverie, F.; Fernandez, B.; Pecheyran, C.; Alexis, J. \& Donard, O.F.X. Elemental fractionation effects in high repetition rate IR femtosecond laser ablation ICP-MS analysis of glasses. J. Anal. Atom. Spectrom., v.24, p.891-902. 2009

Cunha, P.R.C, Gonzaga; F.G, Coutinho; L.F.C.; Feijó, F.J C. A bacia do Amazonas. Boletim de Geociências, Rio de Janeiro,v. 8(1);p. 47-55, 1994 
Comyns, B. H; Rakocinski, C. F.; Peterson, M. S.; Shiller, A. M. Otolith chemistry of juvenile spotted seatrout Cynoscion nebulosus reflects local natal regions of coastal. Mississippi, USA.Mar. Ecol.: Prog.Ser. v.371, p. 243-252. 2008

DeNiro M. J. \& Epstein S. Influence on the distribution of carbon isotopes in animals. Geochimica et Cosmochimica Acta. V 42:495-506. 1978

Di Paola-Naranjo RD, Baroni V, Podio NS, Rubinstein HR, Fabni MB, Badini RG, Inga M, Ostera HA, Cagnoni M, Callegos E, Gautier E, Peral-Garcia P, Hoogewerff J, Wunderlin DA. J. Fingerprints for Main Varieties of Argentinean Wines: Terroir Differentiation by Inorganic, Organic, and Stable Isotopic Analyses Coupled to Chemometrics Agric Food Chem 59:7854-7865.2011

Domingues, T. F.; Martinelli, M. C.; Martinelli, L. A.; Ehleringer, J. R. Assessing Feeding History Recorded on Tropical Fish Scales. In: 3rd International Conference - Applications of Stable Isotope Techniques to Ecological Studies, 2002, Flagstaff, AZ, 2002.

Duponchelle, F.; Pouilly, M.; Pécheyran, C.; Hauser, M.; Renno, J.-F.; Panfili, J.; Darnaude, A. M.; GarcíaVasquez, A.; Carvajal-Vallejos, F.; García-Dávila, C.; Doria, C.; Bérail, S.; Donard, A., Sondag, F.; Santos, R. V.; Nuñez, J.; Point, D.; Labonne, M.; Baras, E. Trans-Amazonian natal homing in giant catfish. J Appl Ecol. 2016 doi:10.1111/1365-2664.12665

Faure G; Powell J. Strontium Isotopic Geology. New york Spring- Verlag Berlin. Heidelberg, 1972

Figueiredo, Ellen Sílvia Amaral (Org.) Biologia, conservação e manejo participativo de pirarucus na PanAmazônia. Organizado por Ellen Amaral. Tefé: IDSM, 2013.278 p, il.

Fortunato G, Mumic K, Wunderli S, Pillonel L, Bosset JO, Gremaud G. Application of strontium isotope abundance ratios measured by MC-ICP-MS for food authentication. J Anal At Spectrom 19:227234.2004

Fuck R.A, Neves B. B. B., Schobbenhaus, C. Rondina descendants in South America. Precambian Research: 160:108-126. 2008

Fry, B. Stable Isotope Ecology. $3^{\text {th }}$. USA: New York: Springer Science. 2008.283p.

Forsberg, B. R., C. A. R. M. Araujo-Lima, L. A. Martinelli, R. L. Victoria, J., Bonassi A. Autotrophic carbon sources for fish of the central Amazon. Ecology 74:643-652. 1993

Gaillardet J; Dupre B; Allègre CJ; Négrel P. Chemical and physical denudation in Amazon River basin. Geology v.142: p.141-173. 1997 
Garcez R. C. S.; Humston R.; Harbor D.; Freitas C. E. C. Otolith geochemistry in Young-of-the-year peacock bass Cichla temensis fot investigating natal dispersal in the Rio Negro (Amazon- Brazil) river system. Ecology of freshwater fish 24.2: 242-251. 2015.

Gillanders, B. M. Using elemental chemistry of fish otoliths to determine connectivity between estuarine and coastal hábitats. Estuarine, Coastal Shelf Sci., v.64, p. 47-57. 2005.

Gibbs, R.J.; The geochemistry of the Amazon River system. The factors that control the salinity, composition and concen-tration of the suspended solids. Geol. Soc. Am. Bull. v.78, p. 1203-1232. 1967

Goulding M; Barthem R. Ferreira E.J.G.The Smithsonian Atlas os the Amazon. Smithsonian Books Press: Washington. 2003

Hermann T. W.; Stwart D. J.; Limburg K. E.; Castello L. Unravelling the life history of Amazonian Fishes trough otolith microchemistry. R.Soc.open sci. 3: 160206.

Hegg, J.C.; Giarzzo T.; Kennedy B. P. Migratory Amazonian Catfish: Implications for Conservation and Management. Plos One 10 (7). e0129697-19. http://doi.org/10.1371/journal.pone.0129697

Hobson, K.A. Tracing Origins and Migration of Widlife Using Stable Isotopes: A Review. Oecologia, v.120, p314-326.1999

Hrbek, T., Crossa, M.cand Farias, IP. (2008) Conservation strategies for Arapaima gigas (Schinz, 1822) and the Amazonian várzea ecosystem. Braz. J. Biol., v. 67(4, Suppl.): p. 909-917, 2007

Imbiriba,E.P. Potencial de criação de Pirarucu, Arapaima gigas, em cativeiro. Acta Amazonica. v.31(2): p.299316. 1991

Imbiriba, E.P. Reprodução, Larva e Alevinagem do Pirarucu (Arapaima gigas). Recomendações básicas no. 26. EMBRAPA/CPATU. Belém, PA. 1994

Imbiriba, E.P.; E.P.Lourenço Jr., J.B.; Carvalho, L.O.D.M.; Góes, L.B.;Juliana, D. \&Filho, L.B. 1996. Criação de Pirarucu. Coleção Criar. EMBRAPA, SPI. Brasília. 93 pp.

Ingram BL; Weber P.K; Salmon origin in California's Sacramento-San Joaquin river system as determined by otolith strontium isotopic composition. Geology v.27: p.851-854. 1999

Jepsen D.B; Winemiller K. O. Basin geochemistry and isotopic ratios of fishes and basal production sources in four neotropical rivers. Ecology of Freshwater Fish. V 16: 267-281, 2007

Junk, W.J. The Central Amazon floodplain. Ecology of a pulsing system. Ecological Studies No. 126. Springer, Berlin, 1997, 525 pp. 
Kalish JM Determinants of otolith chemistry: seasonal variation in composition of blood plasma, endolymph and otoliths of bearded rock cod Pseudophycis barbatus. Mar Ecol Prog Ser 74:137-159, 1991.

Kennedy B.P.; Folt C.L.; Blum J.D.; Chamberlain C.P. Natural isotope markers in salmon. Nature p.387:766. 1997.

Kennedy B.P.; Blum J.D.; Folt C.L.; Nislow K.H. Using strontium isotopic signatures as fish markers: methodology and application. Can J Fish Aquat Sci v.57: p.2280-2292. 2000.

Kennedy B.P; Klaue A.; Blum J.D.; Folt C.L.; Nislow K.H. Reconstructing the lives of fish using Sr isotopes in otoliths. Can J Fish Aquat Sci v.59: p.925-929. 2002.

Kennedy B.P.; Chamberlain C.P.; Blum J.D.; Nislow K.H.; Folt C.L.; Comparing naturally occurring stable isotopes of nitrogen, carbon, and strontium as markers for the rearing locations of Atlantic salmon (Salmo salar). Can J Fish Aquat Sci v.62: p.48-57. 2005.

Kerr, L.A;, Campana,S.E Chemical Composition of Fish Hard Parts as a Natural Marker of Fish Stocks . Second Edition. Academic Press, San Diego, 2014, Page 566, ISBN 9780123970039, http://dx.doi.org/10.1016/B978-0-12-397003-9.01001-8.

Laraque A.; Guyot J. L.; Filizola N. Mixing process in the Amazon River at the confluence of the Negro and Solimões Rivers, Encontro das Águas, Manaus, Brasil.Hydrological process, 23, 3131-3140. 2009.

Maia D.P. Le rôle des échanges entre le fleuve Amazone et la plaine d'inondation dans les processus de transport, de spéciation et de piégeage du mercure. 2008.

McCrea J. M. On the isotopic chemistry of carbonates and a paleotemperature scale. The Journal of Chemical Physics. 1950

Marshall B. G.; Forsberg B. R; Thomé-Souza M. J. F. Autotrophic energy sources for Paracheirodon axelrodi (Osteichthyes, Characidae) in middle Negro River, Central Amazon, Brazil. Hydrobiologia. V 596: 95:103, 2007

Martin J; Bareille G; Berail S; Pecheyran C; Daverat F; Bru N; Tabouret H; Donard O Spatial and temporal variations in otolith chemistry and relationships with water chemistry: a useful tool to distinguish Atlantic salmon Salmo salar parr from different natal streams. J Fish Biol v.82: p.1556-1581. 2013a. 
Martin J; Bareille G; Berail S; Pécheyran C; Gueraud F; Lange F; Daverat F; Bru N; Beall E; Barracou D; Donard O Persistence of a Southern Atlantic salmon population: diversity of natal origins from otolith elemental and Sr isotopic signatures. Can J Fish Aquat Sci v.70: p.182-197. 2013.

Matsui, E., Salati, F., Friedman, I. and Brinkman, W.L.F., Isotopic hydrology in the Amazonia: 2. Relative discharges of the Negro and Solimões rivers through ${ }^{18} \mathrm{O}$ concentrations. Wat. Ress. Res. 12, 4, 781 785. 1976

Moura Carvalho, L. O. D. \& Nascimento, C. N. B. 1992. Engoda de pirarucus (Arapaima gigas) em associação com búfalos e suínos. Embrapa-CEPATU, Circular técnica, 65. Belém, 21pp.

Moretti, V.M.; Turchini, G.M.; Bellagamba F.; Caprino, F. Traceability Issues in Fishery and Aquaculture Product. Veterinary Research Communications,v 27 Suppl. 1 497-505. 2003.

Mortillaro, J. M., Pouilly, M., Wach, M., Freitas, C. E. C., Abril, G., \& Meziane, T. Trophic opportunism of central Amazon floodplain fish. Freshwater Biology, 60(8), 1659-1670. 2015.

Nelson, J.S. 1994. Fishes of the World. Third Edition. John Wiley \& Sons, Inc.New York. 600pp.

Newman, S.J.; Steckis, R.A.; Edmonds, J.S.; Lloyd, J., 2000. Stock structure of the goldband snapper Pristipomoides multidens (Pisces: Lutjanidae) from the waters of northern andwestern Australia by stable isotope ratio analysis of sagittal otolith carbonate. Mar. Ecol. Prog. Ser. v.198, p. 239-247.

Nonogaki H.; Nelson J. A.; Patterson W. P. Dietary histories of herbivorous loricariid catfishes: evidence form ¿13C value of otoliths. Environmental Biology Fish.v 78:13-21, 2007.

Paca V; Moreira D.; Monteiro A.; Roig H. Geochemistry of Amazon basin supported by ADCP measurements. In: EGU General Assembly. v 16, p 15647. 2014.

Palmer MR; Edmond JM. (1992). Controls over the strontium isotope composition of river water. Geochimica et Cosmochimica Acta v.56: p.2099-2111.

Patterson, W.P., Smith, G.R., and Lohmann, K.C. Continental paleothermometry and seasonality using isotopic composition of aragonitic otoliths in freshwater fishes. Geophys. Monogr. 78: 191-202.1993.

Pouilly M.; Point D.; Sondag F.; Henry M.; Santos R.V. Geographical Origin of Amazonian Freshwater Fishes Fingerprinted by ${ }^{87} \mathrm{Sr} /{ }^{86} \mathrm{Sr}$ Ratios on Fish Otoliths and Scales. Environmental Science \& Technology v. 48 p.: 8980-8987. 2014. DOI 10.1021/es500071 
Pracheil B. M.; Hogan J. D.; Lyons J.; McIntyre P. B. Using Hard- Part Microchemistry to Advance Conservation and Management of North American Freshwater Fishes. Fisheries, 39:10, 451-465. 2014 DOI: $10.1080 / 03632415.2014 .937858$

Queiroz, H.L. 2000. Natural history and conservation of pirarucu, Arapaima gigas, at the Amazonian Várzea: red giants in muddy waters. Ph.D. Thesis. St. Andrews (UK): University of St. Andrews. 226 pp.

Queiroz M.M.A.; Horbe A.M.C.; Seyler P.; Moura C.A.V. Hidroquímica do rio Solimões na região entre Manacapuru e Alvarães: Amazonas-Brasil. Acta Amazon., v.39, p.943-952. 2009.

Radke R. L.; Showers W.; Moksness E.; Lenz P. Environmental information stored in otoliths: insights from stable isotpes. Marine Biology.v. 127: 161-170. 1996.

Rojas, J.M.M.; Serra F.; Giani I.; Moretti V. M; Reniero F.; Guillou C. The use of stable isotope ratio analyses to discriminate wild and farmed gilthead sea bream (Sparus aurata). Rapid communications in mass spectrometry v.21: p.207-211. 2007.DOI: $10.1002 / \mathrm{rcm} .2836$.

Rummel S; Dekant CH; Hölzl S; Kelly SD; Baxter M; Marigheto N; Quetel CR; Larcher R; Nicolini G; Froschl H; Ueckermann H; Hoogewerff J. Sr isotope measurements in beef-analytical challenge and first results. Anal Bioanal Chem 402:2837-284. 2012.

Sánchez, J. R. El "paiche”: aspectos de su historia natural y aprovechamiento. Revista de Caza y Pesca, v. 10, p. 17-61, 1969.

SEBRAE. Manual de Boas Práticas de Produção do Pirarucu em Cativeiro. Sebrae, Brasília, 2013. 46p.

Schobbenhaus,C.Geologia do Brasil. Publicação da Divisão de Geologia e Mineralogia, Departamento Nacional de Produção Mineral- DNMP) 1984

Santos, R. V.; Sondag, F.; Cochonneau, G.; Lagane, C.; Brunet, P.; Hatting, K.; Chaves, J. G. S. Source area and seasonal ${ }^{87} \mathrm{Sr} /{ }^{86} \mathrm{Sr}$ variations in rivers of the Amazon basin. Hydrol. Process. V.29, p. 187197.2014.

Solomon C. T.; Weber P. K; Joseph J.; Cech J.J; Igran L. B; Conrad M. E; C; Machavaram M. V.; Pogodina A.R.; Franklin R.L. Experimental detemination of the sources of otholith carbono and associated isotopic fractionation. Can. J. Fish. Aquat. Sci. Vol. 63, 79-89, 2006.

Sousa R.G.C; Humston R.; Freitas C.E.C. Movement Patterns of adult peacock bass Cichla temensis between triibutaries of midlle Negro River basin (Amazonas- Brazil): na otholith geochemical analysis. Fisheries Management and Ecology, 23, 76-87. 2016. 
Stallard, R.F. Major Element Chemistry of the Amazon River System. Ph.D. dissertation. 1980 MIT/WHOI.

Stallard, R.F.; Edmond; J.M.. Geochemistry of the Amazon, 2. The influence of geology and weathering environment on the dissolved load. J. Geophys. Res. v.88, p.9671-9688. 1983.

Stallard, R.F.; Edmond, J. M. Geochemistry of the Amazon, 3. Weathering chemistry and limits to dissolved inputs. J. Geophys. Res. v. 92, p. 8293-8302. 1987.

Swearer, S. E.; Forrester, G. E.; Steele, M. A.; Brooks, A. J.; Lea, D. W. Spatio-temporal and interspecific variation in otolith trace-elemental fingerprints in a temperate estuarine fish assemblage. Estuarine, Coastal Shelf Sci. v.56, p. 1111-1123. 2003.

Tabouret, H.; Bareille, G.; Claverie, F.; Pecheyran, C.; Prouzet, P. \& Donard, O.F.X. Simultaneous use of strontium:calcium and barium:calcium ratios in otoliths as markers of habitat: Application to the European eel (Anguilla anguilla) in the Adour basin, South West France. Mar. Environ. Res., v.70, p. 35-45. 2010

Trincherini PR, Baffi C, Barbero P, Pizzoglio E, Spalla S Precise determination of strontium isotope ratios by TIMS to authenticate tomato geographical origin. Food Chem 145:349-355. 2014

Turchini, G.M.; Quinn,G.P; Jones,P.L; Palmeri,G; Gooley G. Traceability and Discrimination among Differently Farmed Fish : A Case Study on Australian Murray Cod. Society,v.57 p.274-281.

Thorrold, S.R., Campana, S.E., Jones, C.M., and Swart, P.K. Factors determining $\delta^{13} \mathrm{C}$ and $\delta^{18} \mathrm{O}$ fractionation in aragonitic otoliths of marine fish. Geochim. Cosmochim. Acta, 61: 2909-2919. 1997a.

Trevethan M.; Santos V.S; Ianniruberto M.; Martinelli M. O; Gualtieri C. Influencio f tributary water chemistry on hydrodynamics and fish biogeography about the confluence of Negro and Solimões Rivers, Brazil. In 11th ISE 2016, Melbourne, Australia. 2016

Viers J.; Roddaz M. Filizola N; Guyot J-LL; Sondag F; Brunet P.; Zouiten C, Boucayrand C; Martin F; Boaventura GR. Seasonal and provenance controls on $\mathrm{Nd}-\mathrm{Sr}$ isotopic compositions of Amazon rivers suspended sediments and implications for $\mathrm{Nd}$ and $\mathrm{Sr}$ fluxes exported to the Atlantic Ocean. Earth and Planetary Science Letters v.274: p.511-523. 2008

Walther, B.D.; Thorrold, S.R. Water, not food, contribuites the majoritary of strontium and barium deposited in the otiliths of a marine fish. Mar Ecol Prog Ser v.311: p. 125-130. 2006.

Walther, B. D.; Dempster, T.; Letnic, M.; McCulloch, M. T. Movements of diadromous fish in large unregulated tropical rivers inferred from geochemical tracers. PLoS One v.6, No . e 18351. 2011 
Watson, L. C.; Stewart, D. J.; Teece, M. A. Trophic ecology of Arapaima in Guyana: giant omnivores in Neotropical floodplains. Neotropical Ichthyology, v. 11(2), p. 341-349, 2013.

Woodhead, J; Swearer,S; Hergta, J; and Maasa, R. In situ Sr-isotope analysis of carbonates by LA-MC-ICP-MS: interference corrections, high spatial resolution and an example from otolith studies. Journal Analysis at Spectrometry. v.20, p.22 - 27. 2005

World Conservation Monitoring Centre. 1996. Arapaima gigas. In 2004 IUCN Red List of Threatened Species. http://www.iucnredlist.org. Downloaded on 28 de agosto de 2013.

WWF Brasil, 2011 Manejo do pirarucu sustentabilidade nos lagos do Acre. Brasília. 67pp. 


\section{ANEXO 1. Licença de coleta}

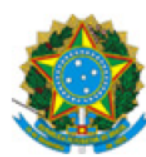

Ministério do Meio Ambiente - MMA

Instituto Chico Mendes de Conservação da Biodiversidade - ICMBio

Sistema de Autorização e Informação em Biodiversidade - SISBIO

\section{Autorização para atividades com finalidade científica}

\begin{tabular}{|c|c|c|}
\hline Número: 49527-1 & Data da Emissão: 05/06/2015 16:04 & Data para Revalidação*: 04/07/2016 \\
\hline * De acordo com o art. 28 da IN 03/2014, esta autorização tem prazo de validade equivalente ao previsto no cronograma de atividades do projeto, \\
mas deverá ser revalidada anualmente mediante a apresentação do relatório de atividades a ser enviado por meio do Sisbio no prazo de até 30 dias \\
a contar da data do aniversário de sua emissão.
\end{tabular}

a contar da data do aniversário de sua emissão.

Dados do titular

\begin{tabular}{|l|l|}
\hline Nome: Luciana Alves Pereira & CPF: 016.644.671-81
\end{tabular}

Título do Projeto: Macadores biogeoquimicos da origem da pesca do Arapaima gigas (Schinz, 1822) na Bacia Amazônica

Nome da Instituição : FUNDAÇÃO UNIVERSIDADE DE BRASÍLIA

CNPJ: 00.038.174/0001-43

Cronograma de atividades

\#

Observações e ressalvas

1 As atividades de campo exercidas por pessoa natural ou juridica estrangeira, em todo o território nacional, que impliquem o deslocamento de recursos humanos e

materiais, tendo por objeto coletar dados, materiais, espécimes biológicos e minerais, peças integrantes da cultura nativa e cultura popular, presente e passada
obtidos por meio de recursos e técnicas que se destinem ao estudo à difusão ou à pesquisa, estão sujeitas a autorizacăo do Ministério de Ciência e Tecnologia

obtidos por meio de recursos e técnicas que se destinem ao estudo, à difusão ou à pesquisa, estão sujeitas a autorização do Ministério de Ciência e Tecnologia.

como do consentimento do responsável pela área, pública ou privada, onde será realizada a atividade, inclusive do órgăo gestor de terra indigena (FUNAI), da

unidade de conservaçấo estadual, distrital ou municipal, ou do proprietário, arrendatário, posseiro ou morador de área dentro dos limites de unidade de conservação

federal cujo processo de regularização fundiária encontra-se em curso.

especifica esta Autorização, não podendo ser utilizado para fins comerciais, industriais ou esportivos. O material biológico coletado deverá ser utilizado para atividade

cientificas ou didáticas no âmbito do ensino superio

A autorização para envio ao exterior de material biológico năo consignado deverá ser requerida por meio do endereço eletrônico www.ibama.gov.br (Serviços on-line -

Licença para importação ou exportação de flora e fauna - CITES e não CITES).

O titular de licença ou autorização e os membros da sua equipe deverão optar por métodos de coleta e instrumentos de captura direcionados, sempre que possivel,

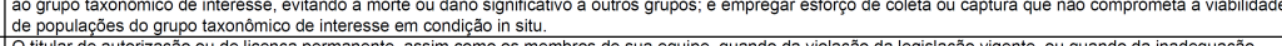

O titular de autorização ou de licença permanente, assim como os membros de sua equipe, quando da violaçăo da legislaçãão vigente, ou quando da inadequ

suspensa ou revogada pelo ICMBio, nos termos da legislação brasileira em vigor.

Este documento năo dispensa o cumprimento da legislaçąăo que dispöe sobre acesso a componente do patrimônio genético existente no território nacional, na

plataforma continental e na zona econômica exclusiva, ou ao conhecimento tradicional associado ao patrimônio genético, para fins de pesquisa cientifica,

8 Em caso de pesquisa em UNIDADE DE CONSERVAÇAOO, o pesquișador titular desta autorizaçẵo deverá contactar a administração da unidade a fim de CONFIRMAR

AS DATAS das expedições, as condições para realização das coletas e de uso da infra-estrutura da unidade.

Locais onde as atividades de campo serão executadas

\begin{tabular}{|l|l|l|l|l|}
\hline$\#$ & Município & UF & Descrição do local & Tipo \\
\hline 1 & TEFE & AM & Reserva de Desenvolvimento Sustentável de Mamirauá & Fora de UC Federal \\
\hline 2 & AM & Manacapuru & Fora de UC Federal \\
\hline
\end{tabular}

Atividades $X$ Táxons

\begin{tabular}{|c|c|c|}
\hline$\#$ & \multicolumn{1}{|c|}{ Atividade } & Táxons \\
\hline 1 & Coleta/transporte de amostras biológicas in situ & Arapaima gigas \\
\hline
\end{tabular}

Material e métodos

\begin{tabular}{|l|l|l|}
\hline 1 & Amostras biológicas (Peixes) & Fragmento de tecido/órgão, Escama \\
\hline 2 & Método de captura/coleta (Peixes) & Outros métodos de captura/coleta, Captura manual \\
\hline
\end{tabular}

Este documento (Autorização para atividades com finalidade científica) foi expedido com base na Instrução Normativa n 03/2014. Através do código de autenticação abaixo, qualquer cidadão poderá verificar a autenticidade ou regularidade deste documento, por meio da página do Sisbio/ICMBio na Internet (www.icmbio.gov.br/sisbio)

Código de autenticação: 19842247 


\section{ANEXO}

Ministério do Meio Ambiente - MMA

Instituto Chico Mendes de Conservação da Biodiversidade - ICMBio

Sistema de Autorização e Informação em Biodiversidade - SISBIO

\section{Autorização para atividades com finalidade científica}

Número: $49527-1$

Data da Emissão: 05/06/2015 16:04

Data para Revalidação*: 04/07/2016

* De acordo com o art. 28 da IN 03/2014, esta autorização tem prazo de validade equivalente ao previsto no cronograma de atividades do projeto, mas deverá ser revalidada anualmente mediante a apresentação do relatório de atividades a ser enviado por meio do Sisbio no prazo de até 30 dias a contar da data do aniversário de sua emissão.

Dados do titular

\begin{tabular}{|l|l|l|l|l|l|l|l} 
Nome: Luciana Alves Pereira & CPF: 016.644.671-81
\end{tabular}

Título do Projeto: Macadores biogeoquímicos da origem da pesca do Arapaima gigas (Schinz, 1822) na Bacia Amazônica

Nome da Instituição : FUNDAÇÃO UNIVERSIDADE DE BRASÍLIA

CNPJ: 00.038.174/0001-43

Destino do material biológico coletado

\begin{tabular}{|c|c|c|}
\hline$\#$ & Nome local destino & Tipo Destino \\
\hline
\end{tabular}

Este documento (Autorização para atividades com finalidade científica) foi expedido com base na Instrução Normativa $n^{\circ} 03 / 2014$. Através do código de autenticação abaixo, qualquer cidadão poderá verificar a autenticidade ou regularidade deste documento, por meio da página do Sisbio/ICMBio na Internet (www.icmbio.gov.br/sisbio)

Código de autenticação: 19842247 


\section{ANEXO}

Ministério do Meio Ambiente - MMA

Instituto Chico Mendes de Conservação da Biodiversidade - ICMBio

Sistema de Autorização e Informação em Biodiversidade - SISBIO

\section{Autorização para atividades com finalidade científica}

\begin{tabular}{|c|c|c|}
\hline Número: $49527-1$ & Data da Emissão: 05/06/2015 16:04 & Data para Revalidação*: 04/07/2016 \\
\hline $\begin{array}{l}\text { * De acordo com o art. } 28 \text { da IN 03/2014, esta autorização tem prazo de validade equivalente ao previsto no cronograma de atividades do projeto, } \\
\text { mas deverá ser revalidada anualmente mediante a apresentação do relatório de atividades a ser enviado por meio do Sisbio no prazo de até } 30 \text { dias } \\
\text { a contar da data do aniversário de sua emissão. }\end{array}$
\end{tabular}

Dados do titular

\begin{tabular}{|l|l|l|}
\hline Nome: Luciana Alves Pereira & \multicolumn{1}{l|}{ CPF: 016.644.671-81 } \\
\hline Título do Projeto: Macadores biogeoquímicos da origem da pesca do Arapaima gigas (Schinz, 1822) na Bacia Amazônica \\
\hline Nome da Instituição : FUNDAÇÃO UNIVERSIDADE DE BRASÍLIA & CNPJ: 00.038.174/0001-43 \\
\hline
\end{tabular}

\section{Registro de coleta imprevista de material biológico}

De acordo com a Instrução Normativa $n^{\circ}$ 03/2014, a coleta imprevista de material biológico ou de substrato não contemplado na autorização ou na licença permanente deverá ser anotada na mesma, em campo específico, por ocasião da coleta, devendo esta coleta imprevista ser comunicada por meio do relatório de atividades. O transporte do material biológico ou do substrato deverá ser acompanhado da autorização ou da licença permanente com a devida anotação. O material biológico coletado de forma imprevista, deverá ser destinado à instituição científica e, depositado, preferencialmente, em coleção biológica científica registrada no Cadastro Nacional de Coleções Biológicas (CCBIO).

\begin{tabular}{|c|c|c|c|c|}
\hline Táxon* & Qtde. & Tipo de amostra & Qtde. & Data \\
\hline & & & & \\
\hline & & & & \\
\hline & & & & \\
\hline & & & & \\
\hline & & & & \\
\hline & & & & \\
\hline & & & & \\
\hline & & & & \\
\hline & & & & \\
\hline & & & & \\
\hline & & & & \\
\hline
\end{tabular}

* Identificar o espécime no nivel taxonômico possivel.

Este documento (Autorização para atividades com finalidade científica) foi expedido com base na Instrução Normativa $n^{\circ} 03 / 2014$. Através do código de autenticação abaixo, qualquer cidadão poderá verificar a autenticidade ou regularidade deste documento, por meio da página do Sisbio/ICMBio na Internet (www.icmbio.gov.br/sisbio).

Código de autenticação: 19842247 
ANEXO 2- Coordenada geográfica dos pontos de coleta de água e otólitos

\begin{tabular}{ccc}
\hline & \multicolumn{2}{c}{ Água } \\
\hline CIDADE & $\mathrm{S}$ & $\mathrm{W}$ \\
\hline Manacapuru & $03^{\circ} 17.383^{\prime}$ & $060^{\circ} 37.914^{\prime}$ \\
Itacoatiara & $02^{\circ} 48.115^{\prime}$ & $057^{\circ} 56.085^{\prime}$ \\
Novo Airão & $2^{\circ} 39.688^{\prime}$ & $60^{\circ} 53.032^{\prime}$ \\
Mamirauá & $2^{\circ} 58.164^{\prime}$ & $64^{\circ} 53.911^{\prime}$ \\
Santarém & $2^{\circ} 24.212^{\prime}$ & $54^{\circ} 44.149^{\prime}$ \\
Santarém & $02^{\circ} 23.663^{\prime}$ & $054^{\circ} 43.468^{\prime}$ \\
Porto velho & $8^{\circ} 42.619^{\prime}$ & $63^{\circ} 55.425^{\prime}$ \\
Ariquemes & $9^{\circ} 53.682^{\prime}$ & $63^{\circ} 3.977^{\prime}$ \\
Beni & $11^{\circ} 01.276^{\prime}$ & $066^{\circ} 06.462^{\prime}$ \\
Beni+ Madre Dios & $10^{\circ} 59.191^{\prime}$ & $066^{\circ} 03.440^{\prime}$ \\
Madre Dios & $10^{\circ} 58.201^{\prime}$ & $066^{\circ} 05.500^{\prime}$ \\
\hline
\end{tabular}

\begin{tabular}{ccc}
\hline & Otólitos & \\
\hline Código do indivíduo & $\mathrm{S}$ & $\mathrm{W}$ \\
\hline CAT-COOP-AM-01 & $03^{\circ} 17.383^{\prime}$ & $060^{\circ} 37.914^{\prime}$ \\
NAT-ITA-01 & $02^{\circ} 48.115^{\prime}$ & $057^{\circ} 56.085^{\prime}$ \\
NAT-ITA-02 & $02^{\circ} 48.115^{\prime}$ & $057^{\circ} 56.085^{\prime}$ \\
NAT-ITA-03 & $02^{\circ} 48.115^{\prime}$ & $057^{\circ} 56.085^{\prime}$ \\
NAT-ITA-04 & $02^{\circ} 48.115^{\prime}$ & $057^{\circ} 56.085^{\prime}$ \\
CAT-N.AIRAO-01 & $2^{\circ} 39.688^{\prime}$ & $60^{\circ} 53.032^{\prime}$ \\
CAT-N.AIRAO-02 & $2^{\circ} 39.688^{\prime}$ & $60^{\circ} 53.032^{\prime}$ \\
CAT-N.AIRAO-03 & $2^{\circ} 39.688^{\prime}$ & $60^{\circ} 53.032^{\prime}$ \\
CAT-N.AIRAO-04 & $2^{\circ} 39.688^{\prime}$ & $60^{\circ} 53.032^{\prime}$ \\
CAT-FEIRA-MAM-01 & $3^{\circ} 10.719^{\prime}$ & $60^{\circ} .02613^{\prime}$ \\
CAT-FEIRA-MAM-02 & $3^{\circ} 10.719^{\prime}$ & $60^{\circ} .02613^{\prime}$ \\
CAT-FEIRA-MAM-03 & $3^{\circ} 10.719^{\prime}$ & $60^{\circ} .02613^{\prime}$ \\
NAT-MAM-01 & $2^{\circ} 58.164^{\prime}$ & $64^{\circ} 53.911^{\prime}$ \\
NAT-MAM-02 & $2^{\circ} 58.164^{\prime}$ & $64^{\circ} 53.911^{\prime}$ \\
NAT-MAM-03 & $2^{\circ} 58.164^{\prime}$ & $64^{\circ} 53.911^{\prime}$ \\
NAT-MAM-04 & $2^{\circ} 58.164^{\prime}$ & $64^{\circ} 53.911^{\prime}$ \\
NAT-MAM-05 & $2^{\circ} 58.164^{\prime}$ & $64^{\circ} 53.911^{\prime}$ \\
CAT-SAT-01 & $2^{\circ} 24.212^{\prime}$ & $54^{\circ} 44.149^{\prime}$ \\
CAT-SAT-02 & $2^{\circ} 24.212^{\prime}$ & $54^{\circ} 44.149^{\prime}$ \\
CAT-SAT-03 & $2^{\circ} 24.212^{\prime}$ & $54^{\circ} 44.149^{\prime}$ \\
CAT-SAT-04 & $2^{\circ} 24.212^{\prime}$ & $54^{\circ} 44.149^{\prime}$ \\
CAT-SAT-05 & $2^{\circ} 24.212^{\prime}$ & $54^{\circ} 44.149^{\prime}$ \\
NAT-SAT-01 & $2^{\circ} 24.212^{\prime}$ & $54^{\circ} 44.149^{\prime}$ \\
NAT-SAT-02 & $2^{\circ} 24.212^{\prime}$ & $54^{\circ} 44.149^{\prime}$ \\
NAT-SAT-03 & $2^{\circ} 24.212^{\prime}$ & $54^{\circ} 44.149^{\prime}$ \\
\hline
\end{tabular}




\begin{tabular}{ccc}
\hline NAT-SAT-04 & $2^{\circ} 24.212^{\prime}$ & $54^{\circ} 44.149^{\prime}$ \\
NAT-SAT-05 & $2^{\circ} 24.212^{\prime}$ & $54^{\circ} 44.149^{\prime}$ \\
CAT-ROD-01 & $9^{\circ} 53.682^{\prime}$ & $63^{\circ} 3.977^{\prime}$ \\
CAT-ROD-02 & $9^{\circ} 53.682^{\prime}$ & $63^{\circ} 3.977^{\prime}$ \\
CAT-ROD-03 & $9^{\circ} 53.682^{\prime}$ & $63^{\circ} 3.977^{\prime}$ \\
CAT-ROD-04 & $9^{\circ} 53.682^{\prime}$ & $63^{\circ} 3.977^{\prime}$ \\
CAT-ROD-05 & $9^{\circ} 53.682^{\prime}$ & $63^{\circ} 3.977^{\prime}$ \\
YA-1 & $10^{\circ} 59.191^{\prime}$ & $066^{\circ} 03.440^{\prime}$ \\
YA-12 & $10^{\circ} 59.191^{\prime}$ & $066^{\circ} 03.440^{\prime}$ \\
YA-13 & $10^{\circ} 59.191^{\prime}$ & $066^{\circ} 03.440^{\prime}$ \\
FL-1 & $10^{\circ} 59.191^{\prime}$ & $066^{\circ} 03.440^{\prime}$ \\
FL-2 & $10^{\circ} 59.191^{\prime}$ & $066^{\circ} 03.440^{\prime}$ \\
FL-20 & $10^{\circ} 59.191^{\prime}$ & $066^{\circ} 03.440^{\prime}$ \\
\hline
\end{tabular}




\section{ANEXO}

\section{ANEXO 3- Especificações de análise dos otólitos}

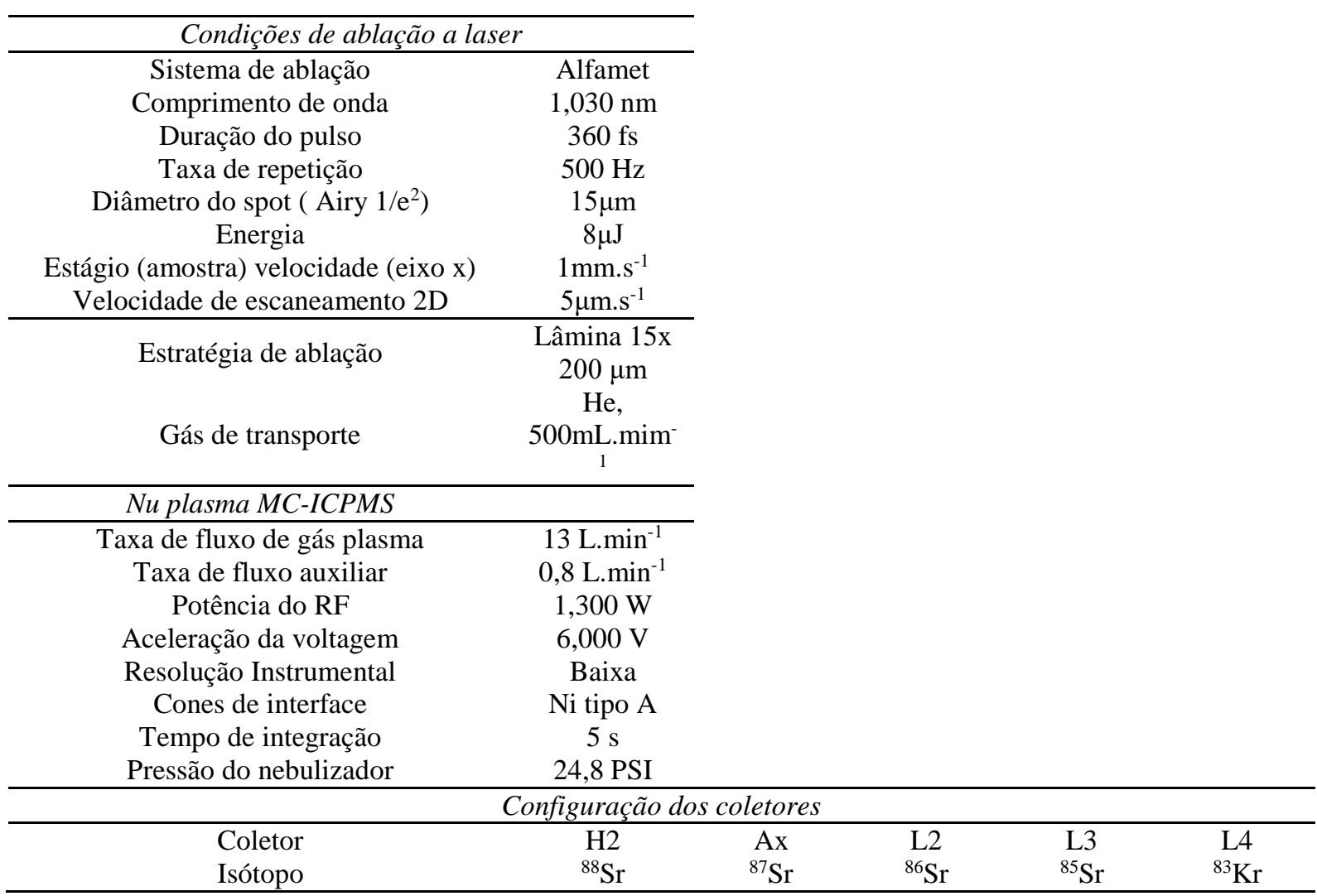

